\title{
PACIFIC WOMEN'S STORIES OF BECOMING A NURSE IN NEW ZEALAND: A RADICAL HERMENEUTIC RECONSTRUCTION OF MARGINALITY.
}

MARGARET R. SOUTHWICK

A thesis presented in fulfilment of the requirements for the degree of Doctor of Philosophy

VICTORIA UNIVERSITY OF WELLINGTON

NEW ZEALAND

JANUARY 2001 


\section{ACKNOWLEDGEMENTS}

This thesis would never have seen the light of day were it not for the unstinting and generous support that I received from many sources during the time of my candidature.

The generosity of the women who entrusted me with their stories is humbly acknowledged, along with my thanks to the many Pacific nurses and students who have encouraged me. Your courage and determination to succeed in the face of many obstacles has provided me with inspiration and motivation. Fa'afetai. I should also like to record my thanks to the staff of the Pacific Health Research Centre (Whitireia) and members of the wider Pacific community for their ongoing support. A particular thank you to Fa'fetai Ta'ase for his generous permission to use his poem "New Zealand is a Polynation”.

Being able to complete this thesis would not have been possible without the total support of my family, and I want to acknowledge that without their loving commitment this project would not have been possible. In particular I want to thank my niece Tamara Ross for her careful reading of a number of drafts and my brother Alastair McKenzie for his technical assistance in formatting the final document. Without a doubt the greatest debt is owed to my partner Wendy Scott. She has shouldered responsibility for maintaining our household with precious little help from me over the last few years with good humour. More than that she has been unfailing in her support of the thesis, and has managed to get me back on track whenever I threatened to derail myself.

I should like to thank my supervisors, Professor Alison Dixon, and Professor Judith Clare, for their sage advice and encouragement. Most of all I would like to thank you for your patience. My thanks also to my colleagues at Victoria University, who listened to endless repetition and redrafting with graciousness and fore-bearance. In particular I would like to thank Professor Jill White, Dr Pamela Wood, Dr Margi Martin and Associate Professor Cheryle Moss. I would also like to thank my colleagues at Whitireia Community Polytechnic for their ongoing support and encouragement. 


\begin{abstract}
This thesis examines Pacific women's experiences of becoming a nurse and their first year of practice post Registration, within the New Zealand context. The participant's stories of being students and beginning practitioners are inter-woven with my own reflections as a nurse and nurse educator who also claims a Pacific cultural heritage.
\end{abstract}

To create the space in which our stories can be laid down, the thesis includes a description of the migration and settlement of Pacific peoples in Aotearoa/New Zealand. This description shows how Pacific people have been systematically stigmatised and locked into marginalised positions by mainstream dominant culture.

The thesis deconstructs taken-for-granted and self perpetuating conceptualisations of marginality that currently underpins most theoretical explanations and proposes a reconstructed map of marginality. This deconstructed/reconstructed map of marginality is used as a template through which the experiences of the participants are filtered and interpreted.

Radical Hermeneutics provides a philosophical underpinning for this project that has as one of its objectives the desire to resist reducing complexity to simplistic explanation and superficial solutions. The thesis challenges Nursing to examine its role in reproducing the hegemonic power of dominant culture by applying unexamined cultural normative values that create binary boundaries between 'them' and 'us'. At the same time the thesis challenges Pacific people to move past hegemonically induced states of alienation and learn how to walk in multiple worlds with confidence and power. 


\section{GLOSSARY}

The following terms that are used throughout the text are commonly used within the New Zealand context, but may need explanation for other readers.

Maori:

The name given to the indigenous people of New Zealand.

Pacific Peoples:

The collective term used to describe people from different Pacific Islands within the New Zealand context.

Pakeha:

The Maori term commonly used to describe people of Anglo/European descent within the New Zealand context.

Palagi:

The Samoan word, commonly used by Pacific peoples to describe people of Anglo/European descent. The equivalent term to the Maori word, Pakeha.

Tino Rangatiratanga:

A Maori term usually translated as sovereignty or autonomy. The notion of Tino Rangatiratanga is enshrined in the second clause of the Treaty of Waitangi, guaranteeing to Maori their rights of sovereignty and autonomy.

Tangata Whenua:

Maori term literally meaning "people of the land”. In it's modern usage the term is usually used to denote Maori as the indigenous people of Aotearoa/New Zealand.

Treaty of Waitangi: $\quad$ The treaty signed between the British Crown and Maori in 1840 that has become recognised as the founding document of New Zealand. 
Whanaunatanga:

Maori term used to indicate the extended family. It is also a term used to indicate the nature of the relationship between Maori and other Pacific cultures, in which historical connections are acknowledged while at the same time respecting the distinctions. 


\section{CONTENT}

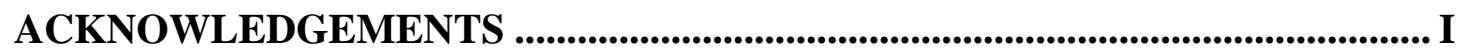

ABSTRACT ...................................................................................................................II

GLOSSARY ................................................................................................................... III

CONTENT ..........................................................................................................

CHAPTER ONE: SETTING THE SCENE ................................................................1

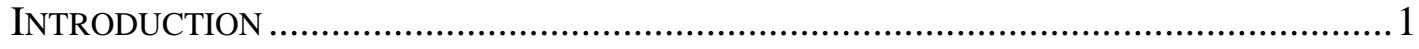

BACKGROUND …………………………………………………………....

LOCATING THE AUTHOR AS CO-PARTICIPANT AND RESEARCHER..................................... 4

NAMING THE BOUNDARIES ...............................................................................

A PHILOSOPHICAL POSITIONING ..........................................................................

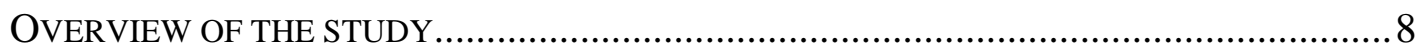

CHAPTER TWO: THEORETICAL FOUNDATIONS..........................................11

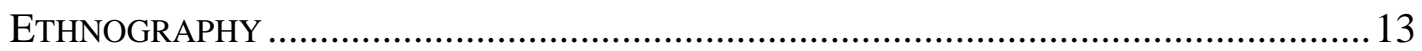

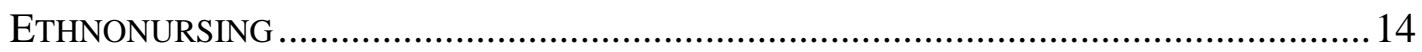

FEMINIST THEORY …………………………………………………….....

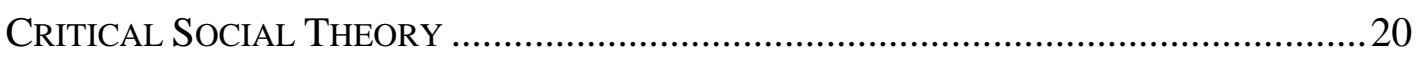

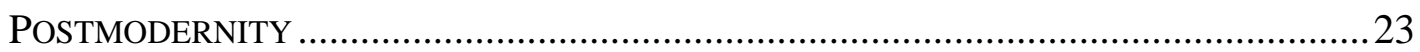

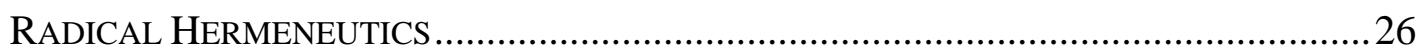

CHAPTER THREE: MIGRATION AND SETTLEMENT ...................................32

THE DEMOGRAPHIC PICTURE ………………………………..............................

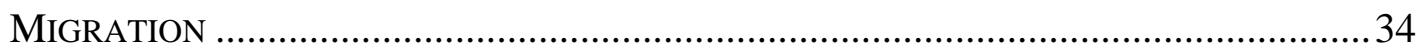

SETTLING IN NEW ZEALAND...............................................................................

A LOCAL SETTLEMENT STORY ………………………………………………........ 41

CHAPTER FOUR: RE-FRAMING MARGINALITY .............................................4

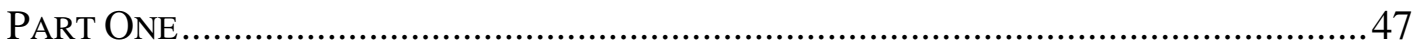

Deconstructing Marginality................................................................................ 48

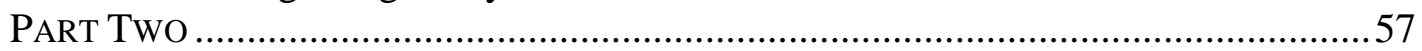

Reconstructing Marginality................................................................................. 57

CHAPTER FIVE: METHOD AND DESIGN .................................................64

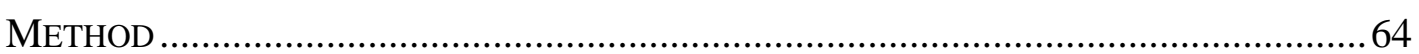

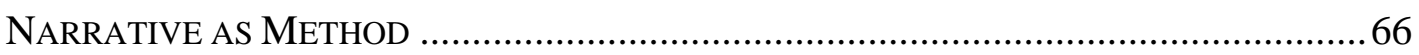

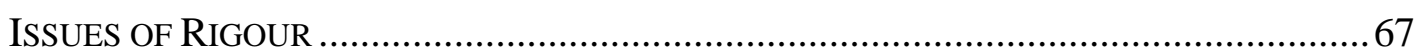

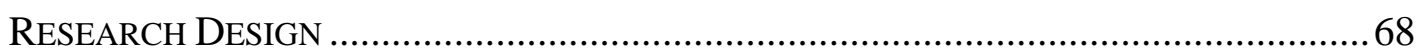

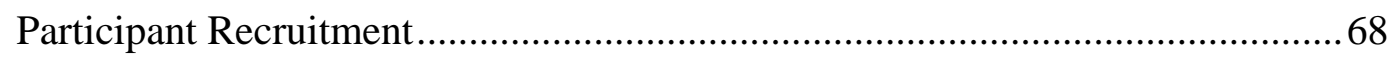

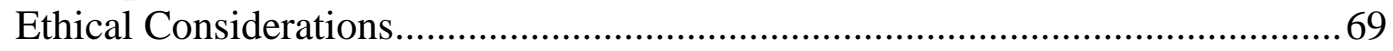

Rationale for Inclusion Criteria...........................................................................

Confidentiality and Anonymity.........................................................................71

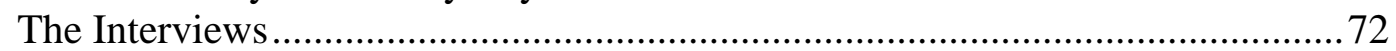

CHAPTER SIX: THE INTERVIEWS................................................................

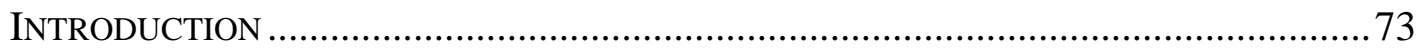

INTERVIEW ONE: BECOMING A NURSE................................................................. 


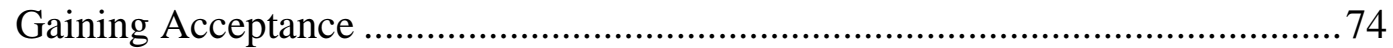

Mediating Discontinuous Worlds - Working The Margin .................................. 79

INTERVIEW TWO: THE BELONGING/BE-LONGING STORIES ......................................96

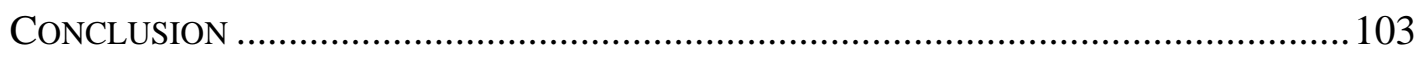

CHAPTER SEVEN: INTERVIEW AND DISCUSSION .....................................105

INTERVIEW THREe: THE BEING/WOUNDED STORIES ................................................105

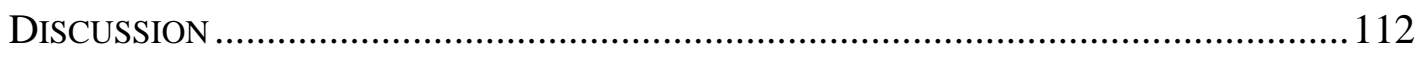

CHAPTER EIGHT: RADICAL REFLECTIONS ..............................................120

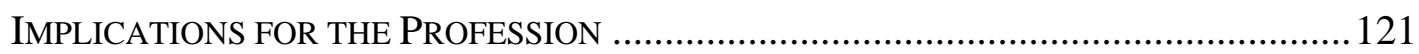

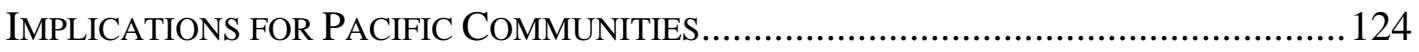

IMPLICATIONS FOR INDIVIDUAL STUDENTS/NURSES ............................................126

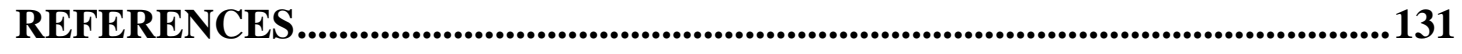

APPENDIX I: PARTICIPANT INFORMATION SHEET ...............................143

APPENDIX II: PARTICIPANT CONSENT FORM ...........................................146 


\section{CHAPTER ONE: SETTING THE SCENE}

\section{Introduction}

This research project explores the stories of Pacific women's experiences of their three year Comprehensive Nursing programme and their first year of practice post Registration within a New Zealand context. The purpose of the project was to gain an understanding of the meaning the participants had constructed for themselves of their experience of becoming a nurse, and to identify whether or not there is a dissonance between their cultural worlds as Pacific women and the world of nursing. The stories of the participants have a dual purpose in this project. They provide an insight into the participants' experiences and at the same time they provide a mirror that reflects back on the profession itself, allowing nursing to be viewed from an entirely different perspective.

I aim to demonstrate through the participants' stories that taken-for-granted, and therefore hidden, dominant hegemonic values are embedded in nursing and that as a result, nurses from ethnic minorities are marginalised within nursing. I will argue that despite the rhetoric surrounding the professions espoused goal of culturally safe nursing, the unexamined and often unintentional consequences of hidden hegemonic values is that the discipline of nursing itself becomes an agency of oppression. In Chapter Four, I have undertaken a deconstruction/reconstruction of the concept of marginality that creates a conceptual template in which these hegemonic forces can be laid open for examination.

Because little research has been undertaken that examines the experiences of students who self identify from a minority culture within nursing, there is value in this project as a descriptive enterprise alone. However, I have chosen to move beyond mere description because that creates a real danger of locating the 'problem' with the participants. In the process of undertaking this project, I have been constantly challenged by the complexities of the issues involved. These complexities relate at one level to the subject matter of the inquiry. A failure to acknowledge these complexities would I believe result in a simplistic rendering of the issues to a kind of 'good guy/bad guy' routine. The central issue at stake here can best be illustrated by asking the question; how can nursing respond to the contradictory forces of cultural 
diversity, while at the same time demand 'standards' for nursing practice that only members of the dominant culture have the power to set? The deconstruction/reconstruction of the concept of marginality creates the space for the development of this argument in a way that enables me to hold to the complexity and resist the tendency to reductionist and simplistic interpretation.

\section{Background}

Over the past two decades there has been a growing recognition in the international nursing literature of the pluralistic and multicultural nature of the societies within which nursing is embedded (Ramsden, 1992; Hall, Stevens \& Meleis, 1994; Meleis, 1996). Nurses have argued that if nursing is to remain viable in the twenty-first century, then the profession must seriously address the question of how to provide accessible and culturally appropriate nursing care for all members of the society. Meleis and Im (1999) go so far as to suggest that,

The future of nursing certainly depends on the ability of the discipline members to reach out to diverse communities and to meet the health care needs of marginalised people (p95).

The promotion of Transcultural Nursing (Leininger, 1978, 1991) in the international context, and Cultural Safety/Kawa Whakaruruhau (Ramsden, 1992; Nursing Council of New Zealand, 1996) within the New Zealand context, are examples of how the discipline is working to address the challenge. While there are fundamental differences between these two approaches, they are nevertheless similar in that they have both been developed to promote nursing care that addresses the cultural and ethnic needs of patients, their families and communities. However, neither position challenges the hegemonic taken-for-granted assumptions of nursing itself. In the absence of this challenge, both of these positions paradoxically act to reinforce the assumption that nursing is a profession undertaken exclusively by members of the dominant group in the society, and simultaneously reinforces the marginalised position of minority groups in the society as 'exotic other'. 
In a discipline such as nursing concerned, at least at the rhetorical level, to ensure that the health needs of diverse cultural and ethnic groups are addressed, one might expect that there would be some interest in understanding why the diversity found in the wider society is not reflected in the demographic profile of the profession itself. But to date there is little evidence that the profession is interested in addressing this question, with the result that the issue of cultural diversity within the profession is rendered invisible.

The justification (if one be needed) for the claim that nursing needs to take seriously the challenge of working with diverse and marginalised groups within society is to be found in the health status of these very same groups of people. Within the New Zealand context, the health statistics for both Maori and Pacific people show that these populations experience significantly poorer health than those New Zealanders who ethnically identify as Pakeha. High levels of poverty related to chronic under and unemployment, poor housing and under-achievement in education are a complex of factors that are determinants of poor health and high illness levels for these two populations (Howden-Chapman, \& Cram 1998). A widely held perception within both Maori and Pacific communities is that mainstream health care services, including nursing, has failed them. A growing trend within these communities is the move to develop their own culturally specific health care services; health services by Maori for Maori, and health services by Pacific for Pacific. The profession needs to reflect on this failure of credibility amongst these more vulnerable populations.

The trend towards more culturally specific services will be celebrated by those who are philosophically aligned to propositions of autonomy and emancipation. As a profession we have a duty to ensure that sufficient Maori and Pacific people are prepared through their nursing education to make a contribution in the development of these services. According to a Ministry of Health report on the current status of the nursing workforce, of the 29,154 nurses who are Registered, only 3.25\% (948) identify as Maori and 1.64\% (477) as Pacific (Kai Tiaki Nursing in New Zealand, 1998, p8). Similar figures are reported by Peach (1999), who argues that there is an urgent need for planning in the area of the nursing workforce. She reports that in the total Registered Nurse and Midwife workforce, 92\% are Pakeha, 2.8\% are Maori and 1.1\% are Pacific Islands people (Peach, 1999, ps22-24). When compared to 
demographics in the wider community, it can be seen that the profession is currently performing poorly in the area of recruiting a proportionately culturally diverse population into nursing.

\section{Locating the author as co-participant and researcher}

This project would appear to be one that I as researcher am particularly well suited to undertake. As a nurse I have had more than fifteen years experience teaching in a Comprehensive Nursing programme, and I have extensive first hand knowledge of the demands that this programme places on nursing students. The programme that I was involved with during these years was in a tertiary institution geographically located in a culturally and economically diverse community (Southwick, 1994). The nursing students who enrolled in this institution more accurately reflected the cultural diversity of the wider community than is usually found in Comprehensive Nursing programmes. This institution has an established track record in recruiting proportionately higher numbers of students who self identify as Pacific. Over the years it has been my observation that 'becoming a nurse' is a substantially different experience for Pacific students than it is for other students. One of the purposes of this study was to explore whether my perceptions could be validated by reference to the experiences of some of the Pacific women who had been students in the programme.

Another key to understanding why the experiences of these students are of particular interest to me is that I also identify in part as a Pacific woman. While saying that this is a key to understanding my identification with the subject matter of this project, paradoxically I would also argue that the nature of my own ethnicity can also obscure and distort understanding. By this I mean that by being identified and identifiable as a Pacific woman suggests that I have a privileged 'insider' view into the world of the participants. To the extent that this is true, I become a co-participant in this project. The ability to use my own experiences of 'becoming a nurse' and being a Pacific woman, provides an insider's knowledge for locating and mapping the stories and experiences of the participants.

But my 'insider' status is only a partial truth. To only present this project as an insider's view would be a distortion. As much as I am an insider, I am also an outsider 
on two counts. As a person who can claim to be only 'part' Pacific in ethnicity, I can claim to belong to two cultural heritages; the cultural heritage of my Tuvaluan mother, and my Pakeha father. This means that while I can claim that my dual heritage provides me access to both cultural heritages, my 'half caste' status also denies me full access to either. This half-castness, problemetises the whole notion of belonging in either culture. How 'acceptable' I am perceived to be in either culture is situationally and contextually dependant.

To some degree I am also an 'outsider' to the Pacific women in the context of this research project because of my different educational, professional and socio-economic experiences. Even if the question of my ethnic status was non-problematic and I fully identified culturally with my participants, these other aspects of my experience place a distance between the participants and myself. In situating myself in this research project, this leaves me located between the two worlds of Pakeha culture, which in the New Zealand context is the culture of the dominant hegemony, and the more marginal culture of Pacific people.

Being socially located 'between worlds' as a researcher contributes its own complexities to the project. Jennifer Pierce (1995), describes how in her research, her training as a lawyer, her experiences as a para-legal and her work as a participantobserver researcher, created dynamic, positionally constructed viewpoints where she moved from "insider-to-outsider” and “outsider-within” positions. The task for her as a researcher was to understand the way these socially constructed positions shaped the way others responded to her. She describes how at times she found herself at crosspurposes with others because where she had located herself, was not always where others had located her. She needed to be constantly aware that the meaning she constructed from any social interaction was dependent on the level of shared understanding or dis-located understanding of her location in her "insideroutsider/outsider-within” framework. And it is her sense of trying to make meaning in a context of constantly shifting ground that I identify as an inherent tension within this project. The challenge has been to articulate all of the complexities while at the same time retaining some sense of coherence. 


\section{Naming the Boundaries}

I have indicated some of the complexities involved in locating myself in this project. The resolution of how to work with this complexity has been achieved by creating a framework for the relative positioning of a mainstream Pakeha world, and a world of Pacific people domiciled in New Zealand. In creating this framework I am creating a conceptual map that enables articulation. But I am conscious that in doing this I run the risk of concretising what is simply a construct. By this I mean that the notion of a 'Pakeha' world and a 'Pacific' world only has meaning when the two worlds are placed in relation to each other. To say a 'Pakeha' world, is shorthand for those people who loosely share a common cultural and ethnic heritage as descendants of Euro/Anglo traditions within a New Zealand context. In the course of everyday living few 'Pakeha' would use this kind of collective description of themselves. Similarly, no Pacific person would describe them-selves as such. They would self-identify as Samoan, Cook Islander or Tokelauan for example. People from these cultural heritages only ever refer to themselves as 'Pacific people' when they want to collectively distinguish themselves from other cultural groups within the New Zealand context. These socially constructed categories serve to identify groups within the New Zealand context and to establish the boundaries between these cultural groups. Creating a category of 'Pakeha' and 'Pacific' is not to suggest that they are totally homogeneic groups, and acknowledges that there is as much diversity within the worlds of Pakeha and Pacific peoples as there is between these worlds. For the purposes of this project however, I have emphasised the difference between the worlds of Pakeha and Pacific people. That is the focus of this project.

In contemporary New Zealand, it is not possible to undertake research without indicating the significance the question may have to Maori. Acknowledging the Treaty of Waitangi as the founding document of New Zealand, requires researchers to reflect on what relevance the project may have for tangata whenua. While some parallels may be drawn between Maori and Pacific populations within the New Zealand context, it would be quite wrong to suggest that their experiences are the same. A failure to acknowledge the differences between these populations would lead to simplistic and universalising solutions to complex issues. For this reason, I acknowledge that in the spirit of whanaunatanga, there may be mutually beneficial 
lessons to be learned for both Maori and Pacific people. However, Tino Rangatiratanga as warranted under the Treaty of Waitangi mandates the right for Maori to speak for Maori. This project is therefore limited to the examining the experiences of Pacific people in relation to the dominant Pakeha culture within the New Zealand context and makes no claims to speak on behalf of, or for Maori.

Despite the paradoxes and contradictions, or perhaps to be more accurate, because of my apprehension of these paradoxes and contradictions, it seems to me that I do have a privileged position that enables me to stand in one world and cast a light on the other. But it is this constant shifting from one perspective to another that makes this project complex. This complexity challenges me to be able to locate myself, and then find the right 'voice' as a researcher and as co-participant. Finding the right voice means finding a way to explain without explaining away, to illuminate without trivialising and to reveal without exposing.

\section{A Philosophical Positioning}

At another level the complexities I have tussled with are entirely of my own making. This complexity primarily relates to the philosophical under-pinnings of the project. This project involves phenomenological, critical social, and post modernist deconstructive aspects. Because this project is limited to the experiences of women, I have also flirted with the question of whether the project sits best within a feminist framework. I have also mused mildly on the value of an ethnomethodological approach, given the centrality of 'culture' to the project. While each of these positions inform different aspects of this project, none of them are sufficiently robust that they can provide a framework that enables other positions to be included. Indeed it could be argued that the danger of such an eclectic use of a range of philosophical positions runs the risk of inadvertently building logical contradiction into the project. Radical Hermeneutics (Caputo. 1987) however provides me with a framework that enables me to situate 'complexity' at the centre of the project rather than a peripheral problem to be worked around. I take encouragement to hold on to the complexity in this project from this philosophical position which problemetises all assumptions and seeks to hold open the questions rather than to be lulled by slick and clever answers into premature foreclosure and superficial resolutions. Caputo argues that while staying in 
the "flux" makes life difficult, it is still to be preferred than the easy way out offered by metaphysics. Critical to the intention of my project is the question posed by Caputo (1987), in which he asks:

... whether existential movement is possible. Is it possible for the existing spirit to live in time without on the one hand being dissipated by the flux and losing his identity or on the other hand, without retreating from time and existence into timeless speculation?... it is in that in-between land which describes the dynamics of freedom (p16).

In Radical Hermeneutics, Caputo (1987) sets out the agenda that this project attempts to address; that life is hard, and no theoretical or philosophical argument ought to offer simplistic and/or superficial solutions and suggest there is a way around the hardness. Radical Hermeneutics does not

... try to make things look easy, to put the best face on existence, but rather to recapture the hardness of life before metaphysics showed us a fast way out the back door of the flux (Caputo, 1987, p1).

This project takes up the challenge of engaging the complexities within the flux.

\section{Overview of the study}

Chapter One: This chapter provides an overview of the project. It sets out the aim of the thesis and provides some background for contextualising these aims. The chapter indicates the theoretical approach taken in the project, and locates the position of the researcher within the study.

Chapter Two: Sets out the philosophical assumptions that provide the underpinning for this project. By laying out my thinking with regard to a range of possible theoretical positions, the reader has access to the interpretive decision making process 
that I have used to create the theoretical arguments and conceptual framework for the project.

Chapter Three: Deals with the journey undertaken by Pacific people migrating from their various homelands and their settlement in New Zealand. It presents a picture of their migration patterns and an argument for how they have become marginalised within the New Zealand context. I argue that this experience of marginality has a profound effect on the way they identify themselves with Pacific ethnicity and culture.

Chapter Four: In this Chapter I pick up this phenomenon of marginality and deconstruct the concept through a critique of Feminist and Critical Social Theory. I then undertake a reconstruction of marginality that I use as a template for the participants' stories.

Chapter Five: Provides the reader with an understanding of the design and method used to collect and discuss the participants' stories. Included in this Chapter is a discussion of the ethical concerns that were involved in undertaking this project.

Chapter Six: Involves the stories and discussion from the first two interviews undertaken with the participants. The Chapter is divided into two parts. Part 1, which I have called the "Becoming Stories", covers the first interview in which each of the participants talked about their experiences in their Comprehensive Nursing programmes. Part 2, which I have called “The Be-longing Stories" covers the participants stories of their “new graduate” experiences as Registered Nurses.

Chapter Seven: Begins with the participant's stories from the third interview and continues with an interpretive commentary on the texts provided by the participants' and my own stories. In this Chapter, I use the reconstructed understanding of marginality developed in Chapter Four as a basis for this interpretation.

Chapter Eight: Summarises the major insights gained from this project. It critiques the original aims of the project and provides some reflections on the value of Radical Hermeneutics as a theoretical foundation. It also discusses the way insights gained 
from this project may be practically applied. The Chapter sets out the significance of the project and the original contribution it makes to nursing knowledge development. Finally, the Chapter sets out the limitations of this study and suggests ideas for further research. 


\section{CHAPTER TWO: THEORETICAL FOUNDATIONS}

In this Chapter I set out the theoretical assumptions that underpin this thesis. The more conventional way of presenting the theoretical issues that support a researchers' claim is by way of a methodology chapter that usually contains a discussion of the theoretical assumptions, the design of the project and then the methods used. In this thesis, I have chosen to separate the theoretical discussion from the discussion about design and method, and introduce the theoretical foundations of this project here. The discussion on design and method are to be found in Chapter Five. My reason for taking this approach is that this project is essentially a de-centring project. I am setting out to challenge a number of taken-for-granted assumptions, and I believe it is important therefore that I foreground the philosophical arguments before I go on to develop the de-centring critique in Chapters Three and Four. This current Chapter is limited to a discussion of the theoretical assumptions that underpin the whole project and describes the process I went through to arrive at this position.

How nurse researchers go about the task of methodologically locating their research can take many forms. In some cases the nurse researcher is committed to a particular theoretical and methodological position and their research questions are framed from within their chosen paradigm. In this way researchers become associated with particular methodologies as much as they are with the findings of particular projects. I am thinking here of the way for example, that Benner's name has become synonymous with Heidegerrian Phenomenology, Leininger with Ethnography, or Chinn with Feminist theory. While it seems to me that the research findings of each of these people have made a significant contribution to the development of nursing knowledge, it could be argued their greater contribution is in the development of different methodological approaches for nursing research.

This development in nursing research has both advantages and disadvantages. The advantages are that collectively researchers such as these have helped create an environment in which qualitative research is firmly legitimated within the discipline of nursing. Being able to locate ones own methodological position by reference to a legitimised body of scholarship makes the task of undertaking qualitative research for the novice researcher a less tenuous exercise. 
The disadvantage of having theoretical and methodological positions already well articulated and established, is the temptation to become bogged down in orthodoxy. Theoretical and methodological positions can become formulaic when used uncritically or as “off the shelf” recipes for doing research. I think this is a particular danger for the researcher who has an area of inquiry or research question they want to explore, and then goes about the task of deciding what might be the best way of carrying out the research. Naming a particular methodological approach without indicating the logic for this decision-making, often leaves the impression that this process is non problematic in qualitative research.

Showing how I came to decide how to position this research methodologically is an important part of fore-grounding my own assumptions. What is frequently glossed over in the writing up of research is the decision making process the researcher goes through, leaving the impression very often that methodological positioning is nonproblematic. Without access to the researcher's decision making trail, it is difficult to see the internal validity of the project, and contributes to the impression that qualitative research can be undertaken by applying methodological 'recipes'.

In the very early days of this project I began with the question: "How do Pacific women mediate their multiple worlds in order for them to become nurses?” As I began to reflect on just what assumptions were embedded in this question, and what I would need to do as the researcher to make these assumptions manifest, I began to look for a theoretical and methodological framework that would best enable me to carry out the inquiry. I needed a framework that could enable me to hold the question at the centre of the enterprise and provide an internal line of logic that would allow me to explore and articulate the complexities that I saw inherent in the research question.

This early stage was frustrating but not without its own moments of amusement. I seemed to go through a rather protracted period during which, whatever I happened to be reading at the time became the preferred methodological position. This would last only as long as it took me to find another book or article that set out a different methodological position. Unable to discard previously examined positions, I resolved 
the problem by simply hyphenating the new position. It began to dawn on me that this level of eclecticism was seriously flawed when I found myself describing my methodology as one of 'Critical-Feminist-Hermeneutic-Ethnography'. Clearly some serious reassessment of the theoretical and methodological underpinning of this project was required. What follows is a discussion of each of these positions in which I set out their principle distinguishing features and my rationale for their ultimate inclusion or exclusion. I begin with an examination of Ethnography.

\section{Ethnography}

Ethnography is the methodological position first developed in Anthropology and is characterised by its particular method of participant-observational fieldwork. In its classical period ethnography was primarily used by ethnographers to study cultures other than their own (Clifford, 1988; Alasuutari, 1995; \& Van Maanen, 1995). Holloway and Wheeler (1996) describe the ethnographic interests of anthropologists in the following way:

In the beginning ... anthropologists explored only 'primitive' cultures.... [and when these] ... cultures became more linked with each other and Western anthropologists could not find homogeneous isolated cultures abroad, they turned to researching their own cultures, acting as ‘cultural strangers’ (p82).

According to Van Maanen (ibid) this historical association between ethnography and anthropology and perceived practices of Western imperialism and colonialism created a crisis of confidence in this methodological position in the early 1960s and 1970s. Anthropologists began to question their own ethnocentric assumptions and practice in the way ethnographic research was being conducted. Their voices were joined by those writing from the position of 'exotic other' who were uncompromisingly critical of the colonial assumptions of Western ethnographers. Clifford (1988) states that “...after 1950 peoples long spoken for by Western ethnographers, administrators and missionaries began to act and speak more powerfully for themselves on a global stage. It was increasingly difficult to keep them in their (traditional) places” (p6). Stepping out of “their (traditional) places” were the voices from writers such as Fanon (1963 
reprinted 1990) and Said (1993) who challenged the ethnocentric view of Western ethnography.

This crisis of confidence in ethnography has resulted in a greater level of reflexivity amongst some anthropologists and can be seen in the emergence of a more Critical Ethnography which attempts to problematise the role of the researcher (Clifford, 1988, p80). Despite this development however, the failure of ethnography to deal whole-heartedly with the methodological issues of power relationships is reflected in the challenge laid down by hooks (1990). She argues that despite the emergence of a “new” ethnography, “black people” are still being "talked about”. She asks:

Can we believe that no one has considered and /or explored the possibility that the experiences of non white scholars may have been radically different in ways from their white counterparts and that they possibly had experiences which deconstructed much old-school ethnographic practice (p126).

So, although there is evidence that Ethnographers have begun to question some of their own methodological assumptions, hook's challenge would indicate that the methodology remains almost exclusively one in which the dominant culture “explains” the cultures of others.

\section{Ethnonursing}

The foregoing discussion of ethnography serves to show how this methodology emerged primarily from the discipline of Anthropology. In this section I am going to discuss the application of this methodology in nursing research. Within Nursing, ethnography has become synonymous with the development of Transcultural Nursing and ethnonursing by Madleine Leininger (Holloway \& Wheeler, 1996). Leininger (1985) herself makes the link between anthropology, ethnography and nursing research when she states:

The use of the ethnographic method in nursing has been promoted and used largely by nurse anthropologists [in] the past two decades, but the method is 
now being recognised by other nurses as a means to understand people of different cultural backgrounds and from time and place perspectives ( p35).

Coming to Leininger's work after one reads how ethnographers in other disciplines are beginning to grapple with issues of ethnocentrism, colonisation, inscribed identity and the appropriation of other culture's knowledge is a sobering exercise. The richness of the debate being engaged in the wider field of ethnography seems to have passed by Leininger. It is difficult to read a description of ethnonursing published in the mid 1980s, (see for example Leininger 1985) which might have been written in the 1950s, and not think one has entered a time warp.

There appears to be no self-consciousness that what is described as "Transcultural" nursing is in reality the exclusive voice of white nurse ethnographers interpreting the "cultures" of ethnic minority groups. It is truly awful to read in a nursing text, statements such as, "Chinese people prefer care patterns that include the family rather than self-care patterns", or, "The Truk people believed one should not be touched by non-Trukese people when ill or well” (Leininger, 1985,p40).

One might hope that since 1985, Leininger, as the self declared pre-eminent authority on ethnography in nursing, may have had the opportunity to catch up with some of the more reflexive discussions taking place in the wider field of ethnographic scholarship. However her staunch defence of Transcultural nursing in the late 1990s (Leininger 1997), and her apparent inability to concede that ethnography as used in her model of nursing research privileges "Western" culture while at the same time represents all other cultures as 'exotic other', would indicate that such a shift has not happened. This is damaging to the credibility of ethnonursing and makes this methodology unacceptable and inaccessible to those of us who are not western and/or white. In the words of Clifford, "the time is past when privileged authorities (can) routinely 'give voice' (or history) to others, without fear of contradiction” (1988, p7).

Ethnography has been used in Nursing research to examine 'cultures' such as nursing itself, as distinct from the study of 'ethnic culture'. The work undertaken by Walker (1996) is a case in point. In her inquiry she uses an ethnographic methodology to describe the 'cultures' of two groups of nurses, (clinicians and academics), and how 
as a researcher she mediated the space between. But this example of the use of ethnography is unusual compared to the use that is made of this methodology to study ethnic minority groups.

Given that my own research is centrally interested in the experiences of Pacific women in nursing, I was concerned that assumptions would be made that would try to place the study in a Transcultural framework simply because the subjects of this inquiry are 'ethnic' or 'other cultured' than mainstream nurses. 'Explaining' the ethnic culture of the participants is not the central focus of this study. In her argument that nursing needs to develop culturally competent scholarship, Meleis (1996) rightly argues that nursing practice would be better served by research that looked at the reasons people in diverse societies become marginalised than trying to describe their 'cultures'. She argues that ... “a focus on culture may ... contribute to the current ... conceptual stagnation in the discipline of nursing” (p4). She believes that simply focussing on describing culture can lead to groups becoming stereotyped and homogenized. Perhaps more critically she claims that:

It is less powerful to develop knowledge about culture in nursing, which promotes the premises of relativism, than to develop knowledge about how societies at large, and health care systems in particular, tend to marginalise patients because of their culture (Meleis, 1996, ps4-5).

For these reasons I did not think that there was a good enough 'fit' between Transcultural nursing as a theoretical framework or ethnography as a methodological position and the research project that I wanted to undertake.

\section{Feminist Theory}

At a superficial level at least, Feminist theory looked like a plausible option for a theoretical location for this research. The project is primarily concerned with the experiences of a particular group of women within the context of Nursing, a profession that is socially perceived to be women centred and women dominated. Chinn (1999) argues that “... nursing as a social category has acquired gender traits 
that are associated with 'feminine', regardless of the sex of it's individual members” (p462).

While acknowledging that there are many forms of feminism, and no single feminist methodology, common to all the different schools of thought in this paradigm is an overarching assumption that women's experiences and women's lives are central to the feminists agenda (Holloway \& Wheeler, 1996; Crotty, 1998). An example of the assumptions that are commonly held by feminist scholars irrespective of the particular form of feminist theory they subscribe to is provided by the following authors.

The fact that human experience is gendered is central to the radical implications of feminist theory. The recognition of the impact of gender and an insistence on the importance of the female experience have provided the initial common ground for feminist research and thought. Feminist theory emerges from and responds to the lives of women. ( Personal Narratives Group, 1989, p4).

It is the hidden contradiction embedded in such statements that in the end persuaded me that feminist methodologies did not provide an adequate foundation for this project. In essence my critique is not new, but centres on the ability of this position to be conceptually adequate to hold the notion of 'difference' and to deal with forms of oppression that are not limited to critiques of patriarchal dominance.

Along with the previously cited authors, Speedy (1991) argues that ... "there is not 'one' feminist research methodology”. What is commonly held by all who claim to use feminist methodology however, “... is that feminist scholarship and research seeks to address women's lives and experiences in their own terms, which requires that the theory is grounded in actual experiences and language of women” (p194). Speedy goes on to argue that feminist research has been critical of the way traditional research has assumed a patriarchal world view which, “...treats the male as the norm, as the recognised frame of reference for all human beings” (p196).

There is an irony in Speedy's critique of the tendency for 'traditional research' to normalise 'man' as the frame of reference for all human beings. The critique of feminist research by women of colour, is the practice of norm referencing the 
experience of white middle class women to be the taken-for-granted experience of all women. In claiming to speak for all women, there has been a tendency for feminist scholars to privilege the critique of the patriarchy as the foremost cause of all women's oppression, making it difficult for women of colour to examine the intersecting axis of gender and racial oppression (hooks 1981, \& 1989; Rika-Heke \& Markmann, 1996).

Green and Curry (1991) challenge the "now standard processes of feminist theorising that excludes and marginalises the experiences of women of colour, working class women, and women of non-Western cultures” (p39). These authors argue that this tendency of feminism to speak for others derives from a “... Greek essentialist logic underlying traditional understandings of the concept of 'woman' [which] leads us to seek out shared, universal features of the instances of the concept, and to treat other characteristics of individual women as not features of their woman-ness as such.” (p39)

Green \& Curry's reference to feminists tendency to universalise and essentialise the experiences of some women to be that which is true for all women raises divergent points of view about the nature of the relationship between feminist theory and postmodernism. There are those who see postmodernism as a way of opening up a space that enables a more inclusive development of feminist theory. For others, postmodernism represents a fundamental challenge to feminist theory itself. Hartsock (1996) for example argues that a "number of feminist theorists found postmodernist theories attractive”. They have, she argues, used the modern critiques developed by Foucault, Derrida, Rorty and Lyotard to reject the philosophy of the European Enlightenment that sought to develop universalising arguments. In Hartsock's critical view this leads to a form of “... social criticism that was ad hoc, contextual, plural and limited" (p40).

In their discussion of the relationship between feminist theory and postmodernism, Fraser and Nicholson (1997) state that, “... other differences notwithstanding, feminists and post modernists have worked independently on a common nexus of problems" that is rethinking "the relationship between philosophy and social criticism so as to develop paradigms of criticism without philosophy” (p132). They go on to 
argue that these two currents have “... proceeded from opposite directions” with the result that "the two tendencies have ended up with complimentary strengths and weaknesses” (p133). According to these authors, postmodernism “... offers sophisticated and persuasive criticisms of foundationalism and essentialism” while feminists “offer robust conceptions of social criticism.” The respective weakness of each of these tendencies according to Fraser and Nicholson is that the postmodernist conception of social criticism tends to be anaemic, while feminists have a tendency to lapse into essentialism and foundationalism (ibid).

At the heart of this debate between feminist theory and postmodernism is the tension between the 'Universal' and the 'Particular'. Feminist theory is quintessentially concerned with the oppression of all women, but paradoxically is able to speak for only some women because of its insistence on privileging the oppression of the patriarchy. Moreover, while feminist theory is critical of many of the institutions of the Enlightenment it remains dialectically engaged with the epistemological foundations of the Enlightenment. Hartsock (op cite) states that:

The Enlightenment was marked by a faith in the neutrality of reasoned judgement, in scientific objectivity, in the progressive logic of reason in general and science in particular... It claimed to assume human universality and homogeneity, based on the common capacity to reason. Differences were held to be fundamentally epiphenomenal. Thus one could speak of human nature, truth and other imperial universalities. ...[A]ll of this had the effect of allowing for the transcendence through the omnipotence of reason (p41. My italics).

The feminists' agenda has been to challenge the Enlightenments' belief that 'man' could stand for 'human', but not to the extent that the fundamental epistemological premises of the Enlightenment are rejected. It is the postmodernists challenge to, and “... abandonment of the category of the subject as a rational transparent entity that could convey homogeneous meaning” (Mouffe, 1997, p534), that many Feminist scholars find troubling.

I abandoned the attempt to locate this research project within a feminist methodological position. Despite more recent attempts by feminist scholars to 
develop an inclusive approach, the epistemological underpinning of feminism remains problematic. The privileging of patriarchal oppression reduces other (different) experiences of oppression to the marginalised position of being "fundamentally epiphenomenal”. The marginalised position of Pacific women within Nursing is a central focus of this project and feminist methodology is unable to provide a theoretical defence for the claim that Nursing, by not addressing this tendency to marginalise 'others', is itself an agency for the production and reproduction of hegemonic oppression.

Postmodernism on the other hand does provide some useful ways of re-examining the question of 'the particular' and I have used these insights in the discussion of ‘identity’ in Chapter Three.

\section{Critical Social Theory}

The genesis of Critical Social Theory is generally attributed to the work of a group of philosophers associated with the Institute of Social Research in Germany. In the early 1920s this group, which became known as the Frankfurt School, had as its original purpose the aim of creating an institutional focus for examining the ideas of Marxist Theory (Carr \& Kemmis, 1986., Fay,1987., Kincheloe \& McLaren, 1994., Crotty, 1998., \& Welch, 1999).

Under the leadership of Horkheimer, the second Director of the Institute, the original aims of the school were broadened to begin questioning how in modern Capitalist societies, basic social, political, cultural and economic assumptions maintained hegemonic power (Welch, 1999, p355). This kind of inquiry tended to take a very philosophical approach, to the extent that some have challenged just how "Marxist" the School's endeavours were at this stage, or even how unified the "Frankfurt" approach really was (Crotty, 1998, p126). Kincheloe and McLaren (1994) argue that notwithstanding these observations, “... there is general agreement that the School fostered an interest in a critical approach” (p138).

One of the early concerns of Critical Theorists was their critique of the emergence of the power of “...the instrumental rationality of positivism” in modern Capitalist 
societies, in which the role of science had become redefined as "technical problem solving”, which in turn diminished the field of epistemology to an "ideology of scientism” (Carr \& Kemmis, 1986, p131). According to these authors, “... the critical theorists saw a great danger for modern society: the threat of the end of reason itself”. Reason, Critical Social theorists argued, had been "replaced by technique, (and) critical thinking about society by scientific rule-following. ... Science had become an ideology, a culturally produced and socially supported, unexamined way of seeing the world which shapes and guides social order” (ibid p132).

The role Critical Social Theorists defined for themselves was to demonstrate the way this ideology created particular forms of power relations and particular patterns of domination and oppression. The concept of hegemony first attributed to Gramsci (1942), describes how power is exercised in modern capitalist societies in such a way that those who dominate in the society are thought to have the legitimate right to do so, even by those who are dominated. Hegemony involves "the ideological domination of one class by another such that conceptions of what exists, what is appropriate, what possibilities are open to it, and what it should rightfully expect reinforces the position of ... the powerful class”. In a hegemonic society, the powerful groups “... assume a cultural ascendancy” to such a degree that their culture becomes the basis of normative standards for the whole society, including those who are subordinated and oppressed by these standards (Fay, 1987, p138).

These two themes, the development of 'science' as an ideologically privileged form of knowledge and the way hegemonic power enables the reproduction of power relations in modern societies has become associated with the work of Jurgen Habermas, probably the pre-eminent Critical Social Theorist of the $20^{\text {th }}$ Century. (Jay, 1973., and Giddens, 1994).

For the purposes of my study I am less interested in rehearsing the particulars of Habermas' well-known typology of cognitive knowledge interests, because they do not have direct relevance. What is relevant is an examination of the underlying epistemological assumptions that lead Habermas to develop his theory of knowledge and first published in Knowledge and Human Interests (1971). 
Habermas was critical of the work being undertaken by members of the Frankfurt School, and in particular the works of Horkheimer and Adorno. Central to their critique of modern capitalism was their argument that 'reason' had become reduced to instrumentality. According to Crotty (1998), “Horkheimer and Adorno depict(ed) Western society as a social and political economy, at once capitalist and bureaucratic, which reduces all social relations to the level of objectified and commodified administered systems” (p141).

Habermas (1971) was not persuaded that a social theory critical of capitalism had to necessarily abandon the concepts of rationality or universal laws. He argued that it was possible to "provide a normative basis for a Critical Social Theory" (ibid). His development of the threefold typology of human knowledge was his attempt to articulate such a normative theory. His concern in this theory was to liberate 'reason' from the hegemonic tendencies of modern capitalism, but at the same time he was not prepared to accept the radical rejection of 'reason' that marked Adorno's critique. The normative basis for Habermas' defence of reason is the source of his dis-juncture with post-structural theorists such as Derrida and Faucault .

According to Habermas, the tendency to hegemonic instrumental rationality can be challenged by self-reflexive members of a society who willingly engage in communicative rational discourse to seek agreement when disputes arise (Habermas, 1979). At the same time, the development of dialogic communities is a defence against relativism. Habermas' discomfort with relativism is revealed in his continued attempts to fashion a normative, that is to say universal, basis for his Critical Social Theory, and to rescue 'reason’ from technical decision making. (Giddens, 1999, p133)

Communicative rationality became a central organising theme, in Habermas' work. But this work is for me fundamentally flawed by his claim that there is a hierarchy of evolutionary development that makes some societies more "cognitively adequate” to engage in communicative rationality than others. Giddens (1999) exposes this ethnocentric tendency in Habermas’ work where he argues that:

Small-scale, traditional societies are dominated by myth and... are characteristic of societies which have not developed distinct intellectual arenas within which 
argumentation can be carried on... According to Habermas, the West alone is marked by the pre-eminence of 'post-conventional' cognitive domains... For Habermas, therefore, there is a sense in which West is best (Giddens, 1999, ps 132-133).

The ethnocentrism revealed in this passage makes it rationally and ethically impossible to locate my research within a Critical Social Theory paradigm. But even putting these concerns to one side, there remain limitations in the Critical Social Theory position. Like feminist theory, this theory remains dialectically engaged with some aspects of Enlightenment philosophy although in this case it is 'reason' which becomes privileged. As Fay (1987) argues, the problem with Critical Social Theory is its “excessive rationalism”. In his view, critical theories would have greater validity if they were “... self consciously local, particular, situated, and whose values were not those of rational self-clarity and autonomy, but were something far less grandiose and mundane” (p212).

Although I have rejected Critical Social Theory as an underpinning theoretical basis for the thesis, I have found that aspects of the theory have provided useful insights in the deconstruction of marginality that I have set out in Chapter Four.

\section{Postmodernity}

Crotty (1998) argues that postmodernity can be defined in two broad ways. In the first it is seen to "emerge out of and in reaction to modernity". In the second it is seen as a "definite rupture with modernism; it calls into question - indeed stands in total opposition, to virtually all that modernism asserts and holds dear” (p184). Many authors have, like Crotty, attempted to define the difference between modernity and postmodernity. Most conclude that the reported rupture between them is frequently overstated, and that it is probably more accurate to locate the rupture between postmodernity and the traditions of the Enlightenment (Harvey, 1977., Eagleton, 1996., Sarap, 1993., and Anderson, 1996). 
Postmodernity, for all its different expressions, has a common goal of deconstructing our cultural confidence in any form of universalising truth, and an interest in trying to disrupt our now institutionalised faith in human rationality. As Crotty (1998) states:

Post-Modernism refuses all semblance of the totalising and essentialist orientations of modernist systems of thought...Instead of espousing clarity, certitude, wholeness and continuity, postmodernism commits itself to ambiguity, relativity, fragmentation, particularity and discontinuity... In the course of all this, post modernism typically engages in a radical decentering of the subject, privileging non-identity (or the dispersal of identity) over stable self- conceptions (p185).

This framing of the postmodernist agenda, precisely encapsulates the value of this approach to my thesis. By deconstructing both Feminist and Critical Social Theory's critique of dominant ideology, I have simultaneously been able to show how these positions recreate the boundary of normative modernist society, and at the same time reveal the universalising tendencies of both these positions. By contrast, the development of a reconstructed understanding of the concept of marginality depends on my ability to engage a postmodernist accounting of the 'particular' social location of my participants. Both philosophical positions are necessary to provide the theoretical positioning of this project. The desire to engage both explanations of the universal and the particular can be best illustrated by reference to the way each deals with the concepts of power and power relations.

Both Feminist and Critical Social Theory rely on showing how power relations in a society operate through hegemonic systems as I have argued above, and which I have critiqued in Chapter Four. While this explanation is necessary to understanding the marginalised experiences of the participants, it is not sufficient because while it exposes the social forces of power, it characterises the position of the participants as powerless. A Post-Structuralist critique of power and power relations such as that argued by Foucault (1989) challenges the determinism of hegemony by focusing on the way power is manifold in modern complex society. 
Foucault's critique of power (1977) provides a counter position to that found in discourses of hegemonic power. In contrast to critics of Modernity who attempted normative and universal explanations of power that they argued accounted for the circumstances of people's lives, Foucault argued for a different conceptualisation of power. In the first place, he challenged the way 'power' was always presented as if it was a negative phenomenon. He argues that:

We must cease once and for all to describe the effects of power in negative terms: it 'excludes', it 'represses', it 'censors', it 'abstracts', it 'masks', it 'conceals'. In fact power produces, it produces reality, it produces domains of objects and rituals of truth ( Foucault, 1977, p194).

Foucault (1989) insisted that his "analyses of the technology of power" should not be reduced to a "kind of metaphysics of Power with a capital P" (p185). To distinguish what he thought were the important questions to be asked in an analysis of power, Foucault argued that his conceptualisation of power was not a deductive phenomenon that emanated from a sovereign or state, and flowed downwards through the society. He argued that power was not something that could be understood as a property of an individual or class of people within a society. Rather it has the character of a network; its threads extended everywhere.

Sarap (1993) argues that Foucault's analysis of power is different from other forms of analyses. Historians, he says, have studied powerful people, and there have been analyses that focus on economic power and the power of institutions. "But power in its strategies and its mechanisms has never been studied”. Even less, argues Sarap, has the relationship between power and knowledge been studied. And it is this very

... interdependence of power and knowledge (pouvoir-savoir) that constitutes the strategic fulcrum of Foucault's later work. ... It is not possible for power to be exercised without knowledge, it is impossible for knowledge not to engender power (p73).

Foucault himself argued that in modern society there are multiple forms of power, both positive and negative, and he was less interested in an analysis of power as "an 
autonomous question”, but rather in the way individuals can be simultaneously both powerful and powerless.

I would say that power as an autonomous question does not interest me. If I tell the truth about myself as I am now doing, it is in part that I am constituted as a subject across a number of power relations which are exerted over me, and which I exert over others. I say this in order to situate what is for me the question of power (Foucault, 1988, p39).

By this Foucault was signalling that in his view power represented a complex of differentiated power relations which; - “...extended to every aspect of our social, cultural and political lives, involving all manner of (often contradictory) 'subjectpositions' and securing our assent not so much by the threat of punitive sanctions as by persuading us to internalise the norms and values that prevail within the social order” (Foucault, 1980, p98). In Discipline and Punish (1977) Foucault demonstrates how the creation of the Panoptican creates subjects who are responsible for their own subjection.

This analyses of power relations by Foucult, opens up the possibility of examining the situation of people who may be marginalised but are not necessarily powerless. For the purposes of my study, I needed a theoretical framework that could hold the explanatory value of the universal and at the same time draw on the particular insights that, for example, Foucault's analyses of power afforded. A choice between the Universal or the Particular is unsatisfactory because while both perspectives are necessary, neither is alone sufficient to deal with the complexity (Caputo 1987, would say the flux), that this thesis is attempting to address.

\section{Radical Hermeneutics}

This thesis is informed by the ideas that Caputo presented in his work Radical Hermeneutics (1987), subtitled Repetition, Deconstruction and the Hermeneutic project. In this work Caputo argues that metaphysical philosophy has posited explanations that provide a false sense of certitude and predictability and which seduces us into believing that the "flux of a chaotic world" has been tamed. 
The task Caputo undertakes is to argue firstly, that metaphysics has "institutionalsied" rationality and reason and in so doing, has created a climate in which we are led to believe that human behaviour can be reduced to the formulation of hard and irrevocable rules. The task of Hermeneutics is, he argues, to deconstruct this myth. We need to...

... take a stand against methodologies, to get beyond the rational/irrational controversy to liberate a more reasonable notion of reason... Our preoccupation with methodology needs to be replaced with a deeper appreciation of methos, meta-odos which is the way we pursue a matter. The concern with method, rules instead of serving, contains instead of liberating and fails conspicuously to let science be (Caputo, 1987,p213).

Caputo's solution to the hegemony of orthodoxy is to use a Derridian deconstruction of Heideggerian hermeneutics to constantly keep open the space of the question, by not allowing us to slip back into the security and complacency that our answers afford us.

He argues that after the publication of 'Being and Time':

... the idea of hermeneutics underwent three significant developments: in the work of the later Heidegger himself: in Gadamer's philosophical hermeneutics: and in the French structuralists, and then post-structuralists critique of hermeneutics, of which Derrida's deconstruction is the form most pertinent to this study (p95).

Following the publication of Being and Time, Caputo argues that Heideggar became his own most important critic, to the extent that he stopped describing his work as hermeneutic at all. At the same time, Gadamer adopted the fundamental standpoint of Being and Time almost without regard for Heidegger's own critique of this work. According to Caputo, Gadamer made a necessity of those aspects of Heidegger's early work - pre-understanding, the hermeneutic circle, the phenomenological theory of horizons which the later Heidegger rejected. 
Having distinguished between Gadamer's more conservative approach to hermeneutics, and Heidegger's critical appraisal of hermeneutics, Caputo (1987) places Derrida in a deconstructive relationship with Heidegger. This is his formulation of Radical Hermeneutics, in which he argues that “... deconstructive criticism is ... the gateway through which Radical Hermeneutics must pass” (p97). His concern is that without this deconstruction, hermeneutics has a tendency to "arrest the play", to become reduced to a reassuring “ metaphysics of meaning making”. He explains this further by saying:

I am interested in letting the play play itself out. But I contend - and this goes to the heart of what I mean by Radical Hermeneutics - that after tracing out this deconstructive course, after allowing the disseminating drift its full play, we are in an odd way led back to ourselves, not in a moment of recovery or selfpresence but in a deeper, less innocent way... I do not mean by this to incite another wave of "humanism" which deconstruction has tried to put down but to evoke the notion of 'facing up' to the limits of our situation, to the illusions of which we are capable, to the original difficulty of our lives. And I call this 'hermeneutics' just because I think there is something liberating about all of this, not dehumanising (p97).

Gallagher (1992) in a Chapter entitled "Radical Hermeneutics and Educational Theory” argues that Caputo's intention is to keep the "trembling and endless mirrorplay of signs and texts in play" rather than allow "tradition to fix meaning". "Deconstruction is thus a hermeneutics beyond hermeneutics, beyond the first essence of hermeneutics, beyond the hermeneutics which looks for meaning and stability” (p278).

While Caputo (1987) emphasised that his formulation of Radical Hermeneutics was based on the interplay he created between Heidegger and Derrida, Gallagher (1992) for his part manages to ignore Heidegger entirely. He has instead Derrida at play with Gadamer. Moreover he makes a distinction between Radical and Critical Hermeneutics in a way that Thompson (1990) fails to do. She states that Critical Hermeneutics, in which she includes Radical Hermeneutics: 
“... operates explicitly on the assumption that not all social actors are heard; that tradition contains many socially accepted meanings that are hegemonic, that represent the interests of a few; and that it is important to demystify socially oppressive meanings that may be unnoticed by the participants themselves” (p258).

Gallagher, on the other hand argues that Radical Hermeneutics is "all this and more". While conservative and Critical Hermeneutics “... uncritically retain the framework of metaphysics which conditions our understanding, Radical Hermeneutics attempts to deconstruct the very framework of metaphysics” (Gallagher, 1994, p282). I want to tease out the distinction that Gallagher makes between Critical and Radical Hermeneutics because I believe that understanding the difference helps to clarify the theoretical foundations of this project.

Thompson (1990) repeatedly cites Caputo (1987) in articulating a description of 'Critical Hermeneutics', whose purpose is to “... demystify [and] go behind given meanings that are illusory, to meanings that actors themselves cannot see" (Thompson, 1990, p263). A definition that neither Critical nor Radical Hermeneutics would seriously challenge. In further elaboration, Thompson goes on to state that:

Postmodernism helps us to notice that only certain privileged voices have been heard in the construction of meaning, and that these voices, which usually belong to white privileged heterosexual men, have had a monopoly on the establishment of meaning (p263).

The slippage from critical hermeneutics to postmodernism goes un-remarked by Thompson. She continues throughout, to conflate critical hermeneutics, postmodernism and radical hermeneutics in her argument that critical hermeneutics (including postmodernism and radical hermeneutics), has an “... explicit focus on uncovering the way tradition operates to establish meaning” (Thompson, 1990, p263).

Olthuis (1997) is very clear that there is a significant difference between a critical hermeneutic understanding of tradition and a radical hermeneutic treatment of the 
question of tradition. In his argument, Olthuis compares the critical theory of Habermas, the hermeneutics of Gadamer and the deconstruction of Derrida (Olthius, 1997,p149).

He argues that Habermas' critical agenda is to "break free from the belongingness of tradition through critical reason", while Gadamerian hermeneutics "sees our belongingness to tradition as our primordial ontological condition. The Derridian deconstructionist would challenge the "underlying unity of tradition and the universal will to understanding and a mistrust of reason's ability to transcend ambiguity, historicality and embodiment (Olthuis, 1997, p150). The difference that Olthuis notes, and Thompson (1990) fudges, is as I have noted earlier, the difference between a critical hermeneutics still caught up in the universalising tendencies of the Enlightenment and a postmodern position which privileges the particular. Olthuis states that:

Derrida's emphasis on the plurality of traditions ... leads Habermassians and Gadamerians to fear that deconstruction easily shades into ethical indifference, non-engagement and indecision. Derridians fear that any talk of Reason and Tradition is a totalising move which inexorably oppresses, dominates and marginalises the “other' (Olthuis, 1997, p150).

This distinction that Olthuis (1997) and Gallagher (1994) make between critical theory and the deconstruction of Derrida demonstrates the significance of Radical Hermeneutics as a theoretical foundation for this thesis. If my project simply set out to be critical of the way mainstream nursing accommodated 'difference', then Critical Social Theory would have been more than adequate as a theoretical foundation. On the other hand, if this thesis was merely interested in describing what it was like for someone from an ethnic or cultural minority to engage with mainstream culture, then an ethnographic or feminist position would have been adequate.

But this project is attempting something more ambitious. I want to understand the experience of people who get marginalised between traditions. In order to do this, I have needed a theoretical foundation that enabled me to articulate both the universal and the particular, and to look at the space that stands between. In Radical 
Hermeneutics, Caputo (1987) employs the devise of placing one theoretical position in relation to another in order to allow new meaning to emerge from their interplay. "Derrida and Heidegger: it is in the space that opens up between them, in their interplay, that Radical Hermeneutics springs up” (p119). And it is this devise that I have used to provide the theoretical foundation for this thesis. Placing Critical Social Theory (universal) in interplay with Deconstruction (particular) creates the space from which a reconstructed meaning of marginality can emerge.

In this Chapter I have set out the theoretical assumptions that underpin this thesis. These assumptions have been derived and revealed through a critical review of a range of different theoretical positions. From this review I have arrived at the conclusion that only Radical Hermeneutics provided me with a sufficiently coherent framework that would enable me to work with the Universal and the Particular. In this thesis, I am arguing that the 'Universal' is reflected in the values and norms that underpin the nursing profession, while the "Particular" is reflected in the marginalised position of Pacific people within the New Zealand context.

In the next Chapter I begin by describing the marginalised position of Pacific people in the New Zealand context. As the Chapter unfolds, I describe their particular circumstances and the impact this has on developing their unique sense of identity. 


\section{CHAPTER THREE: MIGRATION AND SETTLEMENT}

In order to understand the stories of Pacific Islands women's experiences of becoming a nurse, it is necessary to situate their stories in the context of Pacific people's migration and settlement in contemporary New Zealand society.

I have begun this Chapter by setting out in some detail the demographic picture of Pacific people's settlement in New Zealand, including its current size and composition and the projections for growth compared to the total population. I then examine some of the socio-political factors that have emerged over the past sixty years. I argue that the pattern of migration and settlement by Pacific people in New Zealand has been characterised by tension and ambivalence by both mainstream New Zealanders and Pacific people themselves.

During periods of industrial economic growth New Zealand has been happy to exploit the availability of cheap labour that Pacific people's settlement provided. In times of economic downturn pressure has been exerted by successive New Zealand Governments to not only limit further migration but to also reverse this process. This has been done through the manipulation of legislation controlling visitor permits and rules of citizenship.

For Pacific people the tension and ambivalence they experience is related to questions of belonging and identity. What does it mean to be a New Zealander of Pacific Islands descent in an environment that negatively stereotypes ones ethnicity? How do successive generations adapt to living in New Zealand while at the same time hold on to their identity and identification with a Pacific homeland?

\section{The Demographic Picture}

For the past 100 years there has been a history of migration to, and settlement in, contemporary New Zealand by Pacific peoples. Census records from 1945 show that at that time, just over 2000 people were recorded as being of Pacific origin, representing just $0.1 \%$ of New Zealand's total population (Cook, Didham \& Khawaja, 1999). The post war economic boom experienced in New Zealand from the 1960s through to the mid 1970s created a demand for labour that accelerated the rate of 
migration from Pacific Nations. According to a report by Statistics New Zealand (1998) Pacific people now make up 6\% of the total population. Of a total population of approximately 3.8 million, a total of about 227,000 are estimated to be people who claim Pacific ethnicity. Cook et al (1999) argue that "because the Pacific population is expected to grow at a much faster pace than the rest of the New Zealand population, their share of the total New Zealand population will double from 6 percent in 1996 to 12 percent in 2051” (p 36).

Some features of this Pacific population are unique compared to New Zealand's total population and are worth noting. For example, compared to the total population, the Pacific population is relatively youthful. Cook et al (1999) state that the 1996 census shows the median age for the Pacific population is 20.4 years compared with 32.9 years for the total population. This comparative youthfulness accounts in part for the projected accelerated growth of the Pacific population over the next fifty years. The Pacific Direction Report (Ministry of Pacific Island Affairs,1999) estimates that there will be a $12 \%$ increase in the Pacific population by the year 2051. This population growth will occur as a result of children being born in New Zealand rather than by growth through migration. An accelerated period of growth of the Pacific population occurred in New Zealand between 1950 and 1980 as a result of migration. By the end of the 1990s however, 58\% of Pacific people resident in New Zealand had been born in this country. Of those who were born overseas, the majority, (61\%) have been resident in New Zealand for ten years and more (Statistics New Zealand, 1998).

The final points to be made about the demography of this Pacific population is it's diversity and geographic distribution. According to the Pacific Directions Report (Ministry of Pacific Island Affairs, 1999), the Pacific population in New Zealand is comprised of 50\% Samoans, 22.5\% Cook Islanders, 15.5\% Tongans, 9\% Niueans, 2\% Fijian and 1\% Tokelauans. Other Pacific groups make up less than 1\% of the total Pacific population and includes people from Tuvalu, Vanuatu, the Solomon Islands and Kiribati. Within these classifications there is even greater diversity.

Pacific people living in this country represent at least 22 different cultures and speak an even greater number of languages. Therefore the term "Pacific people" does not refer to a single nationality or ethnicity, but is a collective term for a diverse range of 
people from the South Pacific region. Despite these differences all Pacific people share a common migration and assimilation history in New Zealand (Ministry of Health. Making a Pacific Difference, 1997, p5).

According to Cook et al (1999), the most striking feature of the distribution of the Pacific population is the fact that $97 \%$ live in urban areas, and $87 \%$ of that total are to be found living in just five of New Zealand's largest urban agglomerations. This is contrasted by the $48 \%$ of the total New Zealand population. By far the largest proportion of the Pacific population lives within the Auckland region. An estimated 66\% live within the Auckland region, about 17\% live within the Wellington region and the remaining $17 \%$ live in smaller concentration throughout the rest of New Zealand.

In summary one can say that these demographic figures show that there has been some level of migration and settlement of people from Pacific Nations to New Zealand for most of the last century. An acceleration of this trend occurred in the period between the 1950s and the 1970s in response to New Zealand's demand for a labour workforce. While the present and future growth of the Pacific population is occurring at a faster rate than for the total population, this is no longer as a result of migration but of the fertility patterns of Pacific populations resident in New Zealand compared to other groups within the total population.

\section{Migration}

Into the multicultural society of New Zealand in the late twentieth century, are threaded and woven the cultural inheritances of two great traditions of myth and legend. From those people who trace their antecedents back through Western and Continental civilisations to the early Greeks come the stories and myths of Odysseus, the archetypal journeyer and traveller. Within modern New Zealand, all people who claim a common Polynesian bond carry the knowledge of another archetypal journeyer and traveller tradition in the myths and legends of Maui.

In both traditions these mythical figures symbolise the cultural recognition that while journeying involves great danger and the possibility of annihilation, accepting the 
challenge to journey also opens up the possibility of new knowledge, and more significantly the possibility of self-knowledge. It is this transformative possibility that makes these mythical figures "heroic", and this symbolic knowledge is recognisable to any New Zealander familiar with the legends.

This level of recognition is not so equally attributed to the historical travellers and adventurers from both cultural traditions. While most New Zealanders can readily cite the names of journeyers from the Western traditions, such as Columbus, Drake, Tasman and Cook for example, many would be hard pressed to name the Polynesian counterparts. Perhaps Kupe is the only generally recognisable name, and many are confused about whether he was a mythical or historical figure.

The focus of most written accounts of Pacific people's migration to New Zealand has been from a Euro-centric point of view. That is to say, that they are generally written by non Pacific people, and record the actions and effects of migration patterns from a New Zealand perspective. Albert Wendt has argued that:

If we look at written Pacific history we find that most of it is the work of papalagi/outsiders and that most of it is based on the records written and kept by papalagi explorers, missionaries, clerks etc. So we can say that history is a papalagi history of themselves and their activities in our region: it is an embodiment of their memories and perceptions and interpretations of the Pacific (Wendt, 1987, p86).

Even when commentators are critical of various New Zealand policies as they have impacted on Island Nations, the legitimacy of New Zealand as the appropriate central point of reference is seldom challenged. This hegemonic dominance means that the 'taken-for granteds' of the dominant group come to be represented as the natural order of the things. Their priorities and concerns become privileged.

This privileged position is reproduced in an education system that gives primacy to written histories and makes invisible or trivialises the oral histories of Pacific people and is itself symptomatic of the hegemonic power of a dominant ideology. The result is that most New Zealanders remain largely unaware that journeying in the Pacific has 
a long history amongst Pacific people. Even when some of the stories are known, they have been denigrated as 'mythical' or discredited as 'accidental discovery'. It is part and parcel of an ethnocentric view of...

Westerners (who) assume that they are the only ones capable of purposeful exploration, and that others (ie Polynesians) did it by accident while exploring coastal areas in simple watercraft (Keegan \& Diamond,1987, p66).

The case put by Geoffrey Irwin argues strongly that Polynesian people have a different world-view about the great Pacific Ocean than do Westerners. He states that to the people of the Pacific “...the sea is a highway not a barrier. Islanders (sic) saw the Pacific as a sea of Islands or a highway, whereas Continental humans see it more as an expanse of empty ocean” (Irwin, 1992, p54). According to Irwin the Pacific was settled by returning voyages, that developed skills of exploration and oral traditions of navigation.

All of this is by way of a challenge to the popular and contemporary representations of Pacific people's migration to New Zealand as a recent phenomenon. From a Pacific perspective, modern migrations are simply a continuation of a very ancient tradition. What has changed in the last sixty years has been the exportation to Pacific Islands of materialist values of a commodity capitalist economic system that has steadily undermined subsistence and peasant economies, and represents itself as the means to a "good life". This breaking down of traditional value systems coupled with improved transport systems has created the situation in which many Pacific people have been drawn to the metropolis communities of the Pacific rim; particularly North America, Australia and New Zealand.

In the case of New Zealand the initial post war migration of Pacific people was a welcome boost to the unskilled labour workforce in a buoyant growth economy. Migrant labour was a source of cheap labour. As Spoonley (1988) argues, they also provided an economic boost to landlords in city locations where demand for housing, particularly in Auckland and Wellington had been declining. 
In the last decades of the twentieth century, the relationship that exists between New Zealand and many of the Island States has been characterised by a push on New Zealand's part to encourage political and economic independence of these Island States. This move has been a delicate balancing act on New Zealand's part. On the one hand it has wanted to maintain it's power of influence over those States with whom they have enjoyed 'traditional' ties, such as the Cook Islands, Niue, Tokelau and Western Samoa. In particular New Zealand has been careful to preserve these 'markets' for it's own exporting and economic advantage. On the other hand, New Zealand has been reducing the amount of Foreign Aid it has been prepared to continue to invest in these Island economies.

It can be argued that in this endeavour New Zealand governments have at least been as consistent with these Island Nations as they have been with their own internal policies. The same language that has been used to articulate the change in Government direction within the New Zealand economy is also used in relation to redefining the relationship between New Zealand and these Island States. For example, in the 1990s New Zealand has had to adjust to a restructured economy that has shifted core values of social equity and social responsibility to values of selfreliance and individual autonomy. The mid 1990s saw the introduction of aggressively monetarist policies and values which advocated that the proper role of government was minimalist intervention, which was founded on the belief that the 'market' was the appropriate regulating mechanism for economic growth and development. And just as many New Zealanders have remained suspicious of the claimed benefits of self- reliance and individual autonomy, so too, Island States have been suspicious that the rhetoric of 'independence' has been a code word for abandonment.

The history of the relationship between the different Island States and New Zealand can be characterised by a complex of mixed motives and actions, each intent on maximising self- interest and advantage while using a rhetorical language of mutuality and collaboration to minimise and disguise differences. Geoff Bertram argues that a hallmark of New Zealand's decolonisation programme involved developing commodity markets in Island States and encouraging a trend towards economic integration with New Zealand, while at the same time moving these same 
States towards political self government (Bertram, 1987). The difficulty Island States had with this policy was that this imposed model of 'development' was profoundly unattractive because the development of a commercially viable non-subsidised capitalist economy created considerable burdens on the resident populations. As Bertram suggests;

Far more attractive is the development option which Islanders (sic) have pursued on their own initiative: the internationalisation of kin groups, with migrants and their dependants fanning out across the Pacific Basin to colonise niches of economic opportunity wherever they can be found (Bertram, 1987, p28).

Whatever the intent of Government policy, Bertram has articulated a motivational viewpoint that most Pacific people would accept as accurate. For many who moved to New Zealand during the 60s and 70s, the goal was to get an education for their children and to earn sufficient to enable them to remit money 'home' for their kin group. Meltzoff and Lipuma (1986) put it even more forcefully when they state that....

The subject of development is never homo economicus but real people living in the image of their own culture.... People's attitude to modernisation is... their search to innovate in the face of uncertainty (p61).

One of the particular characteristics of this wave of migration consistent with Pacific stories of previous migrations, was that it seldom represented a single one way event on the part of those who migrated to New Zealand. The desire to maintain kinship links is a powerfully held value for most Pacific peoples and this has resulted in a pattern of circling migration. What distinguishes Pacific people’s migration patterns is that it is generally not a definitive 'one time' movement, but is frequently marked by return visits 'home', or relatives making short term visits to family in New Zealand (Bathgate., Alexander., Mitikulena., Borman., Roberts., and Grigg 1994). In a study for example, of Tokelau Island people, Wessen (1992) reports that: 
Only 39\% of the (Tokelauan) migrants to New Zealand did not leave New Zealand for a visit to Tokelau at some stage between 1967 and 1982, and of those classified as "non migrants" who lived in Tokelau during this period, $60 \%$ spent at least 2 months abroad (p43).

The impact of this returning pattern of migration on either the community of origin or New Zealand communities has not been well documented, but it would tend to suggest that Pacific people's frequent returning to their Island homelands would have enormous impact on those communities over time. Equally, it would seem reasonable to suggest that the frequent visits 'home' would continue to reinforce 'home' cultural values so that the assimilation to dominant culture in New Zealand would be a slower process than for other migrant populations.

Crude contrasts between tradition and modern, and between disengagement and incorporation, point to the manner in which migration simultaneously acts as a force of conservation and dissolution (Connell, 1990, p21).

\section{Settling in New Zealand}

The bald statistics of Pacific people's settlement in New Zealand in the latter half of the twentieth century fails to articulate the nature of that lived experience for those who migrated and subsequently settled in New Zealand.

Like the ocean itself, Pacific people's migration from the late 1940s was initially like a slow building wave that gathered momentum during the sixties and seventies, and finally crested in the early 1980s. The speed the wave traveled and the extent to which it grew can in large measure be explained by mutually supportive opportunities to realise ambitions of self- interest. To reiterate, for migrating people from the Pacific homelands this was expressed in a desire to provide better education opportunities for their children, and at the same time fulfill the obligations to their kin groups by remitting money back to their homelands. For New Zealand, the arrival of increasing numbers of people from the Pacific provided a source of cheap labour to meet the needs of the country's industrial growth. 
Following any 'boom' periods in capitalist economies, the inevitable bust years of the mid 1970s and 1980s brought retractions in the New Zealand economy. In this economic climate, Pacific people represented an'underclass' which provided a convenient scapegoat to be exploited as the cause for New Zealand's economic troubles. Spoonley (1988) for example, describes the National party's cynical use of Pacific peoples migration and settlement during the 1975 general election, portraying it as a 'threat' to 'New Zealanders' job opportunities and prosperity. These actions were followed in the 1980s by what has become infamous to Pacific people as the 'over-stayers' campaign, a politically motivated campaign directed ostensibly at all people who were illegal immigrants in New Zealand at that time. It was during this period that the scandalous 'dawn raids' were undertaken by Immigration and Police agencies and executed almost exclusively against Pacific people. Ross (1994) argues that as a result there remains an ideological legacy of negative stereotyping of Pacific people that persists in this country. She states that:

The stereotypes that had been created in the previous decade (1980s), those of the “overstaying Islander”, “the lawbreaker”, and the immigrant who took “New Zealanders” jobs, continued to influence people's perceptions of Pacific Islanders” (p143).

This perception she further argues, citing newspaper editorials, cartoons and letters to editors, illustrates a deep sense of fear New Zealanders of European descent have towards Pacific migrants, creating a "spectre of the 'immigrant threat' from the Pacific" (p155). A fear that is not supported by any rational examination of the facts of the situation.

For a start, during the 'overstayer' campaigns no care was taken to distinguish between Pacific people who are New Zealand citizens by right, such as Tokelaaun, Niuean and Cook Islands Maori for example. Nor was there any acknowledgment that most Pacific people resident in New Zealand were in fact legal immigrants. It was a period when all Pacific people were conscious that they were tarred by the same 'overstayer brush' unless proven otherwise. 
That the campaign waged against Pacific people was racially and or ethnically motivated can be argued by the fact that at the height of the overstayer campaign, the Government claimed that there were approximately 9500 illegal immigrants in the country. Pacific people accounted for less than a third of this number but they were virtually the only ethnic group arrested, prosecuted and deported for the offence. By far the biggest proportion of people overstaying temporary visitor permits consisted of North Americans, Britons and Continental Europeans (Ross, 1994).

Perhaps the most instructive aspect of this whole episode in New Zealand's history is that it provides an example of the way hegemonic power operates to manipulate a society's values by cynical self serving politicians and a complicit press. The actions of both major political parties have "perpetuated ideologies and continued to marginalise Pacific Islands immigrants”(Ross,1994, p181). One of the consequences of this legacy of negative stereotyping has been the creation of a "subtle message that Pacific peoples are visitors as opposed to citizens of this country. Yet the majority of Pacific peoples in New Zealand were born in this country” (Ministry of Pacific Island Affairs, Pacific Directions Report, 1999, p11).

\section{A Local Settlement Story}

Porirua is situated 12 kilometres to the north of Wellington. Its earlier years are associated with the warfaring exploits of Te Raupraha and the establishment of Ngati Toa Rangatiratanga along the Kapiti coastline and Takapuwahia in the 1820s. Initial pakeha settlement from the late 1820s and 30s was related to whaling, forest milling and farming (Carman, 1970., Keith, 1990).

For over one hundred years the name Porirua has been associated with the large psychiatric hospital sited on land donated by Ngati Toa. This association between the hospital and the town has been a source of ambivalence to the people of Porirua. Established in 1887 as a cottage hospital, by 1897 there were some 240 patients, and by the 1920 s over 1200 people were incarcerated in the asylum. On the one hand the 'asylum' challenged the community's need to be distanced from the 'insane'. On the other hand the hospital has always been an important source of employment and economic security for many of the residents in the area. 
In 1945 the population of Porirua was estimated to be about 5000. In the mid 1960s as a result of increased Pacific peoples migration into the country and the migration of Maori people from rural to urban settings, an explosive expansion of Porirua's population took place. According to Keith (1990) this sudden acceleration in families being housed in State Housing created immense infra-structural pressure on basic community facilities such as transport, health and education. The population that moved into Porirua in this period were largely, but not exclusively of Pacific Islands and Maori ethnicity. Many were unemployed or underemployed, and all were lowincome to meet the income test set by Government policy to qualify for a State house. According to Keith, Porirua was a 'dormitory' suburb and most people who wanted paid employment would daily leave the area in their thousands. Keith writes of these decades:

A notable feature of the employment scene then was the train from Porirua to Wellington at 2 o'clock every weekday morning, packed with Pacific Island women. For years these women cleaned offices and buildings in the effort to establish their families in their new lives, returning at dawn to begin another day in unpaid work running their households (Keith, 1990, p54).

This evocative picture provides a memory that is held strongly by the children of these women. Paid employment for many Pacific families living in the area at this time was limited to three principal options. Night cleaning for the women, work for both men and women as hospital assistants at the Psychiatric hospital, or work primarily for men at the local car assembly plant (Todd Motors). The various factors that have been part of the history of development of the area have resulted in a community that has felt itself to be stigmatised and marginalised. Initially this sense of marginality related to the geographical distance between Wellington and Porirua. Over time this marginality has been reinforced by the area's proximity to the Psychiatric Hospital and then later with relatively large populations of Maori and Pacific Islands people. It is from within this stigmatised community that the participants of this research spent their formative years. This Chapter provides a context to situate these participant's stories. 
The following poem written by Fa'afetai Ta'ase (personal communication November, 2000) speaks of his experience of growing up in Porirua and acknowledges the work of his parent's generation in his reference to the arc welders at Todd Motors and the late night cleaners. It also speaks of the parent's aspirations that their children use education as a way of attaining a 'better way of life'.

\section{New Zealand is a Polynation by Fa'afetai Ta'ase}

Hey Daughters of the hibiscus

Sons of the sea and sand!

Remember the old plantation that we worked with the sweat of our land

Caressing life at our fingertips?

Do you remember?

Here our home, our land is not ours

It belongs to The Mortgage

The Housing Corp

The debt collectors

It belongs to a thousand pieces of paper.

But it is ours too.... until a better place comes along.

Do you understand?

Here, my father works in the shadow

Of the flashing arc-light.... And thus he said:

Learn well. Open wide the books!

Learn how to earn the bucks... everyday.

Learn how to do it the palangi way.

So. What now?

I know who we were

I know who we want to be

But who are we Now?!

Is there answer...

Daughters of the hibiscus 
Sons of the sea and sand

For the

Sons of Todds

And the daughters of the late night cleaning.

All I hear is silence.

The poem serves to illustrate a point which is fundamental to the issue of identity formation for succeeding generations who are New Zealand citizens but yet selfidentify with their Pacific descent and heritage.

Clearly the message of the father is that if you want to get on in life, "earn a buck", you have to do things the "palagi way". The way you learn to be palagi is through education. The question for the sons and daughters is how do you become more "palagi" and yet still be " a daughter of the hibiscus", a "son of the sea and sands"?

In more orthodox analyses, marginality is limited to a logo-centric explanation of how diverse populations within a society are excluded and homogenised. The poem serves to introduce the fact that there is diversity within sub-cultural groups. These groups maintain their distinctiveness through their ability to reproduce the normative values and beliefs that set them apart from others. For Pacific people living in New Zealand, claims to a Pacific identity are strongly articulated through attributing greater status to those who are Pacific born and reared, retaining fluency in a home language and having socially acknowledged genealogy lines of descent. Claims to a 'Pacific identity' start to become problematic for the individual as these attributes become weakened by settlement and enculturation in the New Zealand context.

This process is not unique to migrant Pacific people. In discussing the relationship between language and cultural identity for Greek migrants in Australia and America, Papademetre (1994) argues that “... the attitudes of many sociolinguistic groups towards the language-identity link are constantly modified as the dynamically shared culture evolves” (p510). He shows that while language competency is an important part of group inclusion/exclusion rules, particularly for first and second generations, it becomes less significant with succeeding generations. However, other criteria for group formation develop in the place of language. 
Boundaries are used by all social groups to include and exclude members from a group or sub-group, creating in the process multiple memberships for individuals. ... In time, the demarcation shape will change but NOT the demarcation process, which will continue to provide the structural concept of boundary (Papademetre, 1994, p511. Bold and italics in the original).

The dynamic nature of negotiating boundaries that permit an individual to claim membership to the group can, according to Giddens (1991), create an ontological and existential anxiety for the individual. I would argue that particularly for New Zealand born Pacific people, this anxiety lies at the heart of their concerns about their identity, as illustrated in Ta’ase's poem. Tiatia (1998) also illustrates this anxiety in her thesis entitled; Caught between cultures: A New Zealand born Pacific island perspective. In this work, the author articulates the position of many of her contemporaries in which they feel torn between the conflicting values of dominant culture and Pacific cultures. Unable to feel fully accepted in mainstream dominant culture, New Zealand born feel vulnerable to possible exclusion from their own Pacific cultures.

If mainstream dominant culture has a tendency to stereotype all Pacific people as the same, then it must also be acknowledged that within Pacific cultural groups themselves there is a strong tendency to essentialise that which makes one 'Pacific' especially in comparison to non Pacific people. It is in the shared normative rules of what makes one a 'good' Pacific person that one experiences these values.

This Chapter has addressed the issues related to the migration of Pacific people to New Zealand. I have shown how the pattern of this migration and settlement has occurred over the past sixty years with both mainstream New Zealanders and Pacific people using migration and settlement to satisfy their respective self-interests. I have also argued that at times this self interest has created an environment of conflict and mistrust in which Pacific people have been negatively stereotyped and as a consequence found themselves stigmatised and marginalised from mainstream New Zealand society. For Pacific people this experience has raised ontological challenges about how they 'fit in' as New Zealanders while at the same time maintain their identity and identification with their Pacific descent and heritage. An understanding of 
this background provides a context for situating the participant's stories and shows how the concepts of marginality and identity have been extracted as central organising themes for this thesis.

I have also described the boundary that is maintained by Pacific people in relation to mainstream society. The next chapter is divided into two parts. The first describes the boundary that is maintained by mainstream society in New Zealand while the second part envisages a reconstructed map of marginality that creates the space for locating the participant's stories. 


\section{CHAPTER FOUR: RE-FRAMING MARGINALITY}

\section{Part One}

In the previous Chapter I described how Pacific people migrated to and settled in New Zealand. While first welcomed as a boost to the unskilled labour force during a period of industrial expansion in the 1950s and 60s, this welcome was short-lived. Antagonistic attitudes directed at Pacific people became a legitimised mainstream discourse as a downturn in the country's economy resulted in a diminished need for unskilled labour. Pacific people become a convenient scapegoat for mainstream New Zealand society. One could argue from a Marxist perspective, that within the New Zealand context, they became a 'reserve army' of chronically under and un-employed. Marx argued that the function of this 'reserve army' in capitalist economies is to create competition for jobs and by doing so "act as a constant depressor on wages”(Giddens, 1971, p56).

Despite the fact that the majority of Pacific people resident in New Zealand are citizens of this country, the legacy of the 'overstayer' campaign is that in the eyes of many 'New Zealanders', Pacific people are transient. Their presence in this country is perceived as evidence of the 'generosity' and 'tolerance' of New Zealanders rather than as a result of New Zealand's neo-colonialist activities in the South Pacific region or the contingencies of a capitalist economy. These attitudes and values have the effect of locating Pacific people at the margins of New Zealand society and frames the concerns of these citizens as a 'problem for New Zealand society' rather than a 'problem of New Zealand society'.

The question of the social location of Pacific people within the New Zealand context will be discussed in this Chapter by deconstructing the concept of marginality. Using a range of theoretical positions I intend to show that marginalisation is a process that creates, and over time recreates, the boundary between mainstream New Zealand society and Pacific people. Central to this argument is my contention that the process of negatively stereotyping Pacific people has occurred to such an extent that their 'marginalised' status in this country has become a 'taken-for-granted' fact of life. 
I want to show how these forces of inclusion/exclusion operate in the wider society before applying the arguments to nursing. Without an appreciation for how the process of marginality privileges one cultural group at the expense of others, it is difficult to get to the contradictions that I would argue are embedded in the nursing discourse. Our language of 'empowerment', 'partnership' and 'equity' is strangely at odds with the fact that the nursing workforce is almost exclusively the domain of Pakeha women.

\section{Deconstructing Marginality}

The use of a deconstruction approach within the context of this thesis is to foreground the concept of marginality as a central organising theme. As Crotty (1998) argues:

Deconstruction makes a major theme of 'the positive side of Otherness - of being excluded, shunned, “frozen out”, disadvantaged, unprivileged, rejected, unwanted, abandoned, dislocated, marginalised (p168).

Within a Radical Hermeneutic framework, Derridian deconstruction creates an opening. It is the beginning point for a Hermeneutics that can hold to the complexity and not retreat into the comfort of metaphysical explanations. According to Caputo (1987), the essential thing about deconstruction is the “...opening it creates ... it is not the resolution" (p5).

In this thesis, deconstruction begins with a description of the way marginality has been articulated in a range of theoretical positions. The concept of marginality has become the term used to describe the process by which some members of a society are relegated to its peripheral edges. Different theoretical explanations have been developed to explain how and why this process occurs. What all these positions have in common is that they take for granted a binary inclusive/exclusive model of social order.

Without equivocation, Giddens (1991) baldly declares that Modernity “...produces difference, exclusion and marginalisation”. He goes on to state that (while) 
“...holding out the possibility of emancipation, modern institutions at the same time create mechanisms of suppression rather than actualisation of the self” (p6).

From a more conventional sociological perspective Erikson (1970) argues that the 'social system' is the “...organisation of society's component parts into a form which sustains internal equilibrium, resists change and is boundary maintaining”(p122). An example of a typical framing of the relationship between those at the centre of a society, and those at the periphery, is provided by Hall, Stevens and Meleis (1994). They write; "Mainstream society is depicted as at the centre of a community, and those relatively excluded from power and resources are at the periphery” (p26). Being marginalised means that those who occupy this location in society have limited access to material resources or the power to significantly alter their circumstances.

Marginalisation, I am arguing, is not a process of idiosyncratic 'accident'. Nor is it an example of some kind of natural law as is sometimes argued by latter-day Eugenicists, in which those most worthy and capable naturally migrate to the centre while those less capable are flung by some strange social centrifugal force out to the periphery. Rather, in keeping with a Critical Social Theory approach (Fay, 1987., Crotty, 1998), I am making the claim that the process of marginalisation results from a socially constructed 'centre' that systematically represents and reproduces the visible normative values of invisible hegemonic power relations. The exercise of this power to name normative practices and simultaneously inscribe 'the other' enables members of a dominant culture to control the processes by which their power can be reproduced over time.

This process is cloaked in self serving explanations of the 'natural' and the 'normal' that enable a taken-for-granted form of cultural blindness. By this I mean that in a modern society such as New Zealand the major institutions of the society are presented as if they are 'culturally neutral'. The social institutions of health and education for example are predicated on culturally specific normative values, which, because of their very taken-for-grantedness are hidden to the dominant culture that produces them. There is in all of this a double whammy for those who do not or cannot belong to the dominant cultural group. The first of these is the perpetuation of the fiction by the dominant group that the social institutions of the society are 
culturally neutral. The second is that by denying that social institutions are in fact culturally specific, the dominant culture has the power to locate the problem with the marginalised rather than with the system. The documented failure of Pacific people within the education system, along with their failure to access health care 'appropriately' is used by members of the dominant culture as evidence that the failure lies with Pacific people themselves rather than the social system.

The value of Critical Social Theory is that it reverses 'the gaze' of inquiry and focuses attention on the way hegemonic power operates to systematically privilege one group over others in the society. The declared fundamental intention of Critical Social Theory is to disrupt and de-centre this hegemony. Fay (1987) argues that Critical Social Science’s aims are “...achieved only when all three phases of the tripartite process of enlightenment, empowerment and emancipation” of marginalised people is achieved (p29).

As previously discussed in Chapter Two, while I am sympathetic to the Critical Social position, there are nevertheless serious limitations to this theoretical perspective. The most compelling limitation is the unacknowledged paradox that is created by Critical Social Theory taking as a given the binary relationship between the dominant culture and those it marginalises. In the very act of their critique Critical Social Theorists recreate the very relationships of which they are critical.

Another limitation of this theoretical position is that the 'critical gaze' can only focus in one direction. This has the effect of valorising the position of the marginalised. The practical effect of this is that the marginalised are not themselves ever the subject of the critical gaze. The perhaps unintended consequence of this is that marginalised people/groups become universalised and romanticised to the extent that one cannot acknowledge the power relations that operate between and within marginal groups themselves.

What all these forms of explanation do is produce a construction in which marginality can only be understood as a necessary but excluding process of the subordinate groups within the society. In her writing about the marginalisation of African- 
American women within American society, Collins (1991) provides an example of this process.

As the "others' of society who can never really belong, strangers threaten the moral and social order. But they are simultaneously essential for its survival because these individuals stand at the margins of society and clarify its boundaries. African-American women by not belonging, emphasise the significance of belonging (p68).

From a functionalist perspective then, marginalised groups in a society serve the function of creating and maintaining the boundaries between the 'us' and 'them'. Almost without exception, marginals are 'spoken for', they seldom speak for themselves. This construction of marginality as exclusion, paradoxically creates the very power relations that ensures the dichotomy is reproduced and maintained. By exercising their power to 'talk about' or 'on behalf of', commentators simultaneously recreate the category of marginality while at the same time obscuring the fact that their own voice is privileged in the discourse. Fay argues that the exclusionary power of the ruling culture is its ability to represent as 'natural', their right to assign normative values that determines the roles and actions of all members of the society. Almost inevitably this results in acts of appropriation and erasure by those occupying privileged positions at the centre, on those inscribed as marginal. Firstly we define and inscribe the 'other' and then we problemetise them. In doing this we can locate the problems 'out there'. In this way, society is able to maintain a mythological and cultural sense of homogeneity, while at the same time relegating and neutralising any groups of people who would challenge the taken-for-granted constructed sense of social order and cohesion.

It is interesting to look at the way Nursing has engaged in the discourse of diversity. The first sentence in the previously cited article by Hall et al (1994) provides a rather typical example of the 'voice' of Nursing. The article begins; “The future of nursing depends on the ability of the discipline to reach out to the diverse communities and to meet the health needs of those most vulnerable” (p23). Further on, the authors state that they intend to examine the concept of marginality... "and discuss its implications 
for shaping future research, theory and practice related to the health and health care of diverse populations” (ibid).

So, nursing is not part of, or emerges from a community of diversity? There is an assumption here that reveals the hegemonic nature of nursing itself. By exhorting nurses to 'reach out', it suggests that the authors have unconsciously located nursing at the centre. And one could be forgiven for thinking that reaching out is not an invitation for nursing to de-centre itself. This is not an invitation to a more revolutionary act of relocating itself from the centre to the margins. It is worth noting that while the reason for "reaching out" seems to be about serving the health needs of the 'most vulnerable', the real justification I would argue, is the more primary concern that this action will protect the "future of nursing". In other words, far from being a call for nursing to attend to its duty to care, it is a self-serving strategy to protect the interests of nursing. Not only will nursing mask its own privileged voice, it is proposed that nursing will appropriate the needs of the marginalised in order to preserve that privilege.

While a number of other nursing scholars, ( Le Blanc, 1997., Boutain, 1999., Meleis \& Im, 1999., \& Taylor, 1999), have written eloquently on behalf of, and advocating for, the marginalised and vulnerable in society, they have not appeared to apply their critique to nursing itself. While acknowledging the cultural diversity of the societies about which they write, none of these authors asks why it is that nursing remains the almost exclusive preserve of Anglo/Euro cultures in modern societies which are characterised by increasingly diverse cultural populations

The nursing literature that does address the question of cultural diversity within nursing is almost exclusively from the perspective of nursing education and the challenges of attracting and then retaining students from diverse cultural and ethnic backgrounds. For example, Gerrish, 1997., Vaughan, 1997., Kirkland, 1998., and Dowell, 1996., all challenge the almost exclusively mono-cultural Anglo-Euro characteristic of nursing in relation to the question of recruiting a wider ethnic diversity into nursing education. An important exception to the claim made here that nursing has not been critical of it's own role in reproducing hegemonic power relations is provided by Giddings (1997). In her thesis, she argues that the 
profession’s tendency to create, “... homogeneous categories of diverse cultural or ethnic groups as minorities serves to make invisible the very real differences between the ethnic or cultural groups and encourages a 'one fix for all' approach from those in power in the 'majority' culture (p17). Giddings uses a cross cultural approach to illustrate just how diverse nurses are, but at the same time how their marginalised position within the profession makes them invisible. Two other exceptions to the claim that nursing has not been critical of it's own power structures are provided by Blackford and Tanner. Blackford (1997), describes a clinical practice environment in which the predominant Anglo-Australian nurses within the Unit underwent a process of consciousness raising about how their ethnicity privileged them in relation to the ethnically diverse population of their clients. Tanner (1996), in an editorial commentary challenges the Euro-centric world-view of nursing and its slowness to acknowledge the contributions of other cultures.

Within the New Zealand context the whole question of nursing's responsibility to care for a culturally and ethnically diverse population has been taken up in the "Cultural Safety” debate. The issue of cultural safety in nursing emerged as a challenge by Maori nurses in the mid 1980s. They argued that monocultural nursing practice was harmful to the health and well being of Maori. While Ramsden (1990, 1992, 1993, 1995, 1996) and Ramsden and Spoonley (1993) has unquestionably been the principle architect and contributor to this debate, others such as Cooney (1994), Wood and Schwass (1993), Coup (1996) and Polaschek (1998) have also made important contributions. The tenor of this New Zealand literature is largely a normative argument for how nursing should be experienced by Maori patients and their families, and by implication all people whose culture and ethnicity are different from the nurse.

Without question I support the tenets of Cultural Safety as it has been articulated by Ramsden, and endorsed and legitimated by the Nursing Council of New Zealand (1996) the statutary body responsible for regulating nursing in this country. However, I am critical of the fact that while the 'Cultural Safety' debate has focussed on the practice of the individual nurse, it has not challenged the structural and institutional hegemony of 'nursing'. Polaschek (1998), in his critique of Cultural Safety argues that: 
Attempting to de-programme individuals of their societal influences, when the social structures which inculcate and reinforce those individual attitudes remain unaltered, does not seem to be an adequate strategy to achieve the changes which the concept of cultural safety aims at (p454).

By taking for granted the dominance of Pakeha culture in nursing, the Cultural Safety debate has paradoxically legitimated that very dominance, while at the same time reinforcing the position of Maori and other cultural and ethnic minority groups as 'other'. For all its support for Cultural Safety in this country, the Nursing Council of New Zealand is in truth less 'New Zealand' and more 'Pakeha'. Despite almost two decades of working with the concepts articulated in the Cultural Safety debate, Nursing in New Zealand has yet to confront the hegemonic dominance of Pakeha culture as the taken for granted culture of nursing itself.

The significance of all of this can perhaps be illustrated by using my own reflections as an example. If nursing is embedded within and emerges only from the dominant culture, how do I as a woman who self identifies with a minority culture that is marginalised, call myself a nurse? How does any person located in those groups that are excluded and marginalised become a nurse? From a social construction in which marginality is defined as excluded and 'other', I would argue that the answer to these questions is that the individual has to first become 'Pakeha'. This is a process of assimilation.

The utility of functionalist argument is that they describe the way some members of a society are systematically excluded from full participation in the society. The limitations of the explanations are that they tend to take for granted this process and do not challenge the nature of the power relations that operate within the society to create and recreate these very relationships. While Critical Feminist Theory and Critical Social Theory do provide a challenge to hegemonic power relations, I have argued that their tendency to normative explanations has the paradoxical effect of reinforcing the binary opposition between modernist society and marginalised groups such as Pacific people. 
Before I go on to argue a reconstructed map of marginality, I have inserted on the next page a rather extended quote from bell hooks (1990). While the quotation itself has intrinsic relevance to the discussion, the quote also serves as a metaphorical hyphen between the deconstructed and reconstructed arguments of marginality. This is in keeping with a Radical Hermeneutic agenda of trying to stay with the complexity. 
I am waiting for them to stop talking about the "Other," to stop even describing how important it is to be able to speak about difference. It is not just important what we speak about, but how and why we speak. Often this speech about the "Other" is also a mask, an oppressive talk hiding gaps, absences, that space where our words would be if we were speaking, if there was silence, if we were there. This 'we' is that 'us' in the margins, that 'we' who inhabit marginal space that is not the site of domination but a place of resistance. Enter that space. Often this speech about the 'Other' annihilates, erases: "No need to hear your voice when I can talk about you better than you speak about yourself. No need to hear your voice. Only tell me about your pain. I want to know your story. And then I will tell it back to you in a new way. Tell it back to you in such a way that it has become mine, my own. Re-writing you, I write myself anew. I am still author, authority. I am still the coloniser, the speaking subject, and you are now the centre of my talk." Stop. We greet you as liberators. This "we” is that "us" in the margins, that "we" who inhabit marginal space that is not a site of domination but a place of resistance. Enter that space. This is an intervention. I am writing to you. I am speaking from a place in the margins where I am different, where I see things differently. I am talking about what I see. (hooks, 1990, ps151-152). 


\section{Part Two}

\section{Reconstructing Marginality}

The map of marginality previously described constructs the concept as a narrow and limiting dichotomy of either/or, and is inadequate for understanding the experiences of those of us who are marginalised. In that dominant culture construction, the 'marginalised' are reduced to a shadowy residual category, distinguished more by what we are not, (i.e. "not one of us"), than by who we say we are. It is this construction that gives weight to the idea that marginality is merely a residual category for all those human activities and values that are not easily accommodated within the normatively constructed world of mainstream social order. This is a logocentric representation that places mainstream at the centre of the universe, an exclusive and privileged primary point of reference. The attributes which the marginalised themselves may cherish and value are dismissed as irrelevant and made invisible, while at the same time hegemonically inscribed characteristics are uncritically conferred. The reductionism of this construction leads to distortion and paradox.

In this section I am attempting to reconstruct the concept of marginality from the site of 'the other'. Like hooks I am speaking from a place in the margins where I am different and where I see things differently. The need to reconstruct the concept of marginality can be seen as the first step in claiming the space from which we as Pacific women give voice to our own experiences in our own terms.

Articulating a reconstruction of marginality is to begin with a somewhat surprisingly banal observation that marginality is not the binary opposite of mainstream social order. The binary opposite of social order is chaos. In Purity and Danger, Douglas (1966) argued that "society" is made possible through a systematic pattern-making schema of ritual and meaning making. Anything outside of this "meaning sharing community” is consigned to the formlessness of chaos. In Douglas' argument, marginals provide a necessary safety zone between the society and chaos.

In contrast to Douglas who framed the dichotomy between a society and undifferentiated chaos, I would argue that the dichotomy in modern societies is 
between hegemonic social order and differentiated 'others' within the society; between the mainstream culture and the subcultures within any given society. People who locate themselves within these social worlds have what Giddens (1991) describes as "ontological security". The cultural values and norms of these respective groups provide an intra-culturally " shared - but unproven and un-provable" - framework of reality that is both "simultaneously sturdy and fragile" (p36).

It is this shared framework that enables the most mundane activity of day-to-day living by suggesting an ordering of the chaos, and allows us to bracket out "the potentially infinite range of possibilities open to the individual” (ibid). Learning how to belong within these socially constructed groups is constitutive of our sense of identity, - the "I/we/us", and is foundational to healthy living. I would argue that in modern society marginals are those who move between the boundaries of these socially constructed groups within the society.

If an uncontested sense of belonging to a socio/cultural group is fundamental to the formation of a person's identity and “ontological security” the question then arises, how is 'identity' possible for those who are marginalised and stand in the between space. For these individuals, do notions of 'belonging' and 'identity' become issues of profound ontological insecurity?

The task of a reconstructed concept of marginality is to create the space in which the voice of the marginalised can be heard, while at the same time not deny the very real impact of the existence of the boundary between the social location of the marginals and mainstream society. I have shown in the previous section that the dichotomous model of marginality has the effect of making the 'marginalised other' invisible, or visible only through mainstream interpretation.

Giving voice to marginality from the social site of the 'other' runs the risk of valourising the marginal and at the same time demonising mainstream society. It seems to me that this kind of representation of marginality is simply the dichotomous model in reverse, and would result in similar levels of distortion and or reification. 
What I needed was a model of marginality that would acknowledge the reality that society is made up of diverse cultures and that the nature of the relationship between these cultures is co-creational. I also needed to be able to argue that the boundaries that separated groups within the society are not totally closed or impermeable, and that people can get caught between these classificatory boundaries. Being able to create a model of society that can begin to hold to the complexity of its social arrangements without having to prematurely foreclose on this diversity is the Radical Hermeneutic intent of this project.

So much of our thinking has been shaped by binary models that we are sometimes fooled into thinking that this is the only way of viewing the world, and that explanations are complete. We are so habituated into either/or patterns of argument that we are ill equipped to deal with subtlety and complexity. The 'dialectic' has itself become a reified and culturally bound view of the world. While no one would doubt the utility of the dialectic as a model of explanation, we sometimes need to remember that this form itself forecloses on other possibilities. The dialectic contrast of 'night and day' provides a simple example of how binary meaning can simultaneously illuminate the characteristics of each by reference to the other, and at the same time suggest a complete explanation that is not sustained by more careful examination.

To understand something of the quality of 'night' one must also know something of the quality of 'day'. Without night there can be no day, and visa versa. The dialectical understand of night and day is a typical and mundane metaphorical example for understanding contrasting, but at the same time, inextricably linked relationships. An understanding of how blunt and lacking in subtlety this view of the relationship between night and day is, can be grasped when one remembers that our days are not merely the stark contrast between night and day. Our days are also marked by dawns, sunrises, sunsets, dusks, twilights and evenings. Our language reveals that we have a much richer and more complex way of describing time than is revealed in our simple night/day binary. It is something of this challenge to binary conceptualisation that I want to bring to a different articulation of marginality.

In his elaboration of Van Gennup's descriptions of rites of passages, Turner (1977) provided the first clues on how a reconstructed map of marginality might be framed. 
A rite of passage, Turner argued, was a three-phase process that a neophyte had to successfully negotiate. The first phase involved the neophyte having to cross a threshold from their existing place in the society into the unknown. The stepping across the threshold marked the beginning of the rite and separated the neophyte from the world they had known before and cast them into a liminal world. The liminal world was the second phase of the rite and it was in this phase that the neophyte experienced the ritual humiliation that stripped them of their former identity and status, creating the Tabula Rasa upon which the rituals of the rite of passage would inscribe a new identity. The third and final phase of the ritual was what Turner described as the re-aggregation phase. Here the neophyte is returned to their society, outwardly changed and inwardly transformed. Having successfully completed the rite the individual is re-integrated back into the society with a socially constructed acceptance of their new identity and status.

When I first encountered Turner's work nearly twenty years ago I was struck by the way his description resonated with my own experiences of becoming a nurse. Most vividly I recalled the threshold where my parents delivered me to the Nurses home where I was to begin my training. I remembered that they were not allowed to accompany me to my room but were required to hand me over to the "Home Sister" who in turn directed me to my room. My three years training to become a nurse certainly felt like a rite of passage, having all the classic elements that Turner describes, such as ritual humiliations to create the blank slate on which was to be inscribed my new identity as a nurse.

So Turner's model resonated with my personal experience of becoming a nurse, and I returned to this framework when I began trying to reconstruct the map of marginality. And in this re-visitation what I found useful was the simple construction of state/space/state that was in his description of the rite of passage. In this construction I could locate mainstream culture in relation to Pacific subcultures. Significantly for me the construction also identified the space between these social locations which I am arguing is the reconceptualised location of marginalised people. Although Turner's model indicates that there is movement across these sites, it fails at this point to have further utility because the movement that he indicates is possible is linear and unidirectional. In the reconstruction that I was attempting to articulate, movement 
between the states is circular. What was significant for me in Turners work was that the construction of state/space/state did not suggest a simple binary dialectic. The space at the centre breaks open the dichotomy.

In Martin Buber's work I also found a relational model that also seemed to provide a way around binary constructs. In the Kauffmann translation (1970) of Buber's work both forms of the title "I and thou" and the more familiar "I-Thou" are used. On the face of it, Buber seems to argue that the nature of all relationships is dialectical. For example, he says:

The world is two-fold for man in accordance with his twofold attitude. The attitude of man is twofold in accordance with the two basic words he can speak. The basic words are not single words but word pairs. One basic word is the word pair I-You (p53).

What I found significant in Buber's work was the use of the hyphen. For while the hyphen separates the I from the You, it simultaneously keeps the I and You in relation. And in this respect Buber's I-You looked to me like Turners "state/space/state. The hyphen, the space, the non-location, the site of the marginal. But not necessarily a site of loss and deficiency. The verse by Lao Tse gives poetic and spiritual expression to other possibilities.

Join together thirty spokes - you have a wheel:

Where there is nothing,

The wheel is useful.

Mold clay together - make a vessel:

There where there is nothing,

The vessel is useful.

Cut out doors and windows to make a house;

There where there is nothing,

The house is useful.

Though there are advantages in being,

Nothingness is useful ( Lao Tse, 1960, p76). 
In the writings of others such as hooks (1990), Fine (1992 and 1994) and Anzaldua (1986), I found people who also seem to understand the power of the space, even when they have named it differently as margin, hyphen or borderland. What is common in the writings of these authors is their understanding that the 'space' is the location of creative possibility. The natural tendency of social structure is to maintain the status quo, necessarily making them conservative/ conserving and resistant to change. Innovation and change, I am arguing occurs in the inter-structural space between. Observing how closed or permeable the boundaries are around any social structure, how resistant to change from the margins, the borderlands or the hyphenated space is a way of mapping the relationship between 'mainstream' and 'marginalised'.

The notion of 'space' in this context then is not to indicate a place of nothingness. Quite the opposite in fact. It is the site of all possibilities unmediated or ordered by social structure. It is the recognition of 'space' in this sense that created for me the logical resonance with Radical Hermeneutics and its insistence on staying in the 'flux', and chaos. By locating the notion of 'space', (flux, chaos), within a reconceptualsied map of marginality that we are able to hold to the complexity and resist explanations that direct us into simplistic either/or dichotomies.

Nothing in this should suggest that being marginalised is something that any of us welcomes into our lives. If that were the case why would any of us experience anxiety about not belonging. I would argue that entering the space of the marginalised is always a wounding experience, and that being in the margin carries the possibility of annihilation as well as creation.

In the previous Chapter I argued that Pacific cultures themselves create inclusion/exclusion boundaries of group membership in order to preserve their identity as Pacific people within the New Zealand context. In this Chapter I have argued that understanding 'marginality' solely from a dominant cultural perspective is inadequate, even when the boundary between dominant and subordinate cultures is put under the critical scrutiny of Critical Social Theory. 
In the second part of this Chapter I have suggested the way a reconstructed understanding of marginality may provide a richer description of the social location of Pacific people, particularly those who are New Zealand born. This reconstructed map of marginality serves as a template against which I undertook the interviews with the participants in this project. The template that I developed from this reconstructed map involved three phases that I named 'Being', 'Becoming' and 'Belonging'. The 'Being phase is congruent with Buber's notion of the 'I' and Turner's notion of the preneophyte. The 'Becoming' phase stands in relation to this work as does Buber's hyphen in the I-Thou, and the liminal phase in Turner's work. The 'Belonging” phase resonates with the Thou of Buber and the reaggregation phase of Turner. In the next Chapter I set out in detail how I used this template as an organizing schema for interviewing the participants. 


\section{CHAPTER FIVE: METHOD AND DESIGN}

\section{Method}

Research that is underpinned by hermeneutic philosophical assumptions does not have a well articulated method as do other research positions (Geanellos, 1999). Van Manen (1997) provides some insight into why this might be the case with particular reference to phenomenological research. From his use of the lower case I have extrapolated his comments to be true for all interpretive inquiry including hermeneutic research. In his argument he suggests that there is no "expectation to arrive at a recipe, a fool proof set of techniques and know-hows that are guaranteed to produce repeatable scientific results”. Understanding phenomenological methodology is to be sensitive to the necessity that one works backwards from "meaning to method", and that there is "no single method, just as there is no uncontested truth”(p346). To attempt to achieve a single method or to achieve "the truth" is to misunderstand the hermeneutic enterprise, which as Van Manen puts it, is to "discover the historical approaches and suppositions that may hold promise in rendering human experience interpretable and understandable in our present time and place” (p346).

In this research project I wanted to know what the experience of becoming a nurse was like for women who self-identified as a person of Pacific ethnicity. My foregrounded belief was that their experiences were substantially different from non Pacific students undertaking the Comprehensive Nursing education programme. This belief was founded on my own life experiences as a self-identified person of Pacific ethnicity and from more than fifteen years experience in Nursing education. It was this personal experience that opened me to the possibility that the Pacific student's experience was different from other students.

This difference was reflected in the number of times these students had to re-sit tests and assignments to achieve pass grades, the proportionately higher number who failed to complete the programme and the number who had to re-sit State Final Exams in order to Register. While some attempts had been made over the years to address these issues they were generally Faculty initiated, and directed towards students on an 
assessment of individual remedial need. Within the Faculty there had always been an acknowledgement of a Bourdieu-like explanation that Pacific students, who in the main come from a lower socio-economic class, lacked the "cultural capital” to do well in tertiary education.

The problem has been that these issues have been identified as 'deficiencies' in the student with the focus then becoming a question of knowing how to address them effectively. For example, one explanation for lower academic achievement was that Pacific students as English Speakers of Other Languages (ESOL) found it harder to achieve in a programme that was taught in English. Extra support with language skills was provided, but no quantifiable difference in performance was demonstrated. What this explanation and remedy failed to address was the fact that the majority of Pacific students are New Zealand born and educated. English is the first, and for many, their only language. The explanation also failed to address the fact that ESOL students from other cultures seemed to have fewer academic difficulties than Pacific students. All this remedy seemed to achieve was to increase the work-load of students who were already showing signs that they were not coping.

Another explanation for Pacific students' poorer achievement has been that many of them come into the programme as 'second chance' students. That is to say that they are older students who have been in the workforce and make the decision to come into nursing later in life as opposed to those who go into nursing straight from secondary school. People who are 'second chance' students sometimes struggle initially as they make the adaptations of becoming a student again. It is usually the case though, once they have made this adaptation, that 'second chance' students do very well because they are keenly motivated. In the case of Pacific 'second chance' students this explanation is turned on its head and becomes an explanation for why they do not do well in the programme.

In all of this, there was no clear sense of what institutional barriers hindered the learning experience for Pacific students. Nor was there any understanding to what degree their lack of success belonged with the individual student, or in what ways their Pacific identity hindered or supported their efforts. What has become clear over the years is that a culture of low expectation has emerged in relation to Pacific 
student's achievement that is shared both by the Pacific students themselves and by many in the Faculty.

In this project I wanted to focus on what the experience of being a student in the programme was like from the student's perspective. What meaning had they made of their experiences, and how had this meaning been shaped by their life experiences before coming into the programme? In particular I wanted to know how students interpreted their experiences through the lens of their self-claimed identity as Pacific women. The method I believed would provide understanding and insight into these questions was through the use of narrative.

\section{Narrative as Method}

Stories of ones "people” as chosen or enslaved, conquerors or victims, as well as stories about one's nation, social class, gender, race or occupation, affect morale, aspirations and personal life chances. These are not "simply” stories but are narratives that have real consequences for the fate of individuals, communities and nations (Richardson, 1995, p212).

As Richardson argues above, narratives are more than "simply" story telling. Stories are how people tell their lives. They enable us to make meaning and sense of our experiences over time. Chanfrault-Duchet (1991) states that life stories "represent a meaning system complete unto itself, i.e., it is a text.” Embedded within the text is not only the "temporal and causal organisation of facts and events", but also the "value judgements that make sense of this particular life experience” (p77). Geanellos (1995) makes similar claims about the value of storytelling within a hermeneutic paradigm. Expanding on the utility of storytelling she argues that; "Stories reconstruct lived experience, however storytelling is more than recalling past events as it comes complete with emotional aspects of a story that the reader or listener relates”(p56). It is not simply the case that people tell stories about their lives, but rather that we are constituted as knowing subjects by the stories we tell about ourselves. We make meaning of our experiences through stories that are more than a mere reflection of a 'world out there'. They are an "unfolding" of a "knowing because" in the 
“experiencing subject” (Stanley, 1993, p205), and “they are constructed, creatively authored, rhetorical, replete with assumptions and interpretation (Riessman, 1993,p5).

\section{Issues of Rigour}

The critical question that applies to any research project is what knowledge claims are being made and what test can be applied to these claims. In other words, how rigorous is the research. In research projects that set out to achieve knowledge claims about causal explanations, the tests of reliability and validity are conventionally and appropriately applied to measure rigour. Establishing what criteria are appropriate tests to apply to particular research is more than simply arguing that quantitative research uses tests of validity and reliability and qualitative research uses other criteria. For example, researchers who use a qualitative methodology such as grounded theory demonstrate some anxiety in wanting to establish positivist criteria for their knowledge claims. Lather (1986) argues that “... new paradigm researchers must be more systematic about establishing the trustworthiness of the data... in order to minimise the distorting effect of personal bias upon the logic of the evidence" (p65).

In this project, I have not set out to establish knowledge claims of this order. Rather, this project aims at achieving understanding; what Van Manen (1997) describes as "plausible insight”. He argues that good interpretive inquiry has been achieved when it enables us to "suddenly 'see' something in a manner that enriches our understanding of everyday life experiences” (p345). He suggests five criteria for evaluating interpretive research that I have found useful in applying to this project. These criteria he describes as concreteness, evocativeness, intensity, tone and epiphany (p350).

The test of concreteness is that the "phenomenon is placed concretely in the lifeworld so that the reader may experientially recognise it”. (p351) "Evocation”, he argues, "means that the experience is brought vividly into presence so that we can reflect on it". Vividness is "methodologically valuable because it creates the experience of nearness or presence" (p353).

Intensity is the way language is used. Van Manen states that "we must give key words their full value, so that layers of phenomenological meaning become strongly 
embedded in the text” (p355). There is a nuanced difference between between Van Manen's criterion of intensity and tone that perhaps musicians can understand more clearly than those of us who are 'tone deaf'. "Tone”, he states, “means that we must let the text speak to us, address us, so that its deeper meaning has a noncognitive effect on the reader” (p359). Finally, Van Manen argues that an interpretive project must have the quality of epiphany. "Epiphany means that the text must bring about a transformative effect so that its deeper meaning makes an edifying appeal to the self of the reader. Epiphany refers to the sudden perception and intuitive grasp of the meaning of something” (p364).

These criteria seem a more appropriate test of whether or not this project has been able to convey layers of interpreted meaning so that one arrives at a new place of understanding. This text openly acknowledges that 'interpretation' never finally arrives. By this I mean, that whatever is conveyed in this text invites further interpretation in the reading. This is best demonstrated in the way I have written up the third interview with the participants, in Chapter Seven. Three voices are interwoven, and the reader can choose how they want to read the text. Each reading opens the possibility for different interpretations.

\section{Research Design}

\section{Participant Recruitment}

In 1995 I made three presentations to groups of Pacific Registered Nurses in the Wellington region about the research project I was wanting to undertake and included an invitation for those nurses who met the inclusion criteria to participate in the project. The inclusion and exclusion criteria that I had determined for the selection of participants included the following. Each participant was to be a Registered Nurse who self-identified as a person of Pacific ethnicity. I specified women only, and only people who had undertaken their nursing programme at a particular Polytechnic and who had completed their programme at least twelve months prior. The rationale for these criteria is discussed below in the ethics section. Information sheets (see appendix 1) that provided an outline of the project, inclusion criteria and details for how potential participants could contact me, were distributed at each of the presentation meetings. This method of making initial contact with participants was a 
compromise solution to managing the tension between Pacific people's preferred mode of communication and negotiation and the conditions for recruitment set by the Wellington Health Research Ethics Committee. I will discuss this tension in more detail in the ethics section.

From those nurses who did contact me following the presentations, a final selection of four people was made. Of those who made contact but did not proceed with the project, three people had not undertaken their nursing education at the Polytechnic, which was one of the inclusion criteria, and one person who despite her best efforts and mine we could never co-ordinate our diaries. In the end this person goodnaturedly withdrew her offer to participate but left open the possibility that I could contact her at a later date if for some reason any participants withdrew or if I felt I needed to recruit any more participants.

After initial contact from the four volunteers who became the participants in this project, I made arrangements to meet individually with each person. At this meeting I went over the details of the project again to ensure each person understood what they were being asked to participate in. Included in this briefing I gave each person the opportunity to indicate whether or not they agreed to having their interviews taped, and what they wanted done with their tapes at the end of the project. It was also at this meeting that each person was invited to choose the name by which they would like to be known in the project. When each person indicated their readiness we signed the informed consent forms (see Appendix 11) that included contact details of the Wellington Ethics Committee if the participants felt they had any concerns about the way I was conducting the research. Having attended to the recruiting details for each participant, we then made arrangements for the time and venue for the three interviews I was to undertake with each of them.

\section{Ethical Considerations}

Earlier I mentioned that there was a tension between what I understood to be good practice when working with Pacific communities and the conditions for recruitment requested of me by the Ethics Committee. The Committee's concern was the potential for ex-students of mine to feel obligated to comply with direct requests from me for them to participate in the research. For this reason the Committee required that I use a 
method of recruitment that did not rely on personal and direct contact. A not uncommon method of recruitment is through local newspaper advertisements for recruits.

The difficulty I had with using this method for recruiting participants is my knowledge that within a Pacific world-view, if you expect someone to do something for you, then that request ought to be made in direct face-to-face situations. All Pacific cultures are structured around complex webs of relationships that articulate appropriate levels of obligations and responsibility between individuals and families. Before I can make a request of you we must first be in relationship. And before I will agree to do something for you, I first must know who you are. An advertisement in the papers would not have been sufficient. Presenting the project at meetings enabled me to find a middle path. It allowed me to speak directly to the potential pool of participants without breaching the Ethics Committees requirement to not make direct contact with the individual. Having made these accommodations, I was given approval by the Ethics Committee to undertake this research project.

From the outset I did not have a clear sense of how many participants I would need to recruit for this project. I started with the objective of recruiting between four to five participants with the understanding that if necessary I could recruit more. As Sandelowski (1995) has agreed the decision about how many participants to recruit for a qualitative project can seldom be know a priori. She suggests that an adequate sample size in qualitative research is one that yields "new and richly textured understanding of experience” ( $p$ 183). Having initially recruited four participants for this project, I found their stories provided more than sufficient material to allow for deep analysis.

\section{Rationale for Inclusion Criteria}

The rationale for specifying women only in this project was mainly due to a concern to maintain participant anonymity. The potential pool of participants was quite small and within this already small pool Pacific men represented an even smaller group. Having made the decision to limit the participants to graduates from one school of nursing, I was not at all confident that if one of the male graduates from the school had applied to participate that maintaining his anonymity could have been achievable. 
The criterion that participants needed to have completed their pre registration programme at least twelve months prior to the beginning of this project was an effort to acknowledge and manage possible uneven power relationships between the participants as ex-students and myself as researcher and ex teacher. By having at least a twelve months gap I judged that participants would have made the relational transition from student to colleague. As it turned out all of the four participants had more than the stipulated twelve months gap and for three of them the gap was between six and nine years. The measure of whether or not participants felt safe would lie in the quality of the stories they were prepared to share with me. If participants felt unable to trust me, or felt in anyway coerced into taking part in this project, then I believe that would be reflected in them only sharing what they felt safe to share that was likely to result in superficial or mundane stories.

The rationale for limiting the participants to graduates from just one school of nursing was because I did not want the primary focus of this project to be centred on curricula issues. By limiting the participants to graduates from a programme with which I was intimately familiar had the advantage of liberating the participants and me from having to provide contextual details. Our beginning location had a certain taken-forgrantedness that helped us arrive more quickly at a deeper level of storying. Participants did not have to interrupt their story telling to explain structural or contextual aspects of their curriculum to me. Unlike some other research methodologies that strain for objectivity and distance between researcher and researched, Hermeneutic inquiry creates the possibility that both researcher and researched are participants in the project.

\section{Confidentiality and Anonymity}

While there was a risk for participants having their anonymity breached in this project given the relatively small pool of potential participants, I believed there were ways of minimising this risk. One of these ways was to make the decision to only refer to the participants as being of Pacific ethnicity rather than by identifying them by their actual Island homeland. While the populations of Samoan and Cook Islands people are probably large enough that guessing a participants identity is more remote, the smallness of some Pacific groups would have raised the risk of identifying a 
participant to unacceptable levels. Throughout the data Chapters I have removed or disguised any details that would risk inadvertently exposing a participants’ identity. This has in a couple of situations meant that some details of the participants' story has been edited or altered. In every case participants were given the opportunity to review their transcripts to ensure that they were comfortable that their anonymity was not exposed.

\section{The Interviews}

The three, one hour long interviews that each participant agreed to have with me were organised around three narratives. The idea of exploring these narratives was derived from the reconstructed map of marginality discussed in Chapter Four and that I called the 'Being', 'Becoming' and 'Belonging' stories. The purpose of the first interview was to enable the participant to talk about their experiences of their three-year nursing education programme. This was the Becoming story. The second interview invited the participant to talk about their experiences as Registered Nurses and was the Belonging story. In the third interview we shared our 'growing up' stories which was the Being story.

Naming the three interviews 'Being, Becoming and Belonging' became something of a trap because I fell in love with the alliteration and I found myself wanting to protect the form even when it no longer entirely served the purpose. Following the order in which the interviews were undertaken, and the way I have chosen to write them up, the interviews should read 'Becoming, Belonging and Being', the alliteration remains but the rhythm is lost.

In the next Chapter I introduce the participants and present the Becoming and Belonging stories. In Chapter Seven I present the Being stories, and conclude the Chapter with an extensive discussion of all three interviews. 


\section{CHAPTER SIX: THE INTERVIEWS}

\section{Introduction}

The first interviews undertaken with each of the participants involved them telling their story about their decision to choose to go nursing and their experiences of their three year Comprehensive programme. This seemed a natural beginning point for both my self as researcher and for each of the participants because it was in our respective roles as tutor and student that we had first become acquainted. Using the old teaching dictum of starting with the known before moving to the unknown or unfamiliar, I felt that starting the interviews at the point of our first acquaintance would enable me to reconnect with each of the participants and enable them to become relaxed with the interviewing process.

At the outset I had some reservations that each of the participants might be inhibited in their ability to talk freely to me because of the power imbalance that always pervades tutor/student relationships, however friendly or benign that relationship may seem to be. However, it soon became clear that each of the participants no longer saw themselves as "students" and were able to talk freely and frankly to me about their experiences and reflections of their journey to become a nurse.

While the intention of the first interview was to talk about their individual experiences of that journey, it became clear that for each of them there was a story that preceded their stories about their Comprehensive programme. I began each interview by asking the participants to tell me why they had chosen to go nursing in the first place.

What emerged from each of the participants was what I might now describe as a “threshold story”. While the reasons each gave for deciding to go nursing were varied and partial, what stood out as a common theme in all their stories was the level of difficulty each experienced in actually gaining entry into a Comprehensive programme.

I have divided this Chapter into two sections. The first, which I have entitled "Gaining acceptance. Stories from the threshold", documents why and how these participants began their journeys into the profession of nursing. The second section of 
this chapter deals more specifically with the participant's experiences once they had gained acceptance into their nursing programme. This section I have called "Working the margin. Learning to mediate discontinuous worlds.”

\section{Interview One: Becoming A Nurse \\ Gaining Acceptance}

Ann, who at nineteen was the youngest of the four participants when she started her nursing education was probably also the least clear about why she chose to go nursing. No one in her family had been involved in nursing and as she says, "I didn't even have the experience of being a patient before I started.” She described how she and a school friend visited the local polytechnic and checked out the information pamphlets advertising the different programmes available.

"It was scary because I knew I had to do something. Nursing was something I was always interested in, but never knew much about.”

When Ann finally decided to apply to enter the nursing programme she was initially disappointed to find that she was recommended to do a year long 'Bridging' programme first. Asked how she felt about this, Ann was philosophical.

"I felt really let down and disappointed at first because I was keen on moving ahead. But when I thought about it I knew that my school grades weren’t what you would call academic enough. But I knew I wanted to continue my education.”

Retrospectively, Ann was pleased she did the Bridging programme first. She attributes her subsequent success in the nursing programme to the preparatory work she did in this year.

For Tara, entry into the nursing programme was also by way of the Bridging Programme. Originally, Tara had applied to enter the nursing programme in 1986, but like Ann was recommended to do the Bridging programme first. And like Ann, Tara talked about the disappointment she initially felt with this decision. To her it felt like a 
personal failure and rejection. So much so that having successfully completed her Bridging programme, Tara chose not to apply to go into the nursing programme. Instead she joined the workforce, first as a Dental Assistant and then as a Hospital Assistant in a Rest Home. In 1993 she decided to apply once again for the nursing programme, this time at the prompting of a Registered Nurse with whom she was working. Tara talked about how nervous she felt applying the second time. Despite her reservations, it is clear that a stronger motivation for Tara was her sense that Hospital Assistant work was a dead end street, and that she could do better for herself.

"My experience of working at -----, was not very good because I've always been the sort of person who doesn't like taking orders from others, and I didn't like the way I was treated. I was fed up with being told what to do all the time. I decided I could be as good as them, .... even better.”

The support of the Registered Nurse was important to Tara at this time. As she said; ".... the fact that she believed in me was enough for me to believe in myself."

Tara was successful in her second application, although she did have to complete a four week pre-entry orientation programme first. Tara found these four weeks an invaluable preparation.

Of all four participants, Mary probably had the clearest understanding that she was going to be a nurse. She talked about the three things that most strongly influenced her decision. Her own negative experience of being hospitalised when she was a child, and the death of her sister left her with the determination to become a nurse and to “...be so much better than them”. Also Mary’s mother had been training to become a nurse when she became pregnant with Mary, and did not complete her training. In some way Mary felt that becoming a nurse was something she owed her mother. An obligation that she wanted to honour out of her respect for her mother. And she could live with the humorously acknowledged paradox that while this was how she felt, in fact her mother did not want her to go nursing. But even Mary's journey to realise her dream of becoming a nurse was not without some hiccups. 
Mary's first attempt to enter nursing was when she "wagged" school in the Fourth Form to be interviewed for Enrolled Nursing training. Not surprisingly she was turned down and stayed at school after this to complete her School Certificate qualification. A second attempt to get into Enrolled Nursing again resulted in disappointment. Connecting these two rejections with her experiences as a child, Mary commented...

" they treated me like shit when I was a child and here they were turning me away from being a nurse.”

This experience left Mary with:

"... a bit of a chip on my shoulder, and I had a real 'thing' against that Hospital that turned me down."

For a while Mary shelved her plans to go nursing, and became a secretary instead. Mary said that this pleased her mother because she liked the idea of Mary having a career in computers. In her view, working with computers was the kind of work that carried a suitable level of status for her daughter. But Mary could not give up her dream of becoming a nurse, and as a step toward fulfilling that ambition she got herself a job as a Hospital Assistant in a Psychiatric Hospital, and finally got the courage to apply to do her Comprehensive Nursing programme commencing in 1986.

Educated in her Pacific homeland to the Fifth Form level, Lia migrated to New Zealand in 1973 at the age of 18 years. For the next ten years she worked in a variety of settings as a Hospital Assistant. During this period she enrolled concurrently in night classes to develop her English skills. In 1986 Lia successfully completed her Enrolled Nurse's training and in 1988 she applied to enter a Comprehensive Nursing programme. In describing the roundabout route she had taken to get to the point of applying to enter the Comprehensive programme, Lia three times referred to herself and her abilities in self deprecating terms of "being dumb".

So for example she recalled a time when she was working as an Aide being encouraged by one of the Registered nurses to consider doing her training. Lia says her response was to laugh at the idea. As she said in the interview:

"You know us Pacific Islanders.... I thought I was too dumb. And I was frightened because the palagi would laugh at me." 
Again when she talked about doing some University Entrance papers through night school, she felt very unsure of her own abilities because she felt that: "My thinking at that time was that I was still dumb". Describing the hesitation she felt about applying to do her Enrolled Nurse training, Lia says:

"I didn't have any qualifications and I had the idea that they wouldn't accept me because I had nothing and I was dumb."

Despite these anxieties, Lia did complete her Enrolled Nurse training. For several years she worked as an Enrolled Nurse before finding herself becoming frustrated by the limitations of this role. Lia describes her feelings at this time. She says:

"I was desperately trying to reach out to get something better for my future on the one hand, but also feeling really scared that I wasn't really good enough and then the palagi would just laugh at me. And I didn't want to look a fool."

Using the new graduates from the Comprehensive programme as a yardstick, Lia felt that she was capable of nursing at that level, and in 1989, despite still having reservations about her academic abilities applied and was accepted into a Comprehensive Nursing programme.

What each of these four stories illustrate is that none of these participants saw themselves as having a strong academic background prior to their acceptance into their Comprehensive nursing programme. This, coupled with experiences of rejection from prior attempts to enter nursing programmes, left each participant with a sense that somehow they were flawed; judged to be "not good enough". For each of the participants this experience was both shaming and humiliating.

For each of them, except perhaps Ann, the desire to become a nurse had been a long held ambition that in different ways each had worked hard towards achieving. Each of the participants had experienced some form of rejection; some thwarting of their attempts to realise their ambition based on judgements made about their academic ability to succeed in the comprehensive programme. 
Caught between wanting to pursue a career goal and at the same time not wanting to place themselves in situations where they might experience being shamed and humiliated caused considerable anxiety for each of the participants. Perhaps this fear is best illustrated by Lia's comment that she feared being judged by palagi as "too dumb", and this would make her a target for their derision and laughter. This threshold then is a significant location, because for each of the participants it marks the point at which they lose control over what degree or to what extent they can participate in the palagi world. For Mary, Tara and Ann it could be argued that "going nursing" was no different than having to go to school, given that each of these participants had received their education in the New Zealand context.

But there are significant differences. For a start, the very compulsory nature of their pre-tertiary education meant that this was not a personal goal or decision they made for themselves. They went to school because they had to, not because they chose to. And because it was not something they had chosen for themselves, they had nothing personal invested in their success or failure at school. Applying for entry into the nursing programme though was a different matter. For a start it was an active choice on their part, and because they had chosen this pathway they had a personal investment in their choice being realised. So to be 'accepted' or 'rejected' took on a significance and meaning that they had hitherto not experienced.

And it is clear that all of the participants perceived their programmes as 'belonging to the palagi', and that to enter the course was to enter a palagi world. This perception was as true for the three New Zealand educated participants as it was for Lia who had been Island born and Island educated. It was their perception therefore, that palagi had the power to include or exclude them from the nursing programme. Entry into the programme then is a highly significant threshold that marks the boundary between two worlds, the world of the palagi, and the more familiar world of family and culture. For each of these participants these two worlds were largely discontinuous. If Nursing was part of the 'palagi' world, then the other world was that of their respective ethnicities expressed in the cultural life of their families and communities and experienced in their self-identification as Pacific women. Learning how to mediate the boundaries between these two worlds was as important an aspect of these 
participant's experience of 'becoming a nurse' as succeeding in the formal and informal aspects of their nursing curricula.

It may be claimed that in many respects the experiences of these Pacific Islands women were the same as for all students entering the three year Comprehensive programme. But what is significant here is the participants perception that in critical ways it was different for them. The flavour of that difference is what is revealed in their stories about their experiences.

\section{Mediating Discontinuous Worlds - Working The Margin}

In this second part of their first interview, the participants talked about their experiences as students within their nursing programmes. If the "gaining acceptance" story is their "threshold" story, then this section is their "liminal" story. In his classical analysis of Rites of Passage, Turner (1969) argued that the liminal stage begins with the neophyte being reduced to a 'Tabula Rasa', a blank slate upon which new learning is etched. In the case of these women, their 'threshold' story indicates that they enter the liminal stage not so much blank slates but damaged slates.

While other students may enter the programme with some anxiety about whether or not they have the ability to 'make it', that anxiety seldom prevails. Measuring themselves against their peers, their talk is often along the lines that if others have made it, then they can make it as well. This is generally not the experience for Pacific Islands students, particularly those who have been educated within the New Zealand context. These students have been scripted through their previous experiences to accept academic failure as the norm.

Feeling vulnerable and uneasy in a palagi education system is not always ameliorated by familial or cultural support. Pacific parents are keen for their children to be well educated. Enabling their children to get a good education is the single most frequently given reason by parents to migrate to New Zealand in the first place. But often not having been educated in this country themselves, they have a limited understanding of what it takes to succeed in this system. The inevitable clash in cultural values frequently results in parents and communities distancing themselves from the system 
in order to maintain their own cultural integrity. For each of these participants then, their stories about their programme became stories about how they managed to succeed in mediating the differences between the two often discontinuous worlds of their home and culture and their nursing programme.

For Mary, learning how to mediate the two worlds of 'palagi nursing' and her Pacific family and culture was a conscious decision on her part to 'become palagi' within the nursing programme. For her this meant learning how to fit in. She says:

"I felt I had an advantage over those students who were educated in the Islands because I had been brought up here and I knew how to fit in. Before going to Polytech I used to be really shy. At school I was really shy and I always sat at the back. I never talked. But when I came nursing I learned to push myself forward, and I felt safe enough to learn to ask questions, to ask a tutor to repeat something if I didn't get it."

At the same time, Mary was conscious of the fact that her family and community had high expectations of her.

"I always had pressure. Like I wasn't only going in for myself. I was taking my mum and dad and the whole family, and the family name. So that was always on me. I felt that pressure."

Mary felt that this sense of carrying a whole community on your shoulders was one that many Pacific Islands students bore, especially for those students who came from the 'elite' families.

"There were high expectations in regards to the type of family you came from. For those students who came from one of the elite families, they had an even greater burden not to shame their families by failing the course."

But, according to Mary:

"... you had to learn to leave all of that behind you. Like sometimes I had to deny what I felt inside to... fit in. I learned to put on a brave face." 
As well as learning to put on a brave face, Mary learned that developing her sense of humour was also a great help to her 'fitting in'. Asked what skills she thought she had that enabled her to get on with people, Mary quickly responded:

"My sense of humour. But that had to be developed as I went on, it was part of my learning."

Learning to mediate the two worlds was for Tara about learning the significance that language played in creating these two worlds, and then how she learned to use language that enabled her to move from one world to the other.

"I had to try and develop strategies and tactics for myself to try and adapt to... what would you call it... a Western structure of learning. I was trying to bridge the gap. You see there was nothing to translate it with or to compare it with, and so I was always struggling to make sense."

For Tara the 'gap' occurred when in her nursing programme she encountered language and concepts that did not have equivalence in her home language. It was not simply a case that she could not translate some concepts or language, it was more that some language and concepts were not translatable. This illustrates the way these participants experienced their nursing programme as a discontinuous world from the world of their respective cultures experienced in their family life.

In her own way Tara demonstrates that in order for her to succeed in her nursing programme she had to learn to "think like a palagi". This is what she means when she says she learned to "adapt to both worlds". Becoming a nurse for Tara did not mean that she learned to abandon her Pacific culture. What it did mean was that she learned what was appropriate behaviour in both worlds. She talked about learning what she could comfortably carry from her experience of one world into the other world, and visa versa. Using her hands to convey her sense of moving from one point to another and back again, Tara explained: 
"At first I used to try and carry with me this part into my Western mode of functioning, and I used to do the same when I went back into my own world.”

She was clear that this was a strategy she had developed in order to survive. As she reflected on her experience she talked about how she now felt more comfortable with her ability to move in and out of worlds and that she no longer felt so anxious about “carrying things over”.

"I had to learn to survive. Some things now I wouldn't carry over in the same way. For example, I used to go home and say to my family, 'we're going to do this and we shouldn't be doing that'. I wouldn't do that now. At first we tried to turn our families into palagi. I know a lot of my peers and friends used to get really embarrassed about our parents when we had to take them to palagi functions. We would coach them before the event .... you know, .... don't do this or don't do that. What I had to learn was that my mum and dad did things their own way and that was ok, and palagi do things their way. Now when I am home I do things my parents way, and when I am nursing I do things the palagi way."

When asked to explain in more detail what kinds of things they used to coach their parents about, Tara gave two examples.

"One of the things I really used to hate when I was younger was if there was food being served in a palagi setting. On the one hand I used to get embarrassed for my parents when younger people would help themselves to food before the guests and elders were served, because I knew they would interpret this as very rude behaviour towards themselves. On the other hand I could get really embarrassed because we often use our fingers to eat, where palangi might use a knife and fork.

The other thing that really embarrassed me when I was younger was that my parent's English is not very good. At home we only ever use our own language. I can remember when I was younger being ashamed of my parents poor English. Now I don't worry about these things. I've stopped trying to make my parents palagi” 
Ann's experience of learning to mediate discontinuous worlds finds their expression in her stories about trying to balance the demands of home against the demands of her nursing programme. For Ann this created a tension between 'being a good daughter', and 'being a good nursing student'. Within a Pacific world-view, being a good daughter meant respectful obedience to her parents. Ann remembers growing up in a household in which her parents had a deep commitment to their church. This commitment meant that all her parent's time not spent in paid employment was spent on church activities. As a consequence, Ann had the responsibility from an early age for all the household chores. This situation did not change when Ann undertook her nursing education. Whatever the demands of her nursing programme, Ann was expected to maintain all her duties and responsibilities for the running of her family home. At times it was a very busy household involving not only herself, her parents and her three siblings but also frequent family visitors from their Pacific homeland and the church were provided with accommodation and support. Ann describes it this way:

" I am the second eldest in my family, and somehow I was the one who was expected to do all the work around the house. My older sister was sort of protected and guarded from having to do any work, and my younger sisters were always considered too young. It just became a role I was expected to do. We had a lot of relatives that came from ------ (Pacific homeland) and stayed with us, so we had a full house. And, like, the custom is that even if someone arrives at 2 oclock in the morning, you get up and make something for that person to eat and drink. Sometimes I found that hard. I can always remember starting working on my assignments late at night, because that's when the work would be finished and the house was quiet. I used to sit in the lounge with my dad because that's when he used to do his work."

Ann's relative youth meant that she had limited negotiating power in her home or in her nursing programme to manage the competing stress she felt from both sides. Ann's story of her parent's lack of awareness of the pressures she experienced in her nursing programme parallels in some way Tara's story that some things were just not translatable from one world to the other. Some measure of the distance between Ann's 
worlds is captured in her story of her graduation. Although her parents were pleased when she passed her State Final examination, they did not attend her graduation ceremony because that was held on a Saturday which for her parents was their Sabbath and they were not prepared to forego attending church for their daughter's graduation.

Throughout this discussion, Ann was careful not to be critical of her parents. She commented:

"For my mum and dad the church came first. And I've got to a stage where I'm used to it. I respect that this is how it is for them."

Nevertheless, it is possible to hear Ann's regret that such a gap existed.

"I did the whole lot on my own. Doing my nursing just never seemed to be something they saw any value in."

Perhaps not unexpectedly, of all the participants, Lia who was Island born and educated had the greatest difficulty integrating her experience of being in two worlds. Her initial strategy seems to have been to associate almost exclusively with palagi in order to learn about the palagi way of doing things. She says:

"I had no xxxx (name of home Island) friends when I came out of the convent, but I did have a palagi friend who was a teacher and I kind of mixed with her a lot of the time because I wanted to learn the language and culture of New Zealand."

Not having Pacific friends or family in New Zealand with whom she could just 'be', and who could validate her sense of herself in her 'Pacific-ness', Lia seemed distressed by a sense of being 'stuck' in a palagi world that constantly reflected back to her, her different-ness. This sense of isolation was not ameliorated for Lia by finding there were other Pacific students in her class when she began her three year programme. To her mind, they had been New Zealand born and educated, and therefore were more familiar with palagi ways than she was. It is almost as if Lia resented her cultural 
isolation but paradoxically at the same time celebrated the sense of uniqueness her difference gave her.

"When I started my programme I saw that I wasn't the only Pacific student. But then I found out that I was the only one who had been born in the Islands. Well, ... there was 'H____. She had been born in Islands but she was mainly bought up in New Zealand. So that gave me a real bonus and a credit to me." (sic)

Lia seemed to want to establish her credentials, and that in terms of being a Pacific person she was more Pacific than anyone else in her class. What Lia's story demonstrates for us is that to be surprised that Lia found it necessary to distinguish herself from her New Zealand born colleagues, is to reveal a palagi ethnocentrism that categorises the experiences of all Pacific Islands people as 'the same'. Sometimes the differences within groups are as significant to the individual as the differences between groups. For Lia, not only did she have to negotiate the differences between her Pacific world and the world of the palagi, she also had to negotiate the differences between the worlds of an Island born and a New Zealand born Pacific person.

Like Tara, Lia referred to the difficulty of translating from one language to another when there wasn't equivalent concepts. She explained that for her, it was a struggle to learn in English, her second language. She says:

"If you write a story in my language it comes out fine. But when I translate to English, if I translate word for word, it just looks like rubbish. So I have to find a phrase or concept that says as well in English what I have said in my language. The trouble was, I often didn't know what the English word meant that I was trying to translate back to my own language.”

So for Lia, trying to cope with a palagi world that seemed at times very strange and foreign, she tried to stay as much as possible in that palagi world even though at times she found this a painful and lonely thing to do. 
“I think I kind of ended up with a 'split personality'. I feel like I wear a palagi mask on the outside and a Pacific 'me' on the inside. I don't know how to get rid of it.... I don't know how to belong to somebody.... I think somehow I've lost my identity, and I need to go back to my homeland to find myself again."

Her comment, "I don't know how to belong to somebody"... is a poignant glimpse of her sense of the loneliness and the alienation that she bears. A sense of alienation that each of the participants expressed albeit in different ways and to varying degrees.

For example, Ann noted that her experience of being in classes where she was the only Pacific student was different from when she was in classes with other Pacific students.

"It helped to have others around. In one class I think I was the only one and I had that feeling of being alone. In other classes there were a few of us together, and yeah, it helped.”

For Tara, while she felt confident with her ability to negotiate the gap between her home world and the programme. Nevertheless she felt at times a lack of support with having her needs as a Pacific student acknowledged within her programme. In making her point Tara compared her situation and that of other Pacific students with the level of support she saw being given to Maori students in the programme. She comments:

"I think at the beginning of my programme we were talking about setting up a Pacific support group, but it never got developed. I think I used to be jealous that our Maori counterparts always had huis and gatherings and support networks they could link up with. And I always felt sorry for myself and my Pacific peers that we didn’t have the same access, the same support networks set up for us. And that's something that I think could have helped us, could have made things smoother through the three years."

For Mary the situation was less clear cut. She found that while sometimes she felt supported by having other Pacific students in her programme, there were also times 
when she found that association conflicted with her coping strategy of 'fitting in'. This contradiction was the source of some pain for her.

"I felt like I was trying to get ahead, and for some of them I felt I was having to leave them behind. For a long time I used to feel heartbroken that we didn't all make it, and I feel guilty about it too. That's how I felt for a long time.”

While each of the participants was clear that their programme was challenging they were also able to talk about the way they experienced personal growth and development. Indeed, for the three New Zealand born participants they found their programmes to be so supportive in this respect that they each mentioned trying to persuade different members of their families to also enrol in the programme. In no small way, they attributed their success to the quality of support from their peers and from their tutors.

Each of the participants stories share a similar sense of discontinuity from their family/cultural world and the world they encountered on entering their nursing education programmes. For Ann and Lia, negotiating the discontinuity was for them a foreground issue throughout their three year programmes. Mary and Tara on the other hand appear to have developed strategies early on in their programmes that enabled them to put the issues of discontinuity into the background for most of the time. The level of support they all felt they received from their peers and Tutors was sufficiently encouraging for each of them to believe that whatever the difficulties they could nevertheless succeed in their three-year programmes. This sense of being supported was an important balance to the level of hostility each of the participants recalled encountering when they began their clinical placements in the second year of their programmes. Without exception, each participant talked about the sense of dread they felt each time they went into clinical. Ann, for, example, remembered that:

"I hated clinical. I remember cause my dad would always drive me there. The minute he drove into the entrance of the hospital I would feel it in my guts. I just didn’t want to go.” 
And Mary talked about being physically sick every time she went into clinical. She attributes her sickness to the level of stress she felt at these times.

"I used to feel so stressed, balancing everything. You know. Keeping on top of your assignments as well as your family commitments, and at the same time keeping your buddy nurse happy as well as the tutor. I found that absolutely stressful. I used to find myself getting anxious and then I would get a cold sore on my lip. Every time I went into clinical I'd have this blimmen cold sore. It was such a foreign environment and I never found the staff very supportive.”

Challenged to explain why they thought their experience was worse than for any other of their peers going into clinical, the participants freely acknowledged that all students experienced some measure of discomfort going into clinical placements. Clinical staff were generally perceived to be unwelcoming of all students, seeing them as an extra burden in their busy work days. But each of the participants while being able to acknowledge this also argued that sometimes in quite subtle ways, they experienced a level of hostility that was worse than that experienced in general by their peers. While sometimes this hostility was directed at them from patients, most frequently it was the hostility from the nursing staff in their clinical placements that caused them the greatest distress.

"I was treated really, really unkindly by a lot of the European nurses. I think I had to learn along the way, how to cope with these attitudes towards us Maori and Pacific students. It was as if they were saying to us “....this is our turf, and what do you think you are doing here. You don’t belong here.”

Elaborating on her response, Tara goes on to say:

"I mean it's true that all polytech students had a hard time, but I also think that some students don't have to struggle as hard as others. Some students have a bit more to cope with. Just being white... and I am not being racist or anything.... is enough I think to make things smooth for you. If some-one of my colour has to ... not prove themselves.... but have to go through some sort of initiation first, to be accepted.” 
Interestingly, Tara's reference to 'racism' as something she does not want to be accused of, is the only time this term was used by any of the participants during this part of their interviews. While they were clear that they experienced a more difficult time than their peers in clinical, they did not directly label the hostile behaviour as racist behaviour, even though as Tara demonstrated they associate the hostile behaviour with the colour of their skin.

Mary, for example when asked how she knew her experience was different simply replied:

“I don’t know. My gut feeling told me that they did not want a brown skin in their space." She also saw that dealing with this hostility was ... "part of my survival in clinical. First they would ignore you, and then they would treat me as if I was dumb. I learned to expect this every time I went into a new clinical placement. Then I would have to work really hard to warm them up to me.”

Ann recalls the subtle way negative and hostile attitudes were communicated towards her. She says:

"Sometimes it was the way they looked at you, and sometimes it was the way they ignored you. They are very subtle messages you pick up on. Messages that made me feel I wasn’t good enough, or somehow made me feel more foreign than I really am. It was a belittling experience. Just a nightmare. I became determined that I would never work in a General Hospital because that was where I experienced the worst treatment. It made me tend to isolate myself because I didn't want to get in their way. You try to reassure yourself that they are not worth it and all that, but...”

The 'but', and the silence that followed are almost as significant as the stories themselves. What is not reflected in the stories of each of these participants is their demeanour as they speak about these experiences. They tell these stories with heads bowed and voices lowered. Finding words to express what were painful experiences for each of them was difficult enough. Even more difficult is that recalling these 
incidents reminds them of experiences that left them feeling shamed and humiliated. Perhaps the most graphic example of this was told by one of the participants. This incident occurred in her second year. It was her first clinical experience in an acute setting and she was highly anxious and nervous.

"I felt really scared walking into the ward, but I was also excited. I kept thinking to myself, '... hey girl, this is what it's all about'. Now I'm really going to see what it's like. At the same time I was praying that I didn't foul up.

Any-case, I went to the door of the nurse's station and everyone looked really busy. I didn't know what to do, so I just stood there waiting for someone to notice me. Finally, (it felt like I'd been standing there for hours!), one of the nurses kind of looked up and said to me, 'oh, your stuffs down the corridor, $3^{\text {rd }}$ or $4^{\text {th }}$ door on your right'. I didn't know what she was talking about or what I was supposed to do. So I went down the corridor to where she told me and opened the door."

At this point the narrator pauses in her story. Her head is down and she is intently examining her hands resting on her lap. "What was behind the door?” I prompt. Tears start to stream down her face and plop onto her hands.

“It was the ward's cleaning cupboard. She didn't even notice that I was a student. She took one look at me and assumed I was the cleaner. I felt so ashamed. I didn’t know what to do. I just wanted to run away, but I couldn't. After a while I went back to the nurse's station and said, 'My name is and I am a student nurse.'

The nurse who had spoken to me before looked embarrassed and cross. And then she just laughed like she wanted me to understand it was just a mistake that didn’t mean anything. I just felt totally humiliated. Like she hadn’t even seen me. She just saw a 'PI woman' (Pacific Island woman) and thought 'cleaner'. I hated being there after that. It just ruined it for me. I couldn't wait for the day to end.” 
Asked if she had discussed the incident with her tutor when she came to the ward, she replied:

"Nah. What's the point. Besides I felt embarrassed enough. And it wouldn't have changed anything.”

Common to all the participant's stories was the sense they had that complaining to tutors about the hostile behaviour that they had encountered in clinical areas from staff or patients was not the done thing. Several things acting together created a climate in which the participants knew that not only was it not the done thing to complain, but one ran a real risk of experiencing even greater feelings of humiliation and shame if one did. During the time that these participants were undertaking their clinical placements, the Health Care System in New Zealand was undergoing drastic restructuring, including the down-sizing of Acute Services in Secondary Health Care Institutions. One of the effects of these changes was that finding and keeping sufficient clinical placements became a critical issue for many of the polytechnic programmes.

Students were as aware as their tutors that keeping these clinical placements was essential for the continued viability and credibility of their programmes. Together they created a climate of collusion to not critically challenge the educational value of some of these placements. In this culture of denial, it would have been a very brave Pacific or Maori student who complained about a placement on the grounds that some of the staff were hostile in their attitude towards them. As Ann observed, the messages were usually communicated in quite subtle ways. Students would have to have had confidence that they would be taken seriously if they had complained on these grounds. And that was not their assessment of the situation. As Ann says:

"What's the point. I felt embarrassed enough. And it wouldn't have changed anything."

The brevity of these three short sentences does not diminish the eloquence of the sentiment being expressed. In a nutshell it reveals the fact of the experiences, the hurt these experiences caused, and the hopelessness that anything could change the 
situation. A large part of the anticipatory anxiety the participants reported feeling every time they were preparing to go to a new placement was their knowledge that each new place was an unchartered environment where humiliation and embarrassment was always a possibility. Steeling themselves to be ready to deal with a possibility becoming an actuality lay at the core of their anxiety. Perhaps even more painful to reflect on now, is that not only did these students feel it was unsafe to discuss these events with their tutors, they did not share their stories with each other. This research project was the first time any of them had felt able to talk about these experiences. Hearing that the other participants had similar stories to tell was both a surprise and a relief to each of them.

Given the levels of anxiety, stress and loneliness that characterised each of the participants stories, hearing how they managed to survive and what motivated them to stay the distance seemed a logical next step.

Ann saw her survival in the programme as simply that. Surviving.

“I’m always determined to finish what I start, and I just became stubborn that I was going to finish this. I had to learn to trust that I could survive.... To believe in myself.”

Tara expresses herself with more bravado than Ann, but the sentiment of self -reliance is similar. She says:

“I really didn't give a stuff about what people felt or what their attitude was because I was there to get the experience and that was it. I guess I developed an attitude myself where I just toughened myself up.”

Lia seemed the least affected by the negative experiences she had. In her view, New Zealand was a "very racist society", so rather than internalising these experiences as evidence of her own inadequacies, she saw them as evidence of palagi inadequacies. In her stories she talks about feeling angry and frustrated and at times socially isolated. But her stories lack the sense of personal shame and humiliation that 
characterise the stories of the New Zealand reared participants. As a consequence, Lia is almost always 'heroic' in her own stories.

What emerges from this first interview with the participants was the difficulty that each experienced getting accepted into a Comprehensive Nursing programme. Their individual stories document the high level of persistence each needed before being able to achieve even this initial goal. But the achievement of this goal appears to have been won at some considerable cost. Each of the participants stories revealed that the rejections they received were keenly felt. For two of the participants their response to rejection resulted in an anger that saw them go off and try something else before finally having another attempt to gain acceptance into a nursing programme. For the other two participants, one could interpret their response to initial rejection as personal hurt. For all of them, the determination to become a nurse proved to be a stronger motivating force than their fear of further rejection.

Their sense of "gaining acceptance" then is more than just about gaining a place in a nursing programme. For each of the participants, gaining acceptance was also interpreted as a personal affirmation. Successfully crossing the threshold meant finally being accepted. Being acceptable. There is more than just punning games going on here.

But gaining acceptance into the programme was just the first step, as the second part of their first interview revealed. Learning how to mediate the discontinuous worlds of their home and ethnicity with the demands of a palagi nursing programme meant that gaining acceptance was never a taken-for-granted for any of the participants. Developing a range of different coping strategies meant that for each of the participants some level of accommodation and adaption was achieved between their home context and the context of the polytechnic environment. But as each participant clearly articulated, the wider context of their nursing programme remained a potently fearful environment throughout their whole three year programme. There is no accommodation possible in this kind of environment. Survival becomes the only tenable strategy. 
As someone who was a member of the tutorial staff during the period that each of these participants was enrolled, I have a personal sense of shame and grief at how impotent I sometimes was in not being able to acknowledge the reality of these student's experiences. I was confronted with having to come to terms with this in my capacity as researcher in this project. As the participants shared their stories of how they had to learn to mediate their multiple worlds, I also reflected on how I mediated the worlds between being Pacific and being a Tutor and the sense I had of being caught between the two worlds. Initially as a Tutor and then later in my capacity as Head of School, I certainly experienced from time to time criticism from colleagues who perceived me to be "too soft" on the Pacific students. The following excerpt from the interview with Tara gives a sense of the student's expectations of me. Expectations that I was dimly aware of, but only through undertaking this project have I become more sensitive to the importance of my "being there" from the students perspective. Tara said to me;

I have to say that during my training that I always looked up to you. We have a lot of respect for you because you had a link.... You know you were linked ... you are Tuvaluan.... So I had respect for you, both as the Head but also because of the respect for you as a Pacific person.

My response to Tara reflects my sense of inadequacy;

It's kind of you to say, but I'm not sure I ever honoured (their respect) particularly well.

Tara replies by not denying what I have said, but simply stating how she felt;

Yeah... well .... I think sometimes just having someone there... um... it doesn't make you feel so lonely... you don't feel so alienated in these western structured learning environments. So while I felt confident and able to do all that I had to to pass the programme, I also, underneath felt I had a mentor. I know my peers felt the same way too.

She then acknowledges my response by saying;

Sometimes I think, ... and I know some of the others felt... as if maybe you didn't always acknowledge us as much as you should. But regardless of that, the fact that you were there was enough anyway. Enough for us to make a 
connection, even if it wasn't always directly ... just knowing you were like one of us made it easier for us too I think.

One of my anxieties about undertaking this project had been that the participants who had all been former students would find it difficult to be sufficiently frank about their experiences. With my 'researcher' hat on, the level of openness and honesty evident in this conversation with one of the participants was reassuring. At the same time it was difficult to reflect on the criticism, however gently worded, in the participants observations. 


\section{Interview Two: The Belonging/Be-longing Stories}

This Section deals with the stories the participants shared in the second interview. Having successfully graduated from their three year programme, I was keen to know about their experiences as Registered Nurses. During the course of the first interview, each of the participants had graphically shared the difficulties they had experienced during the clinical components of the programme. Given these experiences, I wanted to know how they coped with these situations once they became Registered Nurses. Did they continue to experience the same degree of harassment that they had endured as students, or did their status as Registered Nurses mean that they now experienced a level of acceptance and respect from their nursing colleagues.

Continuing to loosely use the metaphor of a rite of passage as an organising device, if the Comprehensive programme represented the first two phases of threshold and liminality, then the participants experiences as Registered Nurses represents the final phase described by Turner (1969) as reaggregation. In this phase, the person is returned to their community, “outwardly changed and inwardly transformed”. By this Turner was describing the process whereby individuals within a group learn the skills, knowledge and appropriate behaviour needed in order to be able to take on a new socially sanctioned role. The reaggregation phase is the public affirmation by the group or community that a person has successfully achieved this new learning and is now deemed ready to undertake their new place in the group or community.

The purpose of this second interview then was to discover how each of the participants had experienced reaggregation. What difference if any, had they experienced in the family and within their communities since they had become Registered Nurses? Now that they were Registered nurses did they feel that they belonged to the profession of nursing? And did they still feel conflicted in trying to mediate the tensions between their two worlds?

Like all students who successfully complete their three year Comprehensive Nursing programmes, these participants talked about both the elation they felt in achieving this goal and also their apprehension leaving the relative comfort and security of the 
polytechnic to enter the work force as Registered Nurses. Lia talked about what this meant for her.

"So my excitement (at graduating) was the relief I felt that all that hard work, the sweat and tears was finished. I had this medal and qualification. But it was that star that did it for me. I mean you can't walk around with a Certificate pinned onto your chest. But the medal! That really did symbolise something. For me it was proof that I'm not dumb. That Pacific Island people are not dumb."

Having achieved Registration, Lia felt that she no longer experienced her perception of her communities' expectations of her as burdensome, a point that Tara also commented on. Achieving her Registration changed the relationship between Tara and her community. Rather than experiencing her community's expectations as a burden, she now saw this relationship in a different light. She says:

"What I noticed is that I'm getting a lot of respect from my people. You know, a lot of the younger members of my family see me as a role model, and the rest of the community know that I am a Staff Nurse and I find I'm getting a lot of respect from people. People who in the past may not have acknowledged me are now unusually polite.”

Like Lia, Tara was also aware that her new status shifted the way she perceived her community's expectations of her.

"I feel they are quite proud of me and that they see me as someone who can help them. And no, that doesn't feel like a burden. They come and ask my advice and I am pleased to be able to help them.”

Immediately following her graduation, Tara decided to take a some time off to be with her children. Tara had had two babies during the three years that she had been doing her nursing programme, and she felt she needed to spend some time with them before she began working as a Registered nurse. The consequence of this decision was that three months later when she began looking for work she found that most of 
the positions that she could apply for as a new Graduate were already filled. Tara said that she had really wanted to work in the Acute areas of Medical or Surgical nursing. She was aware that these were the areas that had higher numbers of Pacific patients, and she felt she could make a significant contribution to their quality of care. However, it was not to be. Tara was unable to secure a position in the Acute care services and in desperation to get some kind of work she finally accepted a position in a psycho-geriatric unit.

“At the time, I was really disappointed that I couldn't get a job in the Acute area. But now that I am working in the psycho-geriatric unit, I don't think I would like to work any where else. I love it. I just love it.”

Asked what it was about her work that she enjoyed it so much, Tara gave as an example the work she had been doing with an elderly man who was depressed and given up on himself and life in general. She talked with great animation and at great length about the challenges she had experienced working with this particular client. What she felt was so great was the opportunity she had to really get to know this person and to be able to work with him to a positive resolution. Tara's insight around this was her realisation that had she been working in an Acute area she would not have had the same opportunities to work so intensely over time with her clients. The other aspect of her work that Tara enjoyed was working in a multi-disciplinary team. Unlike Ann, who found the incidents of discourtesy she experienced threatening and distressing, Tara relished the challenges the multi-disciplinary team provided. What made Ann fearful seems to have made Tara feisty.

Listening to Tara, one gains the impression that she has found a way of mediating the tensions between her two worlds by simply acknowledging that they are different worlds and is very clear about not getting the roles muddled up. She makes no attempt to integrate them. They are separate and different and she moves with confidence between them. It is very likely that this clarity is what enables her to stand her ground.

Ann's approach is different. She has found that her role as a Registered Nurse enables her to make a different kind of contribution to her community, something she had never felt able or inclined to do before. She talked about the satisfaction she 
experienced participating in her Pacific language community radio programmes, where she was able to provide health information. One of the reasons why Ann found this work so rewarding was because she knew the programme had wide audience appeal, especially for older members of her Pacific community.

Immediately following Registration, Ann was only able to secure work as a Staff Nurse working in the Casual Pool of one of the local hospitals. The lack of orientation she received before being placed in situations involving high acuity patients reinforced for Ann her determination that nursing in the Acute Medical/Surgical areas was not for her. When a position became available in a psycho-geriatric unit she applied for the position and was delighted to be appointed.

Ann recognised that there was a real need for more Pacific nurses to be working in those areas where there were more Pacific patients. She talked about a couple of incidents she had experienced both as a student and as a Registered Nurse where her ability to communicate directly to Pacific patients in their own language was a welcome relief for these patients. However, she also felt that while this was important, it did not override her sense that these environments were not culturally safe places for her. In these environments she felt personally and professionally at risk of being compromised all the time. Ann felt that while staff in these Acute areas were happy to use her language skills when it suited them, they never saw Ann herself as a valued colleague, or that her ability to communicate freely with the Pacific clients might be of value to the clients themselves. So while Ann found that she was frequently asked by other Units to:

“... come and translate for the doctor or the Surgeon. I always felt that I was their resource, (the staff). It never felt like it was for the patient. It just never felt ok.”

For Ann, it never felt good to just be called upon by other Wards or Units to do translating work when she had not been part of any assessment or case consultation. Even in her own Unit, she sometimes found the attitude of some of her colleagues difficult. 
"I don't mind it happening (translating) in the area I work in because it's incorporated into my work and is recognised as a legitimate part of that work. But even in my own multi disciplinary team I get some colleagues who can be sort of sarcastic. 'Oh yes. That's right. You're the only one that can communicate with them'. It's like they are trying to put me down or intimidate me. Mind you, these are the same people who use the same tone of voice to ask me what it is a nurse does. I'm not too sure about these multi disciplinary teams sometimes”, she concludes with a laugh.

Ann and Tara's reflections on their initial experiences as Registered Nurses have a different flavour from those of both Mary and Lia. Throughout their training both Ann and Tara spoke about the tensions that existed for them in trying to balance the demands of the two worlds of their Pacific families and community against the demands of a palagi nursing world. In their stories post registration, both have continued to negotiate a pathway between these two worlds. But one begins to sense that they are taking control of how to play out the tensions in ways that are positive and affirming for them as individuals.

Mary’s stories of her experiences post registration lack that sense of synthesis. During her education programme, Mary’s strategy for success was to “learn to fit in”. To be accepted by palagi even though this often meant having to suppress what she described as her "true feelings". Following registration, Mary had little difficulty finding work as a Staff Nurse at a local Psychiatric Hospital. She had worked there as a hospital assistant prior to commencing her training, which may have aided her application for a staff nurse's position. Returning as a Registered nurse though, Mary had to confront the fact that the 'culture' of the institution was so abusive that she could not reconcile her newly acquired values and beliefs as a Staff Nurse with many of the practices she found. Her strategy for 'fitting in' simply did not serve her in this environment.

“My first experience as a Staff Nurse, and I was put straight into a maximum secure acute ward for women. I found it really scary. And I used to see how the staff treated a lot of the Maori clients. I don't remember seeing any Pacific Islands women there. I felt terrible. I knew what was being done was wrong. A 
lot of the staff were very staunch; been there for years, and I did see physical abuse from staff towards the clients. Sometimes I tried to speak out, but being a new 'grad', I was pretty much ignored. I didn't feel there was much support for me. As I said the staff were pretty clique and if you didn't fit in they would give you hell. The best that I thought I could do was to keep an eye on the young students who came into the unit to make sure they didn't get abused.”

When asked what she had to do to "fit in" in this environment, Mary provided a sickening picture of the kind of harassment she had experienced.

“Well, as I say, the majority of the staff were 'old hands' and they not only worked together they also socialised a lot together. And new staff were expected to join in. This meant a lot of alcohol and marijuana. And the male staff expected the female staff to be sexually available. I was labelled a 'lesbian’ because I wouldn’t part my legs for any of the guys at the parties. It all became pretty horrible. And I was young and naive at the time. Maybe if I'd been a bit older or worldly wise I wouldn't have been as devastated as I was at the time.”

Asked how she coped, Mary replied:

“That's where I picked up my alcohol bingeing. It was the quickest way I could relieve the stress. You know. Go to work, go home, have a few stiff drinks, flake out. Of course I was also smoking two packets of cigarettes a day at that time as well. On the ward I tried to keep my sense of humour. They could never take that away from me. And I also took pride in treating the clients with respect and courtesy. I was determined not to sink to the level of some of the practices I saw around me. But in the end I just felt worn out. Everyday felt like going to war. I left after nine months.”

Shortly after she left, Mary travelled overseas where she worked as a Staff Nurse in Acute Medical/Surgical Units for several years. On her return to New Zealand, Mary chose to apply for a position in a psycho-geriatric unit. She says she enjoys the work. It is challenging without being overly stressful. And while there are few Pacific 
clients, many of her nursing colleagues are of Pacific ethnicity. "Fitting in" is therefore much less of a struggle. The measure of how much less stressful this environment is for Mary is that she now no longer smokes and she no longer binge drinks.

Asked whether she now saw herself belonging to the profession of nursing, Mary replied that she didn't think so. While she felt like a Registered Nurse, and talked with quiet pride of the quality of respectful care she provided for her clients, she had no sense of belonging to a profession. Although she talked in vague terms of one day maybe doing some more professional development, I had the sense that Mary has found a comfortable niche and she has neither the will nor the desire to do anything too different that may threaten the sense of safety she now experiences.

Compared to the other participant's stories, Lia's story about her experiences once she Registered, appear to have been a relatively un-problematic transition from student to staff nurse. Like Mary, Lia applied for a position in the service that she had been working in as an Enrolled Nurse prior to undertaking her Comprehensive training. And like Mary, Lia had no difficulty being re-employed, beginning with part time employment at first but then quickly moving to full time work in a psycho-geriatric unit.

Lia's only commentary on this period was the stand she had to take to ensure she was not given supervisory responsibilities before she felt she had made a safe transition from practising as a new grad to practising as a reasonably competent staff nurse. Because of her familiarity with the unit and the particular client group, Lia felt she made a fast transition. She enjoyed the work because she said it enabled her to be congruent with her cultural values that esteemed and valued older adults. However, because of restructuring changes in the Institution, nine months after beginning work in this unit, Lia was required to transfer to an Acute care unit. Lia did not welcome this change, and within a short period of time she applied for a position working in a community based service.

Lia found this work to be particularly rewarding because for the first time she found herself working with and for Pacific communities. But like Ann, Lia did have 
difficulties working with some of her well intentioned but uninformed colleagues. She said that there was little or no acknowledgment that although she was expected to maintain the same sized case load as her palagi colleagues, she was also used as a resource to deal with Pacific families that her colleagues found problematic. She talked about how angry this made her feel, because she felt powerless to complain about the practice.

"If I complained about my workload I was made to feel less competent than the others. On the other hand if I didn't help them with the families that they thought were a 'problem', then they made me feel that I didn't care enough about 'my own people'. Either way I was made to feel wrong. And at the same time, I had seen how clumsy they could be with Pacific people and I used to feel guilty about not always being there for Pacific clients.”

One of the major differences between Lia's story and the other three participants, is that Lia sees her position in New Zealand as relatively temporary. Whereas Ann, Mary and Tara clearly identify with their Pacific ethnicity they also see themselves grounded in the New Zealand context. So they are New Zealanders of Pacific ethnicity. Lia on the other hand clearly sees herself as a Pacific person currently living in New Zealand. Her long term goal is to return to her homeland and continue her nursing in her own country. Because of this, Lia is more able to objectify her relationship with both mainstream palagi culture and the culture of Pacific island communities located in a New Zealand context.

\section{Conclusion}

In this interview I set out to discover how each of these participants had made the transition from life as a nursing student to life as a Registered Nurse. Three of the participants found the transition difficult, but at the time of these interviews all four of them talked about where they are now in relation to their work with satisfaction.

The difficulties with clinical staff that they had encountered as students continued into their experiences as Registered Nurses. What is significant now is that they have learned different coping strategies. For Tara and Lia this has amounted to confronting 
the issues head on, and demanding respect and courtesy from their colleagues. For Mary and Ann they have chosen to only work in those areas where they know there are likely to be other Pacific Nurses and where they will therefore feel relatively safe.

Each participant has found their own unique way of mediating the tension between their two worlds. Each participant reflected on the way their status as a Registered Nurse has changed the way they are perceived within their own communities. For most of the participants being able to serve their communities in both formal and informal ways is a contribution each is proud to be able to undertake. What is significant about this though is that the locus of control about the nature of this contribution stays with the individual. The participants bridle at the way their mainstream colleagues feel that they have the right to demand access to the cultural skills and knowledge of the participants without those skills ever being formally recognised. Although each of the participants had experienced being asked to provide cultural knowledge as part of their employed/professional work, none of them had ever been able to have this taken into account during performance appraisals or promotion rounds.

While the participants understand they have a duty to the members of their own communities, they deeply resent this sense of duty and obligation being exploited by their colleagues. The double bind the participants feel themselves in at times suggests that while they have achieved a greater measure of control in how they mediate the tensions between their two worlds, these tensions never totally disappear. It is perhaps not difficult to understand why these participants alternate between feelings of anger and resignation. 


\section{CHAPTER SEVEN: INTERVIEW AND DISCUSSION}

\section{Interview Three: The Being/Wounded Stories}

This Chapter deals with the final conversations I had with the participants. In a linear understanding of the world it would have made a neater and more logical sequence to present these stories first, documenting as they do the "growing up" stories of each of the participants. I have resisted the temptation to 'tidy' the re-presentation of these stories for two reasons.

In the first place the data is being presented to the reader in the order with which it emerged from the interview process. More importantly though, re-presenting these stories last is congruent with a radical hermeneutic intention to 'play' with the data in order to show that we do not engage in our internal dialogues in neat logical sequences. Our pasts are the lens by which we experience and make meaning of our present, and how we anticipate our futures.

By choosing to present these stories last, I have endevoured to create a space in which the reader engages with the data from the first two interviews from the place of their own interpretive realities. This Chapter invites the reader to engage with the data from the place of the participant's interpretive reality. If this creates for the reader a tension between these two positions, then there arises a real possibility for creating further meaning.

Three threads have been woven through this Chapter. Firstly there are the voices of the participants as they talk about their growing up experiences. A clear distinction is revealed between the experiences of the women who grew up in the New Zealand context, and that of the participant who grew up in a Pacific homeland. The second thread is the growing up story of the researcher. While no attempt has been made to draw explicit parallels between these stories, nevertheless there is no attempt to disguise the hermeneutic spiral between these two threads. The third thread is the researcher's use of literature to act as commentary, and in doing so itself becomes part of the hermeneutic spiral. 
By laying out these three threads, I have cracked open the space for the reader to see how my own interpretive process moves between and through each of these threads. As the reader engages with this text, they create their own interpretation, their own meaning. Here is the "death of the author”, as proclaimed by the post modernists.

In this interview I asked each of the participants to tell me about their formative years - their 'growing up' stories. I was interested to understand how their experiences contributed to their personal sense of 'identity'. 
Ann had a clear recollection that her first experiences of being made to feel "different" began during her time in pre-school.

"There was this little boy. He used to call me names and make fun of me. I used to watch out for him because he used to pick on me. I didn't know why. I didn't think then about it being because of my colour or racism. I just thought it was something about me that was wrong. That somehow I wasn't good enough.

And then I went to school. You got to hear some of the names from the kids in the playground. You know, names that they call someone who is dark. And they tell you how ugly you are. I learned not to play with the other kids because that way you could avoid some of it."

Asked how this made her feel Ann replied after a long pause:

“Well I knew it wasn't nice. (The names she was called). But I thought it was

I was perhaps three years old at the time. Standing in the hallway watching my mother sweeping the floor. She bends down to sweep the dust into the pan and I notice she is crying. I put my arms around her and comfort her in the way that I had learned to be comforted by her. I am alarmed by the fact that far from being comforting, my ministrations seem to have the effect of making her cry even more.

I have no coherent explanation for my mother's distress. Reflecting back, it could have been any of a number of things including my parent's poverty at that time, my mother's experiences of racism or maybe feelings of homesickness and loneliness. With hindsight, I could concoct an explanation for her distress from any of these reasons. An explanation, (interpretation), which would be both a fiction and a truth.

It is as Barabara Kosta observes in "Recasting Autobiography", ( 1994) profoundly ironic that "just as women and other disenfranchised groups begin to claim the status of author, the author is stripped of function and authority [by] philosophers and critics .... who were challenging the concept of the self, self representation and notions of authorship. (p2).

If I were to hold to a traditional conceptualisation of autobiography as a "linear, progressive development of an enlightened subject" (ibid), then these stories become trivialised to, at best, 'just so' stories, or at worst, 'poor me' self indulgence.

These stories have been deliberately positioned as the last stories to break up any representation of them as linear and progressively developmental. These stories are not offered as some kind of causal explanation. Rather these histories are our best attempt at a particular point in time to represent the context out of which we made, and make meaning of our worlds. That we begin to make sense of our experiences 
While Ann clearly found some of the behaviour of her school mates difficult, the behaviour she found the most difficult to bear was that of some of her teachers. Their names and particular incidents are seared in Ann's memory.

"It wasn't so much what they said. It was the way they said it. I mean, Mrs D for example. She would look at me like I was something that totally disgusted her. And then she would use this tone of voice. It used to make me cringe. She used to make me go to the toilets and wash before she would let me go near her to get my worked marked. I could never please her of course. And of course, she had her favourites, and they would hassle me

At the time I remember feeling frightened and protective of my mother. As I got older my fear translated into shame about my mother. I resented that she was different from my friend's mothers and that because of her difference I was also labelled different. My sense of shame and compensating protectiveness seemed to become translated into both self hating and a capacity to romance the drama of all Pacific Islands women as potentially tragic. My mother's powerlessness (and by extension all Pacific women's powerlessness) evoked in me both a rage with her and with the world that caused her so much pain. Without ever a word having been spoken on the subject, I knew as a child that to call attention to my mother's shame would be to make myself a target for her anger. "Noticing" can sometimes be dangerous if people can see that you can see.

From an early age I was aware that somehow my mother did not 'fit'. But it was not until I had experienced being called names at school that I understood that

We are the embodiment of our histories, but not the linear effects of our histories. When we talk of oppression or colonisation on our lives we are referring to something much more profound than that white people are sometimes unkind to us because of the colour of our skin and call us nasty names. Our oppression is not that others hate us, but that we have learned to hate ourselves. And the genesis of this self hating begins in these stories. The wounding stories, where we first learn to recognise the pain of rejection, of not belonging. A process of alienation that silences us. Without voice, the pain is internalised as self-hate, self-pity and shame. The shame is not that our skins are varying shades of brown and black. The shame is in discovering what the colour of our skins represents in the dominant hegemonic culture. An encoded classificatory system in which the colour white represents all things pure and sacred while black stands for all that the culture fears as dirty and profane. What gives this process it's power is that it is almost impossible to confront and too dangerous to challenge. 
In Tara's case she also remembers the playground bullying from the other children, and the discrimination she felt from some of her teachers.

"I wasn't allowed to have friends outside of my own family. So after school I was expected to go straight home. I couldn't linger in the playground with the other kids. I remember I used to feel angry that things were so strict. That's when I first noticed that my upbringing was different from my school mates. Then I remember the name calling in the playground. I mean I have had them all at some stage. You know. Bonga, coconut, nigger blah blah blah. That was pretty usual fare. And then I used to notice that teachers would treat you differently. Nothing direct. But you can tell when someone really likes you, and is interested in you and when they are not."

I remember a time when I was at Primary school. It was the teacher's practice each Friday afternoon to reward pupils that she believed had worked hard during the week with a treasured picture book to take home for the weekend. The books were eagerly sought by all the children, partly because of the attention the reward bought, but also for the intrinsic reward of the books themselves. As soon as she produced the pile of books, hands would begin waving wildly, accompanied by the excited voices of the children. "Miss. Miss. Please Miss!

This was the weekly ritual. It is a testament to my slowness as a learner that it was quite some time before I realised that I was never going to be rewarded with one of the prized books, no matter how hard I worked or how wildly I waved my hand. I stopped trying to attract her attention. She noticed that I was not playing the game any more and there passed between us a look that almost defies description. But I remember that look. Occasionally I have seen that look in the eyes of shopkeepers who pretend they do not see me while they continue to serve everyone else around me. I have seen it in the eyes of people who want to aive the imnression to casual onlokers that thev are heino friendlv towards me

The howls of derision and accusations of "political correctness" directed at any attempt to address the way our language encodes these values and beliefs are themselves instructive. When the local kindergarten bravely tries to rewrite the words of "Baa Baa Black Sheep", or the local library tries to remove Blyton's "golliwog" from the shelves, these are deeply political and subversive acts. The level of hostility that these seemingly trivial acts can stir up is an indication that there is more involved here than a bit of harmless "colour blindness". Incidents such as these serve as a salutary warning to anyone who would want to challenge cultural classificatory systems. 
Similar reflections are shared by Mary. At times she found this interview so unbearably painful that she requested the tape to be turned off. Three merging existential narratives from her formative years contribute to Mary's present anguish. She explained that she had been brought up by an Aunt in her earlier years and only as an older child rejoined her birth parents and siblings. We did not explore this story any further. But when she is able to continue, she talks about her experiences of rejection and humiliation from both class mates and teachers. Her childhood experience of being treated unkindly by staff when she is hospitalised as a child, is symptomatic of a person whose sense of "self" is being expressed through the lens of her deep woundedness. Without resorting to some kind of trivialising reductionism of causality, it is not altogether surprising that Mary uses a coping strategy for "fitting in" as an adult.

Because we believe the fault lies with us, calling attention to these incidents shames and humiliates us. We learn to take care. "Taking care" takes on many forms. If in doubt stay invisible. Don't attract attention to yourself until you know you are safe. Be so good at what you do that you do not make yourself vulnerable to criticisms. Use humour/ be willing/ apologise..... a lot. Surround yourself with people you know you can trust.

The realisation that I did not belong, somehow different and therefore excluded was a slowly dawning awareness. An awareness that made the exercise of engaging with the outside world seem like a dangerous undertaking. Caught between being careful not to be too visible in case you attracted attention on the one hand, and desperately trying to engage with others in an unquenchable desire to belong/ be accepted on the other. Negotiating between these two possibilities makes me alert for the tiniest cues from the other. Watching for an

It is a good example of how hegemonic power operates as a seemingly invisible force, cloaked in the language of 'normal' and 'natural'. The message is not lost on those of us whose very being is the embodiment of the cultural symbols of that which is profane and dirty.

In her struggle to 'find voice' and break the tyranny of silence, bell hooks (1989) talks about how difficult she found it to make "public the private".

"Moving from silence into speech is for the oppressed, the colonised, the exploited and those who stand and struggle side by side, a gesture of defiance that heals, that makes new life and new growth possible." (p9). 
This third and final interview with each of the participants involved taking them back in their personal histories to their formative years. The purpose of the interview was to seek some understanding of the experiences which had shaped their world views and the understanding they had of themselves within that context.

All four participants told stories of joyful childhoods, surrounded by large numbers of siblings and cousins, in which the differences between brothers, sisters and cousins held little real meaning for them. For Lia, this kind of environment persisted through her whole childhood and adolescent years. Only her migration to New Zealand as a young woman of eighteen years brought a change to her sense of herself, and challenged her notions of self-identity.

For Ann, Mary and Tara the challenge occurred at a much earlier age. In fact for each of them, the innocent security of their childhood was crudely and abruptly interrupted when they started their formal schooling. Each of these three participants found telling their story extremely painful. For each of them, this was the first time they had ever told the story of how they realised for the first time that they were not like many of the other kids and that this different-ness was something that stigmatised them.

One of the things that I find most striking about all of our stories is the way we have been silenced about our experiences, and to reflect on how "keeping silent" has impacted on our lives, on our understanding of ourselves; our identities. A harsh learning. But if one becomes accomplished and survives this stage of the journey you become a skilled observer of people’s behaviour. And here is the delicious paradox. 'Noticing' can be dangerous, but 'not noticing' is also sometimes dangerous. The trick is to notice without being noticed. It is this that can give you power in the moment. The leverage you sometimes need to catch people a little off guard so you can turn the moment to your advantage. Somewhere buried in all of this is the powerlessness of marginality and the magically creative possibility of power in marginality as well. 


\section{Discussion}

In earlier Chapters I argued the inadequacies of theorising the issues of people who are labelled 'marginal' using dichotomous conceptual frameworks. A major aspect of these inadequacies is the fact that underpinning these frameworks are assumptions that the social location of marginality is only and always the excluded binary opposite of a socially constructed 'mainstream' location.

I have also argued that critical explanations try to reverse the 'gaze' by demonstrating how hegemonic forces at work in mainstream culture structurally create 'marginality'. My critique of this position is that while the intention may be to champion the cause of those who are marginalised, the paradoxical effect of the critical position is to simply reinforce and add legitimacy to the mainstream/marginal dichotomy.

Being critical of these positions is not to deny their power. Indeed, as I will demonstrate in this discussion it is the un-reflected social acquiescence to the basic mainstream/marginal dichotomy that enables the reproduction of hegemonic relationships. Using a dichotomous map I want to show through the participant's stories how we as Pacific women learn to take on a hegemonically inscribed identity and how in turn this process leads us to interpret and make meaning of our life experiences.

The experiences of these Pacific women as students in the Nursing programme cannot be fully appreciated except in the context of their own life narratives. Their stories vividly demonstrate how people as meaning making subjects constantly refer to their past in order to interpret their present.

Although the 'Being' stories were shared in their last interviews I want to begin with the interpretation of these stories. And the first thing I want to do is draw attention to the level of similarity between Mary, Ann, Tara and my stories as opposed to the story of Lia. I struggled for a time to understand why Lia's story looked so different, and then the answer was so obvious I was mildly embarrassed that I had not made the connection earlier. 
When I began this interview session with each of the participants I asked them to tell me their 'growing up' story. Initially what Mary, Ann, and Tara shared was their family's migration and settlement story. How their parents came to migrate to New Zealand and where and how their family eventually settled. Ann and Mary shared that they were in fact born in New Zealand. Tara had been born in a Pacific homeland but was just an infant when her family migrated, and all her formal schooling was in New Zealand. In respect of this detail, Tara and I share similar history. Lia on the other hand was born and educated in her Pacific homeland and did not migrate to New Zealand until her early adulthood. In this respect Lia's story has more in common with our parents cohort that with her own age cohort in that Lia migrated to New Zealand as an adult. Her identity as a person is entirely secure. She describes herself as a ___.(naming her homeland), who for the present chooses to live in this country. She has no doubts or ambivalence about who she is or where she belongs.

In response to my question, “what do you remember about growing up?”, all of the participants shared warm stories about growing up in their extended family situations. Each of the participants smiled a lot and recalled humorous incidents of siblings and numerous cousins engaging in play and the kind of mischief that any group of youngsters might get up to. Tara for instance talked about how she and her cousins knew which day of the week different Aunties baked and how they would all make their way to the appropriate back porch in the hope of scoring some delicious treats. She laughed when she said that as children they could never understand how the Aunties knew to have treats ready for their 'surprise raids'. One of Ann's recollections was how much fun she and her siblings and cousins used to have playing on the old car wrecks that were usually parked on their front lawn. She laughed saying that as an adult she now understands that these cars would have been deemed 'eyesores', but as a child they provided a wonderful playground and were the source of great pleasure.

It was clear from the way the participants told these stories that in this stage of their childhood, they experienced what Giddens (1991) refers to as “ontological security”.

It was their response to my next question that threw into stark relief the difference between the growing up stories of Lia with those other participants who were New 
Zealand reared. In answer to my question, "do you remember the first time you experienced feeling different, and what was that like for you”, Lia couldn't answer the question. Her growing up story detailed the security she felt as a young child growing up in her family's village, and her nonproblematic transition into her school years. Clearly from her story, Lia grew up in an environment in which her 'ontological security' remained intact. Lia's first experience of feeling 'different' was when she migrated to New Zealand as a young adult. For the moment then, I want to leave Lia's story, and focus on the stories of the remaining three participants.

Reflecting back on these interviews I am struck by the similarities in the way the New Zealand reared participants respond to my question. Not just the similarities in the content of their stories but also in the way they tell this story. The laughter and humour quickly dies away. A long moment of silence. The first time this happened, I remember having a momentary thought that perhaps she will not answer. After the first time I learned to just hold the silence until they were ready. Then slowly, with eyes downcast they each tell me their story. It's not that they are having trouble remembering- the details in their stories are too vivid to suggest that. These are painful stories to tell.

Despite the fact that they are remembering incidents that happened fifteen and twenty years ago the remembering is calling back into consciousness long suppressed moments of deep shame and humiliation. For each of the participants these stories are located within mainstream early childhood educational settings. For Ann the first incident she remembers is at her pre-school, while Mary and Tara recall their first incidents happened in Primary School. Having begun to tell these stories each of the participants is able to describe a number of different occasions that they recall with great clarity. In each case, at some point in their narration the participants talk about the fact that this is the first time they have ever told anyone about these experiences. It seems clear to me from the coherence they bring to these stories that these incidents lie very close to the surface of their consciousness. In their mind's eye at least, these stories are very much near to hand. Tara expresses surprise at how strongly she still feels the injustice of these incidents, and in response to my question says it makes her feel angry. Her tears begin to flow though when she says that at the time she thought it must have been because the teacher thought she was ugly. She says that what 
distressed her as a child was her not being able to understand what she had "done wrong”. "I used to try hard to be a good girl” she says.

From these stories it is clear that these incidents have the effect of shaking the very foundation of their 'ontological security'. While the incidents which involve the cruelty of other children are remembered it is the cruelty of the adults that cause the greatest pain because they are felt as a betrayal of the trust they have that 'grown ups' look after you.

Using the thesis developed by Giddens (1991) I would argue that the experiences of these participants, particularly where they involved adults as teachers, had the effect of damaging their capacity to trust. Giddens argues that, "Trust in others begins in the context of individual confidence - confidence in care taking figures.” (p51) He goes on to argue that not having the capacity to trust, destroys the ability of the individual to 'bracket' or take for granted any aspect of their everyday world. Confidence in the structured experience of our everyday world enables us to take for granted, (bracket out), much of our background trivial decision making. Confidence in the structure frees us from the tyranny of sifting the chaos of endless possibility of every mundane act. Giddens describes chaos as "not just disorganisation, but the loss of a sense of the very reality of things and other people”. (p36) Without confidence in the structure, people have to negotiate meaning and sense out of the chaos.

For each of these participants, these incidents represent more than that they experienced some moments of unkindness in their formative years. What these experiences represent is a catastrophic assault on their 'ontological security' where they learn not that the 'world' is different, but that they are different from the rest of the 'world'.

We do not even get to ask the question "how do I belong?" First we learn we do not belong and then we are taught who we really are. So Tara learned that she was 'ugly', Ann learned that she was 'dirty', and Mary that she was 'dumb'. Their stories inevitably provoke me to remember that in my own shaming story I learned that I was a "lazy good for nothing". This is who we learn we are, and we are shamed by the knowledge. So shamed that we cannot speak about it to anyone, and we spend the rest 
of lives anxiously trying to anticipate further threats to our being, while at the same time trying to compensate for our ugliness, dirtiness, laziness, stupidity, and our difference. In our life narratives these incidents are more than just careless moments of unkindness, these are primal woundings.

If the analysis of these participants stories stopped at this point, then the dichotomous models of marginality would provide a conceptual framework sufficient for the task. But I am arguing in this thesis, that these participant's stories show that they feel themselves to be caught between worlds. Between the world of mainstream and the world of their Pacific culture. In order to place them in a between space I must first show how they are simultaneously marginalised from their cultural communities.

One of the most frequent responses Pacific people give as a reason for migrating to New Zealand is their desire to see their children are well educated. Within Pacific communities there is considerable ambivalence between the generations about what this actually means. For the parent generation this tends to mean that their children do well academically so that they can get well paid jobs when they leave school, while at the same time remember their duties and obligations to them as parents. The children on the other hand joke about their parents wanting them to do well so they can go to church on Sunday and boast about their children's achievements to the rest of the congregation. On a more serious level, the children find it hard to balance the demands of both being a "good student" and being a "good Samoan/ Tongan/ Tuvaluan etc” (Tiatia, 1998).

As subcultures that take immense pride in being able to identify themselves according to their respective homelands, Pacific communities maintain quite strong boundaries around each of their cultural groups in order to protect the integrity of their separate identities with in the New Zealand context. Strong boundaries are also made between Pacific cultural beliefs and values and those of the dominant culture. Often this means denigrating those things that are seen to represent dominant culture. For example, one of the ways of signalling your disapproval of another Pacific person is to belittle them with the accusation that they are "too palagi". Someone who is too palagi, by definition demonstrates that they are not sufficiently Pacific and therefore does not have to be taken seriously. 
Considerations of whether one is "Pacific enough" determines the individual's claim to 'belong', and is what lies at the heart of the question of "ontological security” for most New Zealand born children of Pacific Islands descent. This is reflected in Lia's interview where she started out by claiming that she was the only Pacific person in her class, and then had to modify her story to account for the New Zealand born Pacific people in her class. Because of her status as an Island born, in her mind, that made her the only "real” Pacific person in her class.

Conscious that many Pacific born people regard them as "not really Pacific", the New Zealand born participants have to take care not to be "too palagi". They simultaneously experience ontological insecurity in regards to their self identity as Pacific people, as well as their self perception as students in mainstream educational institutions. I believe that this is the mechanism by which we begin our rite of passage into marginality and how we begin to take on a hegemonically inscribed self-identity. Understanding this as the foundation upon which these participants make meaning of their life experiences we can begin to see their journey into nursing in a different light.

For a start we can begin to have some different insights into why Pacific children have a pattern of under-achievement in their compulsory schooling, so that gaining acceptance into tertiary education becomes so problematic, as each of the participants stories reveal. It also says something about their courage that they know that 'becoming a nurse' means having to engage in a 'palagi' system that they have every reason to mistrust. I am not so sure that they understood at the beginning of their programme the degree to which 'becoming a nurse' would also marginalise them from their own Pacific communities.

My interpretation of the rite of passage into marginality so far, works in relation to the experiences of the three New Zealand born participants. But the question of how Lia's story sits within this interpretation has yet to be addressed. I said earlier that it took some time to understand the significance of the difference between Lia's story and those of the other participants. Of course the obvious difference was that Lia being 
Pacific born and reared did not experience in her formative years the catastrophic wounding of the New Zealand born participants.

Compared to the other's stories, Lia has no ambivalence whatsoever about who she is, and how she belongs. The way she makes sense of her experiences of becoming a nurse has a different tone from that of the others. To understand the quality of that tone, I think one has to understand how she locates herself in the world. Unlike the other participants who find themselves between a palagi mainstream world and their Pacific communities in New Zealand, Lia locates herself between a palagi mainstream and her Pacific homeland. A homeland in which her self identity is secure. Lia is clear that when she has had enough of living in New Zealand she will return to her homeland.

Continuing the metaphor of a rite of passage, shows the critical difference between Lia's story and that of the other participants. For while Lia knows that at any time of her own choosing she can bring to closure her marginalised status, and experience reaggregation back into her Pacific homeland, that is an option that is not open to the other participants. For them, New Zealand is 'home'.

Does having been 'accepted into nursing', mean that the participants could take on a new identity that finally enables them to have a sense of belonging? Does becoming a nurse rehabilitate them from a socially defined location of marginality? On the evidence of these participants stories one would have to conclude an emphatic no. I believe that the participant's stories reveal their best efforts to mediate the conflicting tensions between the two social worlds that frame their experience. That is, the mainstream world of nursing and the cultural world of their Pacific ethnicity. I believe the stories point also to a deeper tension that they try to mediate. On the one hand they try hard to negate the wounded sense they have of themselves, (low self-esteem seems insultingly trite in these circumstances), by proving to themselves and others that they 'belong'. Balanced against this is that their woundedness makes them vulnerable to further wounding. They find the risk of further wounding creates high levels of anxiety and to coin Kierkegaardes term, “dread” (Kierkegaarde as cited in Marino 1998, ps 308-328). In this process they learn ways to cope, but not I would suggest ways to heal. 
It might appear from this interpretation of these participants stories that $\mathrm{I}$ am suggesting that New Zealand born Pacific nurses have no option but to accept that they will always be marginalised. And I think that is the conclusion I am drawing. But I want to argue that this does not necessarily imply a terrible fate. I want to argue that is only true so long as we continue to use dichotomous frameworks of marginality that define this social location as one of deficiency and loss. If to be marginalised means to stand in chaos, then part of being in chaos is to confront endless possibility. Some of these possibilities may mean deficit and loss, but just as many possibilities exist for creativity and transformation. The radical argument is that in a post modern world marked more by difference than sameness, marginality becomes the social location for many. It is not that we need to be rescued from marginality, but marginality itself needs to be reconceptualised as the social location of possibility.

In the next section I want to explore some of these possibilities for Pacific nurses, and their implications for the wider profession and nursing education in particular. 


\section{CHAPTER EIGHT: RADICAL REFLECTIONS}

This thesis has sought to develop an understanding of the participating Pacific women's experiences within a particular social and cultural context. I began the thesis by asking the question, "how do Pacific women mediate their understanding of what it means for them to be 'Pacific' with their experience of becoming a nurse?” In order to answer the question, I have drawn on the participants' stories and interpreted them through the lens of a reconstructed map of marginality. This interpretation has enabled me to show how the participants are socially located between the normative boundaries of nursing and the world of their Pacific communities.

Demonstrating how the participants engage in the process of moving between discontinuous boundaries moves this thesis beyond mere description of the participants' experiences. Their stories direct our attention to the boundaries themselves, and invite us to ask more questions. What happens to people when boundaries are created? Who has the power to create these boundaries, and what is the nature of that power? Whose voices are privileged and whose voices are silenced when boundaries create dichotomous divisions within a society? This thesis represents a beginning point in addressing these questions. Informed by the voices of the participants and my own experience I have set out a theoretical framework for examining Pacific people's experiences of becoming a nurse within the New Zealand context. Further research undertaken with a wider sample of Pacific Nurses is necessary to demonstrating whether, and to what degree the conclusions drawn here are able to be more generally applied.

Radical Hermeneutics, used as a theoretical foundation for this thesis has created a methodological approach that keeps the space open for these questions to emerge. This has been an important aspect of this project because it has enabled me to be able to stay with the complexities. Meaning-ful solutions can emerge when communities are open to tussling with the complexity, and eschew the temptation to seek causal explanation which because of its reductionist nature leads to premature closure of the issues often resulting in superficial and simplistic interventions. 
I believe this thesis has important implications for the nursing profession, for Pacific communities and for individual Pacific students and nurses to consider. In this final section I offer my own reflections on what I believe these implications are based on what I have learned from undertaking this project and from my own experience.

\section{Implications for the Profession}

A critical issue the profession has to address is the way hegemonic and taken-forgranted values and beliefs are embedded in the nursing profession producing and reproducing conditions of oppression. This oppression arises through the unexamined ethnocentric assumptions that the knowledge, values and beliefs of dominant Pakeha culture are deemed to be the necessary and sufficient standard for what counts as knowledge for all cultures in the New Zealand context. Normative pakeha values are taken for granted to be the normative values for all cultural groups.

The consequence of this is that every step of becoming a nurse and practicing as a nurse is problematised for the Pacific student and practitioner. The entry criteria into nursing education programmes, the criteria for determining successful knowledge and skill acquisition, the standards and competency measures for what constitutes 'good practice' are all uncritically derived from a Pakeha world-view. In a pluralistic society, one has to challenge the authority/power of one cultural group to set the standard for all other cultural groups. That this is hegemonic and oppressive can be demonstrated by the fact that while Pacific students are required to meet the achievement standards set by mainstream Pakeha culture, no Pakeha student has to achieve any standard of practice that a Pacific community may deem appropriate for themselves. The profession requires all nurses to be 'culturally safe' but only one culture has the power to determine what 'safety' means.

The effect of the profession being uncritically located in a mainstream Pakeha worldview is powerfully demonstrated in the participants' narratives. The stories of their struggles to even gain entry into a nursing programme reflected their already internalised acceptance that nursing is a Pakeha profession. And while they were hurt and frustrated by the need to conform with Pakeha rules of entry, they were also vulnerable about not wanting to be shamed in that system either. The skills and 
knowledge they did bring into nursing, such as their language and cultural knowledge were undervalued by mainstream and made invisible (see for example Anne’s comments on p 105 and Lia's comments on p109). What was made visible was their ‘deficiencies’ from a Pakeha perspective.

The overriding theme that comes through the participants' stories of their experiences in their education programme is their sense of vulnerability. This is particularly evident in their stories about entering clinical practice situations. The 'cleaner story' (Ref. Chapter Six) is a particularly graphic example of the sense of risk the Pacific students felt every time they went into a clinical practice setting. While particular events can be dismissed as the unfortunate but idiosyncratic behaviour of individual practitioners I believe that the overall effect of the participants' stories suggest that there is systemic oppression that needs to be addressed by the profession. From a pedagogical standpoint it is astonishing that students who felt so unsafe managed to accomplish any learning. One of the strong recommendations arising out of this thesis is that the profession support the development of education programmes that are pedagogically designed to specifically meet the needs of Pacific students and Pacific communities.

One of the claims made early in Chapter One argues that the poor health statistics of Pacific people in this country is evidence that nursing, along with other health disciplines is not meeting the health and illness needs of Pacific people. Increasingly, Pacific communities are demanding health services that are more appropriate and accessible, either through changes within mainstream services or through the development of services that are 'by Pacific for Pacific'. One of the most remarkable ironies about the professions current pre-registration curricula is that there is nothing in these programmes that specifically addresses the learning needs of Pacific students to enable them to work with their own communities. The consequence of this is that, particularly for New Zealand born Pacific students, when they graduate they feel unprepared and therefore unwilling to work in areas that have high numbers of Pacific people as clients/ patients.

While nursing curricula are currently designed to impart the culturally specific knowledge derived from a 'western' world view, Pacific students are assumed and 
presumed to have access to knowledge of their own cultural groups, and that this knowledge does not have to be taught as part of their formal curriculum. This again demonstrates an ethnocentric mainstream world-view. There is a lack of awareness by mainstream nurses of the difficulty Pacific nurses have in mediating the space between the profession and their communities and this is also reflected in the participants' stories.

Mainstream health professionals often simply assume that Pacific nurses can provide informal translation services in the practice situation. Seldom is this formally incorporated into the their job descriptions. Where no formal protocols exist, the Pacific nurse is placed in the difficult situation of having to assume conflicting role responsibilities. For example, whether s/he is providing the translation for another health professional or for the Pacific client/family. There is a world of difference between the instrumental service s/he may provide the former, and the advocacy role s/he may provide for the latter. As the examples of the participants' stories reveal, (Ref. Chapter Six), they feel manipulated by an emotional blackmail in these situations. If they agree to provide the translation service, they feel negatively judged by colleagues when they then fall behind schedule with their own work. Often they feel they are asked to translate only to suit the needs and convenience of other health professionals, rather than provide assistance for clients/families. If they decline to provide translation services, they feel guilty towards their Pacific communities and negatively judged by colleagues. This is an example of the way Pacific nurses are required to move between two worlds, in a social context does that not even acknowledge there is an issue.

As I argue in Chapter Seven, being unable to 'give voice' to the issues that concern them as Registered Nurses, is itself an indication of hegemonic oppression. Mainstream nursing has a responsibility to critically reflect on how this situation is systematically perpetuated. Pacific nurses in turn have a responsibility to reflect on the way they have internalised dis-empowering messages that inhibit their ability to fully engage and claim the space which is their practice.

I am not, in this thesis, arguing that the mainstream nursing profession deliberately sets out to dominate or oppress other groups. Nor am I suggesting that all Pacific 
nurses are by definition powerless victims. Rather, I believe it is the case that while social conditions change over time, we can lapse into un-reflected habituation and taken-for-granted assumptions that unintentionally lead to oppressive consequences. As New Zealand has moved to become a more diverse and pluralistic society we need to ensure that the profession is able to reflect that diversity.

Locating this thesis in a Radical Hermeneutic framework demands that every time we think we have arrived somewhere, we must challenge our assumptions once again. The deconstructive spin I would place on the challenge I have made to the profession in this work is to acknowledge that I am also a part of this profession. I do not absolve myself from responsibility for the part I have played in maintaining hegemonic oppression in nursing. Having been involved for many years in nursing education, this project has had me confront some of my own assumptions and practices. At the same time, if I reflect on whose voices have been silenced in order to develop the arguments presented in this thesis, then I unreservedly acknowledge that some of my most staunch supporters have indeed been Pakeha colleagues. Again and again we must engage in critical reflection to avoid lapsing into the comfort of dichotomous and binary classifications. This argument is not that the mainstream profession is all bad, and Pacific people are powerless victims. The issues are more complex than that as this thesis has tried to demonstrate.

What this thesis is doing is bringing these issues to the professions' attention in an insight-full way in order that through discourse, more inclusive possibilities can be explored.

\section{Implications for Pacific Communities}

I am aware that Pacific peoples in the New Zealand context are sensitive about their issues being aired in public forum. In part this is because their experience has been that often the issues are used negatively and often unfairly against Pacific communities. The practice of the media to negatively stereotype Pacific people during the 'over-stayer' campaign (Ref. Chapter Three) is an example of this experience. 
One of the strong normative values of all Pacific communities is their group solidarity or loyalty to the group. Public criticism of Pacific communities by a Pacific person is interpreted as disloyal and deviant behaviour. Macpherson (1972) provides examples of this in relation to Samoan culture. The derisory use of the terms, "fia palagi" those who wish to imitate Europeans, and “fa'asusu ile palangi” - literally those who suck up to Europeans, is an indication that 'being European', is not an appropriate aspiration for Samoans.

Respecting this sensitivity, I simply want to direct Pacific peoples attention to the areas of this research that have specific implications for Pacific communities. In particular I want to point to the way the tension between different value systems has the effect of leaving Pacific students caught in a 'no man's land' between palagi culture and their Pacific culture. One of the themes that came out of the participants' stories was how strongly they perceived their nursing programme was located in a palagi world. Indeed, one of the participants went as far as to say that in order to succeed in her nursing programme she “ became a palagi”. A similar story was shared by the other two New Zealand born participants. What all the participants were aware of was that this strategy ran the risk of themselves being isolated from their respective Pacific communities. Of being labelled "fia palagi” or "fa' asusu ile palagi” for the Samoan participants or the equivalent for the other Pacific cultures.

Inevitably this places the students in an 'at risk' between world location, and is the source of anxiety for many Pacific students, particularly the younger New Zealand born. A way has to be found for Pacific communities to support the students in their education programmes while at the same time, affirming their identity as members of their cultural group. Currently, it is fair to say that there exists in Pacific communities a hierarchy of attributes to which a person must conform in order for them to feel they belong. For example, being Island born, being fluent in a home language means that one is more Pacific than if you are New Zealand born and/or do not have fluency in a home language. Given that more than fifty percent of people who live in New Zealand and claim a Pacific ethnicity are New Zealand born, the question of identity becomes a more urgent issue for individual Pacific people and their communities. Exclusionary normative group boundaries mean that over time fewer and fewer people will feel 
comfortable to claim their Pacific heritage, and Pacific communities will become small elite enclaves.

From the stories of the participants in this project, there is an apparent reluctance for New Zealand born and educated Pacific nurses to work in, and with their own Pacific communities.

I have discussed in the previous section, this reluctance may be due to the fact that their nursing programmes do not prepare them well for this work. But also there is reluctance on the part of Pacific graduates to work in Pacific communities because they fear being negatively judged by these communities as "not Pacific enough". Pacific communities, Pacific health providers and nursing education institutions need to create a dialogue in order for these issues to be more fully explored and certainly I would argue that more research needs to be undertaken to test the claims being made here. Government agencies such as the Ministry of Health and the Ministry of Education also have a part to play in this dialogue to ensure that capacity building within Pacific communities is adequately resourced and long term planning to develop this capacity is undertaken.

\section{Implications for Individual Students/Nurses}

In recent times I have had the opportunity to speak to a number of Pacific nursing forums in which I have discussed the findings of this project as 'work in progress'. Without exception I have found that the Pacific nurses in these audiences have strongly identified with the stories of the participants in this project.

While in terms of the research I have found this to be a gratifying response, I have also found these occasions to be poignant. I take no pleasure in the fact that the grief and alienation shared in the stories of the participants is replicated over and over again in the stories of other Pacific student/nurses.

Simply laying out the reconstructed map of marginality as I have done in this project, may in and of itself be a major contribution of this project. By enabling you, as Pacific students/nurses to see another interpretation of your social location may allow you to also understand that the hardships and difficulties you experience are not just evidence of your inadequacies. The sense you have of having to juggle complex social 
relationships is not just a figment of your imagination. The issues are complex and difficult and very real. In post-modern theory, there is an argument that language creates our realities. I think our situation demonstrates that sometimes the lack of a language - that is, the language to describe your reality,- also creates a reality. A reality of dis-empowerment.

Having a 'map'; having a language; knowing that the experiences that have 'shamed' and silenced you in the past- I hope this thesis speaks directly to you and enables you to see that you are neither alone nor have reason to feel "shamed". As marginals we are the "betweens". Not necessarily a site of loss and alienation, but the place from which new and exciting possibility can emerge as well. 


\section{CONCLUSION}

Bringing this project to its conclusion, I have reflected on the opportunity I have had to explore in some detail questions that have been a passionate concern for a long time. Arriving at this point, I reflect again on how it is that one can claim to know something and then be surprised by how much more there is still to learn.

In some respects my pre-understanding provided me with a false sense of security, and throughout this project I found these preconceptions being challenged. Not only was this a challenge at an intellectual level, but in fundamental ways I found my own sense of "being" challenged as I moved between my own experiences and that of the participants. That I was surprised that this should have occurred may be an indication of naivety on my part, but I think that it is also true that some things cannot always be predicted or anticipated. One cannot know in advance what one needs to learn. It is in the doing that the knowing emerges. This personal challenge provides me with a pathway for future action and opens up new possibilities for me to explore in relation to developing new pedagogical approaches for Pacific people in the health sector in general, and Nursing education in particular.

Inevitably at this point, I reflect on what I might have done differently in this project knowing what I now know. Two things stand out for me. At the beginning of the project I had a surface understanding that the perceptions of those Pacific people born and reared in New Zealand were different from those who had migrated to new Zealand as adults. Only through the course of this project have I been able to develop a deeper appreciation of what these different perceptions are and the impact these differences have on the way people interpret their experiences. Had I understood this distinction more fully at the outset, I would have made a greater effort to ensure that there was a better balance of participants. I now see that a limitation of this study is that the Island born/reared perspective is over reliant on the story of a single participant. 
A second issue that caused me difficulty throughout this project was the need to abstract individual participants stories from their specific cultural context to that of a "Pacific" voice. It was a strategy that I employed in order to preserve the anonymity and confidentiality of the participants, and given the small numbers involved in this project I feel this was a proper cause of action. However I remain conscious that the strategy has been a form of erasure as well.

Despite these shortcomings, I think the project nevertheless has an important contribution to make. Most significantly, I believe this thesis has surfaced an issue that previously lacked a language to make visible that which needs to be made visible, and in a way that invites engagement and moves us past recrimination and guilt. While I believe this issue has significance for the Nursing profession, it also has significance for the broader society as well. As we stand at the threshold of a new century, the greatest challenge to all modern societies is how can diversity be managed in a way that makes both civil society possible and at the same time creates an environment that rejoices in difference. Auden's verse holds for me both the promise and the warning.

\author{
All I have is a voice \\ To undo the folded lie, \\ The romantic lie in the brain \\ Of the sensual man-in -the-street \\ And the lie of Authority \\ Whose buildings grope the sky: \\ There is no such thing as the State \\ And no one exists alone; \\ Hunger allows no choice \\ To the citizen or the police; \\ We must love one another or die.
}

(W. H. Auden, September 1, 1939)

I believe the reconstructed map of marginality proposed in this thesis holds the promise of a new dialogue in which the boundaries of conflicting normative value 
systems within a society can be overtly acknowledged, and the 'betweens' have a socially sanctioned role in providing the 'glue' for the society. Radical hermeneutics demands that we do not take comfort from imaging that we have arrived. We have only named the next challenge. 


\section{REFERENCES}

Alasuutari, P. (1995). Researching culture. Qualitative method and cultural studies. London: Sage Publications.

Anderson, W.T.(Ed.). (1996). The Fontana postmodernism reader. London: Fontana Press/ Harpercollins.

Anzaldua, G. (1986). Borderlands/ la frontera. The new mesiza. San Francisco: Aunt Lute/ Spinsters.

Auden, W. H. (1938). Oxford book of light verse. (Reprinted 1980). London: Oxford University Press.

Bathgate, M., Alexander, D., Arbutus, M., Borman, B., Robert, A., \& Grigg,M. (1994). The health of Pacific Islands people in New Zealand. In Analysis and Monitoring Report No 2 Public Health Commission. Wellington New Zealand

Bertram, G. (1987). The political economy of decolonisation and nationhood in small Pacific societies. In A. Hooper, S. Brotton, R. Crocombe, J. Huntsman \& C. Macpherson (Eds.). Class and culture in the South Pacific. Centre for Pacific Studies. University of Auckland and Institute of Pacific Studies, University of the South Pacific.

Blackford, J. (1997). Cultural frameworks of nursing practice: situating the self. Nursing Inquiry. 4. (3). September. ps 205-207.

Boutain, D. (1999). Critical nursing scholarship: Exploring critical social theory and African-American studies. Advances in Nursing Science. 21 (4). June. ps 3747. 
Buber, M. (1970). I and Thou. (Walter Kaufmann. Trans.). New York: Charles Scribner's Sons.

Caputo, J. D. (1987). Radical hermeneutics: Repetition, deconstruction and the hermeneutic project. Bloomington: Indiana University Press.

Carman, A. (1970). Tawa Flat and the Old Porirua road. 1840 - 1970. Wellington: Wright and Carman.

Carr, W., \& Kemmis, S. (1986). Becoming critical. Education, knowledge and action research. London: The Falmer Press.

Chanfrault-Duchet, M.-F. (1991). Narrative structures, social models and symbolic representation in the lifestory. In S. B. Gluck \& D. Patai (Eds.). Women's worlds: The feminist practice or oral history. (pps 77-92). New York: Routledge.

Chinn, P.L. (1999). Gender in nursing science. In E.C. Polifroni, \& M.Welch (Eds.). Perspectives on philosophy of science in nursing: An historical and contemporary anthology. (pps 462-466). Philadelphia: Lippincott.

Clifford, J. (1988). The predicament of culture. Twentieth- Century ethnography, literature and art. Cambridge: Harvard University Press.

Collins, P.H. (1991). Black feminist thought: knowledge, consciousness and the politics of empowerment. New York: Routledge.

Connell, J. (1990). Modernity and its discontents: migration and change in the South Pacific. In J. Connell (Ed.). Migration and development in the South Pacific. Pacific Research Monograph. No24. Canberra.

Cook, L., Didham, R., \& Khawaja, M. (1999). On the demography of Pacific people in New Zealand. Demographic Trends 1999. Keynote address presented at the Pacific Vision Conference. Auckland 22-30 July, 1999. 
Cooney, C. (1994). A comparative analysis of transculturalsafety and cultural safety. Nursing Praxis in New Zealand. 9 (1). ps 6-12.

Coup, A. (1996). Cultural safety and culturally congruent care: a comparative analysis of Irihapeti Ramsden's and Madeleine Leininger's educational projects for practice. Nursing Praxis in New Zealand. 11 (1). ps 4-11.

Crotty, M. (1998). The Foundations of social research. Meaning and perspective in the research process. Sydney: Allen \& Unwin.

Douglas, M. (1966). Purity and danger. An analysis of concepts of pollution and taboo. Harmondsworth: Penguin Books.

Dowell, M. (1996). Issues of recruitment and retention of minority nursing students. Journal of Nursing Education. 35 (7). October. ps 293-297

Eagleton, T. (1996). The illusions of postmodernism. Oxford: Blackwell.

Erikson, K.T. (1970). Notes on the sociology of deviance. In W. R. Scott (Ed.). Social processes and social structures. An introduction to sociology. (pps 119126). New York: Holt, Rinehart and Winston.

Fanon, F. (1990). The wretched of the earth. (C. Farrington Trans). London: Penguin Books. (Originally published 1965).

Fay, B. (1987). Critical social science. Cambridge: Polity Press.

Fine, M. (1992). Disruptive voices: The possibilities of feminist research. Ann Arbor: The University of Michigan Press.

Fine, M. (1994). Working the hyphens. Reinventing self and others in qualitative research. In N. K Denzin \& Y. S Lincoln (Eds.). The Handbook of Qualitative Research. (pps 70-82). London: Sage publication. 
Foucault, M. (1977). Discipline and punish: The birth of the prison. Alan Sheridan. (Trans.). New York: Pantheon.

Foucault, M. (1980). Power/Knowledge: Selected interviews and other writings, 1972-1977. Colin Gordon (Ed.). Brighton: Harvester Press.

Foucault, M. (1988). Politics, philosophy, culture. Interviews and other writings 1977-1984. Lawrence D. Kritzman (Ed.). Alan Sheridan. (Trans.). New York and London: Routledge.

Foucault, M. (1989). Foucault Live. (Interviews 1966-84). S. Lotringer (Ed.), J. Johnson. (Trans.). Semiotext(e). Foreign Agents Series.

Fraser, N., \& Nicholson, L. (1997). Social criticism without philosophy: An encounter between feminism and postmodernism. In D. Tietjens Meyers (Ed.). Feminist social thought: A Reader. (pps 132-146). New York and London: Routledge.

Gallagher,S. (1992). Radical Hermeneutics and educational theory. In S. Gallagher (Ed.). Hermeneutics and Education. (pps 277-317). State University of New York Press.

Geanellos, R. (1999). Hermeneutic interviewing: An example of its development and use as research method. Contemporary Nurse, .8, (2), June. ps 39-45.

Gerrish, K. (1997). Preparation of nurses to meet the needs of an ethnically diverse society: educational implications. Nurse Education Today. 17 (5). October. ps 359-365.

Giddens, A. (1971). Capitalism and modern social theory: an analysis of the writings of Marx, Durkheim and Weber. London: Cambridge University Press. 
Giddens, A. (1991). Modernity and self-identity. Self and society in the late modern age. Cambridge: Polity Press.

Giddens, A. (1999). Jurgen Habermas. In Q. Skinner (Ed.). The return of grand theory in human sciences. (pps 123-139). Cambridge: Cambridge University Press.

Giddings, L. (1997). In/visibility in nursing. Stories from the margins. Unpublished PhD Thesis. University of Colorado.

Gramsci, A. (1942). Selections from the prison note-books .English Trans. 1971 Q. Hoare \& G.Nowell Smith. (Eds. \& Trans.). New York International

Green, J. M. \& Curry, B. R. (1991). Recognising each other amidst diversity: Beyond essentialism in collaborative multi-cultural feminist theory. Sage. .viii. (1). ps 39-47.

Habermas, J. (1971). Knowledge and human interests. J. Shapiro. (Trans.). Boston: Beacon Press.

Habermas, J. (1979). Communication and the evolution of society. T. McCarthy. (Trans.) Boston: Beacon Press.

Hall, J.M., Stevens, P.E., \& Meleis, A.I. (1994). Marginalisation: a guiding concept for valuing diversity in nursing knowledge development. Advances in Nursing Science. 16(4), ps 23-4.

Hartsock, N.C. (1996). Postmodernism and political change: Issues for Feminist theory. In S.J.Hekman (Ed.). Feminist interpretations of Michel Foucault. (pps 39-55). Pennsylvania State University.

Harvey, D. (1977). The condition of postmodernity. UK: Blackwell. 
Holloway, I., \& Wheeler, S. (1996). Qualitative research for nurses. Oxford England: Blackwell Science.

hooks, b. (1981). Ain't I a woman. Black women and feminism. Boston: South End Press.

hooks, b. (1989). Talking back. Thinking feminist: thinking black. Boston: South End Press.

hooks, b. (1990). Yearning: race, gender and cultural politics. Boston: South End Press.

Howden-Chapman, P., \& Cram, F. (1998). Social, cultural and economic determinants of health. Background paper presented to the National Health Committee of New Zealand. Wellington: National Health Committee.

Irwin, G. 1992. The prehistoric exploration and colonization of the Pacific. Cambridge. Cambridge University Press.

Jay, M. (1973). The dialectical imagination: A history of the Frankfurt School and the Institute of Social Research 1923-1950. Boston: Little, Brown \& Co.

Kai Tiaki Nursing New Zealand. (1998). Nurse/midwives numbers are falling. Kai Tiaki Nursing New Zealand. p8. October.

Kincheloe, J.L., \& McLaren, P. L. (1994). Rethinking critical theory and qualitative research. In N. K. Denzin \& Y. S. Lincoln (Eds.). Handbook of qualitative research. (pps 138-188). London: Sage Publications

Keith, M. (1990). They came on the tides. A short history of Porirua and its people. Porirua City Council 
Kirkland, M. L. S. (1998). Stressors and coping strategies among successful female African-American baccalaureate nursing students. Journal of Nursing Education. 37 (1) January. ps 5-12.

Kosta, B. (1994). Recasting Autobiography: Women's counterfictions in contemporary German literature and film. Cornwell University Press.

Lather, P. (1986). Issues of validity in openly ideological research: Between a rock and a soft place. Interchange, 17, (4). (Winter). ps 63-84.

Le Blanc, R. G. (1997). Definitions of oppression. Nursing Inquiry. 4 (4). December. ps 257-261.

Leininger, M. (1978). Transcultural nursing: concepts, theories and practices. New York: Wiley and Sons.

Leininger, M. (1985). Ethnography and ethnonursing: Models and modes of qualitative data analysis. In M. Leininger (Ed.).Qualitative research methods in nursing. (pps33-71). Philadelphia: W.B. Saunders.

Leininger, M. (1991). Cultural care, diversity and universality: a theory of nursing. New York: National League for Nursing Press.

Leininger, M. (1997). Leininger's critique response to Coup's article on Cultural Safety (Ramsden) and Culturally Competent Care (Leininger) for practice. Nursing Praxis in New Zealand. 12. (1). ps 17-23.

Marino, G. D. (1998). Anxiety in the concept of anxiety. In A. Hannag \& G. D. Marino. (Eds.). The Cambridge companion to Kierkegaard. Chapter 12. (pps 308-328). Cambridge University Press.

Martinez, R. (Ed.). (1997). The very idea of radical hermeneutics. New Jersey: Humanities Press. 
Meleis, A.I. (1996). Culturally competent scholarship: substance and rigor. Advances in Nursing Science. 19 (2), ps 1-16.

Meleis, A. I., \& Im, E-O. (1999). Transcending marginality in knowledge development. Nursing Inquiry. 6 (2). June. ps 94-102.

Melzoff, S.K., \& Lipuma, E. (1986). Hunting for Tuna and cash in the Solomons: a rebirth of artisan fishing in Malaita. Human Organisation. 45: ps 53-62.

Ministry of Health. (1997). Making a Pacific Difference: Strategic initiatives for the health of Pacific people in New Zealand. Wellington, New Zealand: Public Health Group. Ministry of Health.

Ministry of Pacific Island Affairs. (1999). Pacific Vision Strategy: Pacific Directions Report. Social and economic prosperity for Pacific peoples. Wellington. New Zealand: Ministry of Pacific Island Affairs.

Mouffe, C. (1997). Feminism, citizenship and radical democratic politics. In D. Tietjens Myers (Ed.). Feminist Social Thought: A Reader. (pps 533-544). New York and London: Routledge.

Nursing Council of New Zealand. (1996). Draft guidelines for the cultural safety component in Nursing and Midwifery. Wellington: Nursing Council of New Zealand.

Olthuis, J. H. (1997). A hermeneutics of suffering love. In R. Martinez ( Ed.). The very idea of radical hermeneutics. (pps 149-165). New Jersey: Humanities Press.ermeneutics. (pps 149-165). New Jersey: Prometheus Books.

Papademetre, L. (1994). Self-defined, other-defined cultural identity. Logogenesis and multiple-group membership in a Greek Australian sociolinguistic community. Journal of Multilingual and Multicultural Development,15. (6). ps 507-525. 
Peach, J. (1999). Workforce planning essential. Kia Tiaki Nursing New Zealand. June. ps 22-24.

Personal Narratives Group (Eds.). (1994). Interpreting women's lives: Feminist theory and personal narratives. Indiana University Press.

Phoca, S., \& Wright, R. (1999). Introducing postfeminism. Icon Books UK, Totem Books USA.

Pierce, J. (1995). Gender Trials: Emotional lives in contemporary law firms. Berkeley: University of California Press.

Polaschek, N. R. (1998). Cultural safety: a new concept in nursing people of different ethnicities. Journal of Advanced Nursing. 27. ps 452-457.

Ramsden, I. (1990). Kawa Whakaruruhau: Cultural Safety in New Zealand. Wellington: Ministry of Education.

Ramsden, I. (1992). Kawa whakaruruhau: cultural safety in Nursing and Midwifery education. Wellington: Nursing Council of New Zealand.

Ramsden, I. (1993). Kawa Whakaruruhau: cultural safety in nursing education in Aotearoa (New Zealand). Nursing Praxis in New Zealand. 8 (3), ps 4-10.

Ramsden, I. (1995). Cultural Safety: implementing the concepts. Paper presented at the Social Force of Nursing and Midwifery Conference. James Cook Centra Hotel. 23 May. 1995. Wellington New Zealand.

Ramsden, I. (1996). The Treaty of Waitangi and cultural safety: The role of the Treaty in Nursing and Midwifery education in Aotearoa. Wellington: Nursing Council of New Zealand.

Ramsden, I., \& Spoonley, P. (1993). The cultural safety debate in Nursing education in Aotearoa. New Zealand Annual Review of Education. 3. ps 161-174. 
Richardson, L. (1995). Narrative and sociology. In J.Van Maanen (Ed.). Representation in Ethnography. London: Sage Publications.

Riessman, C. K. (1993). Narrative analysis. Qualitative Research Methods. Vol. 3. London: Sage Publications. Newbury Park.

Rika-Heke, P., \& Markmann, S. (1996). Common language - different cultures. True or false? In D. Bell \& R. Klein (Eds.). Radically speaking. feminism reclaimed. (pps 505-515). Melbourne: Spinafex Press.

Ross, T. (1994). New Zealand's 'Overstaying Islander': A construct of the ideology of 'race' and immigration. Unpublished thesis presented in fulfilment of the requirements for the degree of Master of Philosophy. Victoria University of Wellington.

Said, E. W. (1993). Culture and imperialism. London: Vintage Books.

Sandelowski, M. (1995). Focus on qualitative methods. Chapel Hill: John Wiley \& Sons.

Sarup, M. (1993). An introductory guide to post-structuralism and postmodernism. $2^{\text {nd }}$ Edition. Athens: University of Georgia Press.

Southwick, M. (1994). Learning to walk the talk. Critical reflections on Curriculum development at Whitireia Community Polytechnic 1985-1993. Nursing Praxis in New Zealand. 9 (2), ps 4-10.

Speedy, S. (1991). The contribution of feminist research. In G. Gray and R. Pratt (Eds.). Towards a Discipline of Nursing. (pps 191-210). Churchill Livingstone Pub.

Spoonley, P. (1988). Racism and Ethnicity: Critical issues in New Zealand Society. Auckland: Oxford University Press. 
Stanley, L. (1993). The knowing because experiencing subject. Narratives, lives and autobiography. Women's Studies International Forum, 16, ( 3). ps. 205215.

Statistics New Zealand. (1998). Pacific Islands People. Census 1996. Wellington: Statistics New Zealand.

Tanner, C. (1996). Cultural diversity in Nursing education. Journal of Nursing Education. 35 (7). October. ps 291-292.

Taylor, J. (1999). Colonising images and diagnostic labels: oppressive mechanisms for African -American women’s health. Advanced Nursing Science. 21 (3). March. ps 32-45.

Thompson, J. (1990). Hermeneutic Inquiry. In: L. Moody (Ed.). Advancing Nursing Science through research, 2 (pp 223-286). Newbury Park, California: Sage Publications.

Tiatia, J. (1998). Caught between cultures. A New Zealand born Pacific Island perspective. Auckland: Christian Research Association. Publisher.

Tse, Lao. (1947). The White Pony. An anthology of Chinese poetry. (pp76). R.Payne.(Ed.). New York: Mentor.

Turner,V. (1969). Liminality and communitas. The Ritual Process. Harmondsworth. Penguin.

Turner, V. (1977). Variations on the theme of liminality. In S. Moore \& B. Myerhoff. (Eds.). Secular Ritual. Assen Van Gorcum.

Van Maanen, J. (Ed.). (1995). An end to innocence. The Ethnography of ethnography. In Representation in Ethnography. London, New Delhi: Sage Publications 
Van Manen. M. (1997). From meaning to method. Qualitative Health Research. 7, .3, August. ps345-369.

Vaughan, J. (1997). Is there really racism in Nursing? Journal of Nursing Education. 36 (3). March. ps 135-139.

Walker, K. (1996). Cutting edges: deconstructive inquiry and the mission of the border ethnographer. Nursing Inquiry. 4 (1). March. ps 3-13.

Welch, M. (1999). Critical theory and feminist critique. In. E. C. Polifroni \& M. Welch. (Eds.). Perspectives on philosophy of science in Nursing. An historical and contemporary anthology. (pps 355-359). Philadelphia: Lippincott Williams \& Wilkins.

Wendt, A. (1987). Novelists and historians and the art of remembering. In A. Hooper, S. Britton, R. Crocombe, J. Huntsman \& C. Macpherson. (Eds.). Class and Culture in the South Pacific. Centre for Pacific Island Studies University of Auckland and the Institute of Pacific Island Studies, University of the South Pacific.

Wessen, A. F. (1992). Migration and health in a small society: The case of Tokelau. Research Monograph on Human Population Biology. No. 8. Oxford: Claredon Press.

Wood, P., \& Schwass, M. (1993). Cultural safety: a framework for changing attitudes. Nursing Praxis in New Zealand. 8 (1). ps 4-15. 


\section{APPENDIX I: Participant Information Sheet}

\section{Project (Working) Title}

Becoming a Nurse: The experience of Pacific Islands women of their three year Comprehensive Nursing programme, and first year of practice post Registration.

\section{Brief description of aims and purpose of the study}

This project is being undertaken by me as part of my Phd candidature.

The research aims to gain an understanding of the experiences of four-five women who identify themselves as belonging to one or more Pacific Islands Nations, and who have successfully completed a three year Diploma in Nursing programme and at least one year of practice since gaining their Comprehensive Registration. The purpose of this research is to identify what the experience of becoming a nurse was like for those who do not belong to either of the two main cultural groups of New Zealand society.

It is hoped that this research will provide a format for participants to talk freely about their experiences as students and as beginner practitioners, and in so doing develop insights into the education and health systems which may be personally healing and transformative. It is also hoped that as a result of this research the wider community may gain some benefit by becoming more informed about the barriers and or opportunities for Pacific Island people to experience inclusive organisations sensitive to the choices of Pacific Islands people.

\section{What I would like you to do}

I would like to talk with you about your experiences as a person who identifies yourself as a Pacific Islands person about your becoming a nurse, your training and beginner practitioner experiences, and also what your aspirations and hopes for the future as a professional nurse. I would like to meet at least three times for an hour to tow hours at a time. We will meet at a place that is convenient to you outside of your work environment.

\section{Description of inconveniences which might be expected}

The meetings will take up to six hours of your time, but will be arranged to suite your schedule. I intend to audio tape our discussions. If you are not happy about being 
audio-taped, or if you have any other concerns about what I am asking of you, please let me know and I will be happy to discuss them with you.

\section{Expected outcomes and benefits of the research}

Understanding of the education experiences of Pacific women in nursing training programmes may lead to purposeful modifications or development of present practices in nursing curricula.

The experiences of participants in this research may provide insights that have positive possibilities for the whole profession of nursing. The research may assist participants to develop insights into how to assist in bringing about changes in the current delivery of health care for Pacific people.

The results of this research any also lead to better understanding by non Pacific Islands nurses of their Pacific Islands colleagues, leading to more empowering models of partnership.

The research findings will be written up and available to members of the Pacific community, health professionals, and copies in the libraries of Victoria University of Wellington, and Whitireia Community Polytechnic.

\section{An assurance that confidentiality will be preserved}

You have my unqualified assurance that your right to confidentiality will be preserved. You will have the opportunity at our first meeting to select the name that will represent you in the research. All audio-tapes will be kept secure during the project, and at the end of the research will be destroyed or returned to you, which ever you prefer. Any transcribing of interview audio-tapes by persons other than myself will require a declaration of confidentiality to be signed by the person. Any personal information will be kept in a separate place to the tape transcripts or tapes. To preserve your anonymity any identifying information will be excluded from any reports, discussions or findings related to this research..

\section{The storage of information and its further use or disposal}

During the study, any of personal information will be kept in a separate place to tape transcripts or tapes. All the information will be kept in a secure place. When we meet, I will ask you what you wish to have done with your information when the research is completed. The possibilities are: disposing of any information provided by you, or 
returning it to you. As it is your personal information you have the right to decide which option you prefer.

\section{Your participation in this research is voluntary}

Your participation in this research is voluntary. You may refuse to participate in this study or choose to withdraw from it at any time without any adverse consequences to you at all.

Please take some time to think about taking part in this research. You may wish to discuss your participation with someone else before you make a decision.

If you have any questions or concerns about the research while it is being carried out please let me know and I will attend to these.

The research will be stopped if it appears to be causing harm to participants.

When the research is completed, I can send you a copy of the report of the finding of the research from the information you have provided me, or I can discuss the findings with you, which ever you prefer.

\section{Investigator's name and contact phone numbers}

Margaret Southwick. Phone: Home xxxxxxxx most evenings except Tuesday and Thursday. Work xxxxxxx.

If you have any concerns about this study you may contact the Chairperson, Central RHA Ethics Committee, Wellington Hospital, Private Bag 7902, Wellington South. Phone (04)3855 999 Extn 5185. Fax (04)3855 840 


\section{APPENDIX II: Participant Consent Form}

\section{PARTICIPANT CONSENT FORM}

Central regional Health Authority Wellington Ethics Committee

\section{Project Title:}

"Becoming a Nurse. The experiences of Pacific Islands women of their three year Comprehensive Nursing programme, and first year of practice post Registration.”

\section{Investigator's name, position, qualifications and contact phone numbers.}

Margaret Rose Southwick.

Phd candidate. Nursing and Midwifery Department Victoria University of

Wellington.

Head of Nursing. Whitireia Community Polytechnic, Porirua.

Contact Phone Numbers (04)2374 869 (Home)

$$
\text { (04)2373 } 103 \text { extn } 3729 \text { (Business). }
$$

Registered General and Obstetric Nurse. 1966

Bachelor of Arts Degree (Anthropology/Sociology). VUW. 1984

Ethnicity. Pakeha/Tuvalu.

Venue of Study.

Phd studies through the Department of Nursing and Midwifery, Victoria University of Wellington, 81 Fairlie Terrace, Kelburn.

Brief description of the aims and purposes of this study.

The aim of this study is to gather stories from five women who self identify as a member of one or more Pacific Islands Nations, about their experiences of becoming a Nurse through successfully completing a Comprehensive Diploma in Nursing programme. The study will also include the experiences of the same women during their first year of nursing practice after they Registered. 
The intention of the research is to identify what the experience of becoming a nurse was like for those who do not belong to either of the two main cultural groups of New Zealand society. Within this project I am particularly concerned to understand how participants form and reform their sense of identity as a nurse in New Zealand.

It is hoped that the results of this research will provide a format for participants to freely talk about their experiences as students and as beginner nurse practitioners, and in so doing, develop or extend insights into education and health systems which may be personally healing and transformative. The results of this research will hopefully develop an appropriate framework for articulating professional identity for women who are also members of the Pacific Islands community.

It is also hoped that the wider community may gain some benefit from the results of this research by education and health care organisations becoming more informed about barriers and or opportunities for Pacific Islands people to experience inclusive organisations sensitive to the choices of Pacific Islands people.

\section{Description of inconveniences which might be expected}

A possible inconvenience to you as a participant could be the time that will be involved in this project. As researcher, I am anticipating that I will be asking you to participate in three interview sessions, each of which will be between an hour to two hours long, to gather your three stories about your background prior to entry into nursing, your learning to become a nurse and your aspirations and hopes for the future. I will be seeking your informed consent to audio-tape these sessions.

I am anxious that if you consent to be interviewed, that this is done in a place that offers you the most comfort, which may be in your own home or mine, or any other place other than your place of employment, that you may choose.

As well, I will form time to time ask you to read transcripts of interviews we have previously undertaken, to check for accuracy, and to provide you with the opportunity to amend or delete anything you feel is appropriate. At all times through out this project, your decision and judgement about what you wish to disclose to the researcher about your experiences will be faithfully respected by myself as Researcher. You will be free to give or withhold your consent to participate in this 
research without any fear of negative consequences. You will also be entitled to withdraw from this research project at any stage. Your informed consent to participate in this project does not remove from you the right to freely withdraw at any stage, without fear of negative consequences to yourself.

\section{An assurance that confidentiality will be preserved}

Each participant in this research project has the unqualified assurance of the researcher that their privacy and right to confidentiality will be preserved.

Each participant will select for themselves the name that will represent them in the research. All audio-tapes will be kept secure during the project, and at the end of the research, will be destroyed or returned to the participant according to their preference. Any Transcribing of interview audio-tapes by persons other than the researcher, will require a declaration of confidentiality to be signed by that person.

Any personal information will be kept in a separate place to the tape transcripts or tape. To preserve your anonymity any identifying information will be excluded from any reports, discussions or findings relating to this research.

At the completion of the writing up of the research process I will provide you with a copy of the final draft of the research so that you can have the opportunity to satisfy yourself that your anonymity has been protected, and that your information has not been misrepresented by me in any way. Your corrections and comments will be strictly adhered to by myself.

\section{Statement to be signed in the presence of the investigator and where possible to}

\section{be witnessed:}

- I have read the consent form and have had the opportunity for discussion with Margaret Southwick.

- I understand that I may withdraw from the study at any time and I understand that this withdrawal will not adversely affect me in anyway.

If I consent to participate in this research, I would like to excise the following choices: At the end of the project I would like any audio-tapes of my interviews to be:

i) Returned to me Yes/No (delete one)

ii) Destroyed Yes/No (delete one) 
At the end of the study I would like to see the final draft of the report for me to make changes and comment in regard to any information I have given the researcher and to ensure that my anonymity is consistently protected. Yes/No (delete one) At the end of this project I would like to receive a copy of the final report.

$$
\text { Yes/No (delete one) }
$$

I understand that this study has been approved by the Central Regional Health Authority Wellington Ethics Committee and if I have any concerns about the study, I may contact the Ethics Committee, Wellington Hospital - Telephone (04)3855 999 extn 5185.

\section{I agree to take part in this study}

Signed (participant) / / (date) (witness) / / (date)

Witness name :

Statement by Investigator:

I have discussed with (participant's name) the aims of and procedures involved in this study.

Signed (researcher) / / (date)

Three copies required: 1 retained by participant: 1 retained by investigator: 1 records. 